\title{
Copyright
}

by

Jason Donald Schukraft

2017 
The Dissertation Committee for Jason Donald Schukraft Certifies that this is the approved version of the following dissertation:

\section{Carving Intuition at Its Joints}

Committee:

\begin{tabular}{l}
\hline Cory Juhl, Supervisor \\
\hline Ernest David Sosa \\
\hline Joshua Dever \\
\hline Miriam Schoenfield \\
\hline Herman Cappelen
\end{tabular}




\title{
Carving Intuition at Its Joints
}

by

Jason Donald Schukraft, B.A.

\author{
Dissertation \\ Presented to the Faculty of the Graduate School of \\ The University of Texas at Austin \\ in Partial Fulfillment \\ of the Requirements \\ for the Degree of \\ Doctor of Philosophy
}

The University of Texas at Austin

May 2017 
Dedication

To Katie 


\title{
Carving Intuition at Its Joints
}

\author{
Jason Donald Schukraft, Ph.D. \\ The University of Texas at Austin, 2017
}

Supervisor: Cory Juhl

Metaphilosophy is the philosophical study of philosophy itself. Metaphilosophers attempt to articulate and evaluate the aim(s) of philosophy, the value(s) of philosophy, and the method(s) of philosophy. One striking feature of contemporary metaphilosophy is the attention it devotes to the investigation of philosophical intuitions.

There is a tacit presumption in this literature, shared by both proponents and critics of appeals to intuition, that philosophical intuitions constitute something like a natural kind. Intuitions may not issue from a single faculty, and the intuitions themselves may concern a heterogeneous collection of propositions, but nonetheless - so this line of thinking goesthere is something unifying about philosophical intuitions that justifies treating them monolithically. This treatment, I argue, is a mistake.

To determine the merit of philosophical appeals to intuition, we need some way to gauge the reliability or justificatory power of such appeals. But attempting to measure the reliability or justificatory power of intuitions immediately generates a dilemma. On the one hand, challenging the reliability or justificatory power of all intuitions leads to self-defeat, as any such challenge will necessarily rely on intuition at some point in the argument. On the other hand, restricting the challenge to a certain subset of intuitions risks a familiar sort of 
generality problem: what makes these intuitions problematic and not their counterparts in other domains?

In response to this dilemma, I argue that metaphilosophy would be best served abandoning intuition talk altogether. 'Intuition' picks out an overly broad and general category. When assessing the reliability or justificatory power of an evidence source, it is necessary to be fine-grained about the evidence source. We ought not ask whether intuition as a whole is reliable; rather, we should ask whether particular kinds of intuition are reliable, leaving open the possibility that some sorts of intuitions are more reliable than others. I explore three principled ways of sub-dividing intuitions in a way that pushes the metaphilosophical dialectic forward. We can individuate classes of intuition by (1) their context of employment, (2) the exoticism of their content, and (3) their psychological provenance. This tripartite division will make it easier to identify which appeals to intuition are problematic without risking wholesale skepticism. 


\section{Table of Contents}

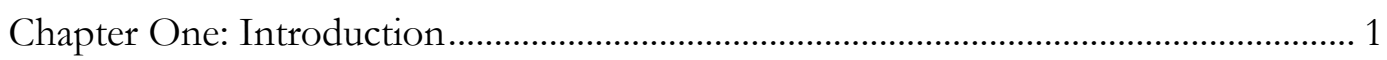

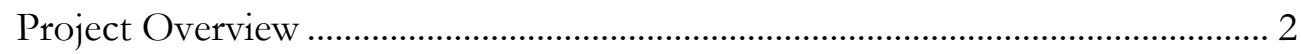

Chapter Two: Methodological Particularism and Descriptive Intuition Skepticism.. 11

Against Methodological Particularism .................................................................... 12

Against Descriptive Intuition Skepticism............................................................ 28

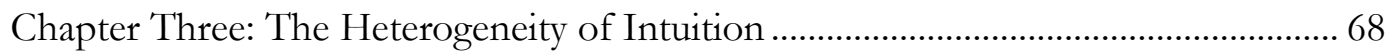

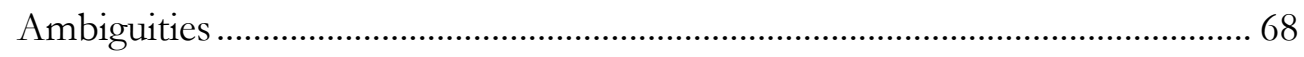

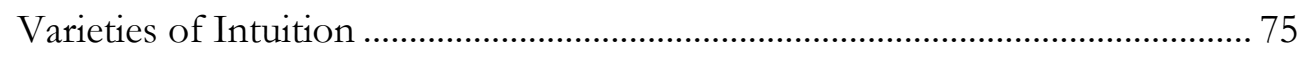

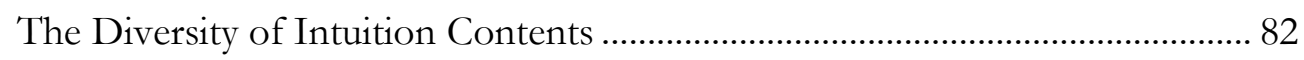

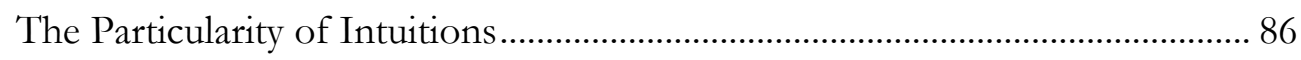

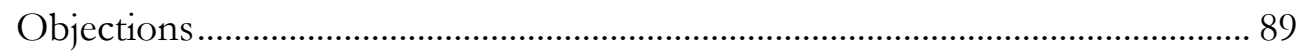

Chapter Four: Metaphilosophical Arguments ......................................................... 101

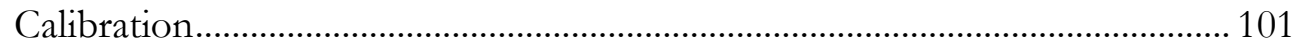

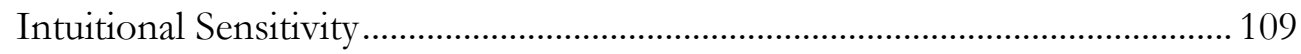

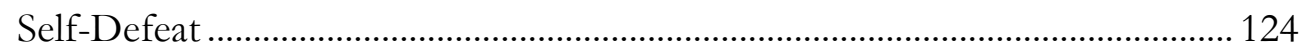

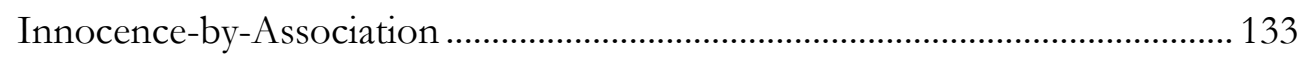

Chapter Five: Carving Intuitions More Finely ........................................................... 140

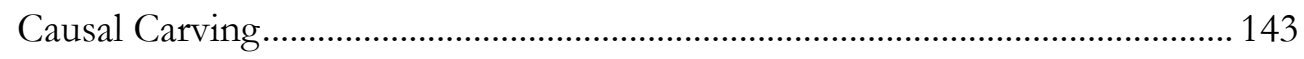

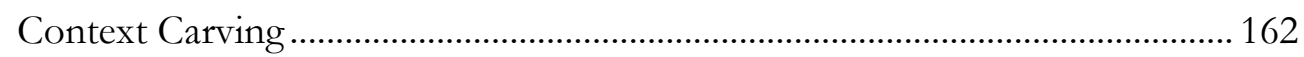

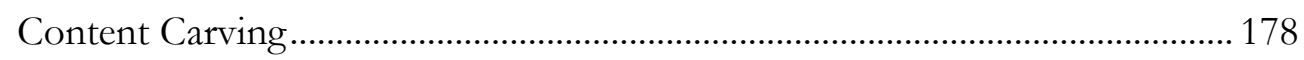

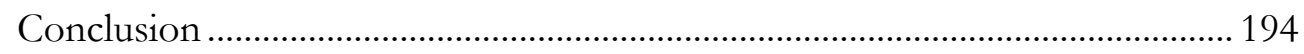

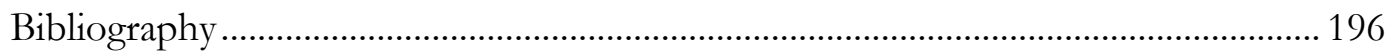




\title{
Chapter One: Introduction
}

\author{
"There are few things that we phrase properly; most things we \\ phrase badly; but what we are trying to say is understood." \\ -Augustine, Confessions, XI.20.26
}

\section{INTRODUCTION}

The thesis of this monograph is a plea: stop talking about intuitions. ${ }^{1}$ Stop utilizing the locution 'it is intuitive that p.' Stop phrasing sentences 'intuitively, p.' Above all, stop reporting 'I have the intuition that p.'

The reason that we should stop talking about intuitions isn't that intuitions cannot be calibrated against an independent standard, as Cummins 1998 and Weinberg et al. 2012 claim. The reason isn't that appeals to intuition are without any respectable theoretical foundation, as Hintikka 1999 and Hales 2000 claim. The reason isn't that appeals to intuition conflict with our commitment to naturalism, as Devitt 1994, Ladyman \& Ross 2007, and Maclaurin \& Dyke 2012 claim. Nor is the reason that appeals to intuitions are argumentative third-wheels, as Cappelen 2012, Molyneux 2014, and Deutsch 2015 claim. And the reason isn't that intuitions are sensitive to non-evidential factors, as Machery et al. 2004; Swain, Alexander, \& Weinberg 2008; Buckwalter \& Stich 2014; and Costa et al. 2014 claim.

The reason that we should stop talking about intuitions is that 'intuition' does not pick out a monolithic, unified kind. The category represents a diverse collection of distinct mental states. ${ }^{2}$ The heterogeneity of the category makes for a term that is vague and

\footnotetext{
1 This plea is directed at, and restricted to, professional philosophers. Intuition talk in other disciplines may be unproblematic.

${ }^{2}$ Indeed, some types of intuition-talk don't refer to mental states at all.
} 
imprecise. Our philosophy would be much improved if we adopted a finer-grained taxonomy to reflect this heterogeneity. Or so I shall argue.

\section{Project Overview}

Metaphilosophy is the philosophical study of philosophy itself. Metaphilosophers attempt to articulate and evaluate the aim(s) of philosophy, the value(s) of philosophy, and the method(s) of philosophy. The specific objectives of metaphilosopy are many and varied. In this monograph, I concentrate on two central metaphilosophical tasks. I'll call them RELIABILITY and JUSTIFICATION:

$\begin{array}{ll}\text { RELIABILITY } & \begin{array}{l}\text { Evaluate the reliability of the purported evidence that } \\ \text { figures in philosophical arguments }\end{array} \\ \text { JUSTIFICATION } & \begin{array}{l}\text { Evaluate the justificatory status of relying on the purported } \\ \text { evidence that figures in philosophical arguments }\end{array}\end{array}$

I don't intend to undertake these tasks. I merely intend to clarify what would be required in order to undertake them.

A few clarificatory remarks are in order. RELIABILITY and JUSTIFICATION presuppose some answer to the descriptive question 'what sort of things figure in philosophical arguments?'. This is no easy question. Much of contemporary metaphilosophy assumes that intuitions are the sort of thing that either appear among the premises of philosophical arguments or support the premises of philosophical arguments, and I defend that assumption in chapter two. I include 'purported' in my formulation of the goals because if evidence is factive, its reliability is guaranteed. Finally, the two goals are interrelated. The reliability of the purported evidence that figures in philosophical arguments may underwrite (or, indeed, constitute, if reliabilism is true) the justification for relying on that evidence. 
The reliability of some belief-forming process $\Phi$ is a measure of the truthconduciveness of $\Phi$. Truth-conduciveness can be decomposed into two subjunctive components: SENSITIVITY and SAFETY:

SENSITIVITY If $\mathrm{p}$ were false, $\Phi$ would not output that $\mathrm{p}$

SAFETY If $\Phi$ were to output that $\mathrm{p}$, p would not be false

A perfectly reliable (and hence infallible) belief-forming process would be wholly SENSITIVE and wholly SAFE. Of course, mere reliability does not entail infallibility. Reliability comes in degrees, and there is some level short of infallibility at which it is appropriate to call a beliefforming process reliable. On the other hand, SENSITIVITY and SAFETY appear not to admit of degrees — as propositions they are either true or false. However, because SENSITIVITY and SAFETY are subjunctive conditionals, gradations can be recovered via a possible-worlds analysis of their truth conditions. Roughly, SENSITIVITY says that in the nearest possible world in which $\mathrm{p}$ is false, $\Phi$ does not output that $\mathrm{p}$, and SAFETY says that in the nearest possible world in which $\Phi$ outputs that $\mathrm{p}, \mathrm{p}$ is not false. Degrees of SENSITIVITY and SAFETY can be measured by modal distance. For SENSITIVITY, go to the nearest possible world in which $\mathrm{p}$ is false and then check if $\Phi$ outputs that $\mathrm{p}$. If $\Phi$ does not output that $\mathrm{p}$, go to the next-nearest world in which $\mathrm{p}$ is false and check if $\Phi$ outputs that $\mathrm{p}$. Repeat the procedure until you find a world in which $\mathrm{p}$ is false and $\Phi$ outputs that $\mathrm{p}$. The farther the world, the higher the degree of SENSITIVITY. If there is no possible world in which $\mathrm{p}$ is false and $\Phi$ outputs that $\mathrm{p}$, then $\Phi$ is wholly SENSITIVE. Mutatis mutandis for SAFETY.

Relying on a sort of evidence is an epistemic practice. An agent is justified in engaging in an epistemic practice just in case either (1) she justifiably believes the epistemic 
practice conduces to her epistemic goals or (2) the epistemic practice in fact conduces to her epistemic goals. ${ }^{3}$ Thus, for example, an agent is justified in relying on a sort of evidence if and only if she is justified in believing that the evidence that $\mathrm{p}$ of that sort in general offers prima facie justification for the belief that $\mathrm{p}^{4}$ The agent need not think that every bit of evidence of that sort justifies the corresponding belief, but, at a minimum, she must believe that more often than not possessing evidence of that sort confers justification on the possessor.

RELIABILITY belongs to a family of goals common to first-order work in other disciplines. Historians, especially historians of the ancient world, do not take for granted that the historical texts upon which they base their theories are reliable; much press is devoted to establishing which texts are dependable and to what degree. Social psychologists must take care not to put too much stock in the self-reported beliefs of their experimental subjects; implicit biases often undermine the accuracy of such reports, and these biases must be accounted for in final theory. In physics, cutting-edge research frequently devotes as much attention to establishing the reliability of its experimental instruments as it does to its experiments themselves; calibration is an essential part of the scientific method. ${ }^{5}$

JUSTIFICATION, on the other hand, is more commonly pursued in second-order work. Set theorists wonder whether they are justified in endorsing certain proofs, given that those proofs rely on various controversial axioms like the axiom of choice or a large cardinal axiom. Economists working in the meso-economical tradition wonder about the wisdom of

3 (1) and (2) correspond, respectively, to internalist and externalist conceptions of justification. I wish to remain neutral as to which conception of justification is more appropriate.

${ }^{4}$ We could reformulate this sentence in terms of true-rather than justified-beliefs, but that would collapse JUSTIFICATION to RELIABILITY.

5 See Franklin 1997 for more on the importance of calibration in the hard sciences. 
drawing conclusions from artificial models with idealized assumptions. Philosophers of science wonder whether we are justified in inferring the existence of unobservable entities on the basis of observable entities.

RELIABILITY and JUSTIFICATION are worthy metaphilosophical goals because if metaphilosophers could get a handle on the reliability and justificatory status of the evidence that figures in philosophical arguments, first-order philosophy could be directly improved. Fortunately, metaphilosophers frequently address RELIABILITY and JUSTIFICATION. Lycan 1996, Bealer 1998, Sosa 1998, Cummins 1998, Papineau 2009, and Weinberg 2012 explicitly address the question of reliability. Tidman 1996, Sosa 2006, Chudnoff 2011, and Brown 2013 explicitly address the question of justification. Unfrotunately, when metaphilosophers pursue RELIABILITY and JUSTIFICATION, they almost always take 'intuition' to be the proper target of their analyses. This is a mistake.

Of course, it doesn't follow from this single-minded attention to intuition that metaphilosophers think intuitions constitute the only sort of evidence that figures in philosophical arguments. Metaphilosophers can be forgiven for ignoring the empirical propositions or logical transitions that often play a role in philosophical theorizing. If there are special problems regarding the reliability or justificatory status of philosophical claims, those problems don't emanate from reliance on empirical data or deduction. For good or ill, what sets philosophy apart from other disciplines, according to the orthodox metaphilosophical view, is its reliance on intuitive data. ${ }^{6}$ This reliance allegedly warrants the focus on intuitions. Thus, to frame the issue, I'll focus on the following two questions:

\footnotetext{
${ }^{6}$ See Andow 2015 for an empirical investigation into the distinctiveness of philosophical intuition talk. The paper questions the assumption that the way philosophers use the term 'intuition' is particularly unique.
} 
RELIABILITY $_{\mathbf{i}}$ Is (relying on) intuition a reliable belief-altering process?

JUSTIFICATION $_{\mathbf{i}}$ Does the intuition that $\mathrm{p}$ confer (prima facie) justification on the belief that p?

My central claim is that asking RELIABILITY ${ }_{i}$ and JUSTIFICATION $\mathrm{J}_{\mathrm{i}}$ doesn't conduce to RELIABILITY and JUSTIFICATION.

Philosophical accounts of intuition are numerous and diverse. They range from the quotidian (beliefs or dispositions to believe) to the exotic (phenomenally distinct products of a special rationalist faculty). Lewis (1983) thinks they are merely opinions. Williamson (2005, 2007) thinks they are counterfactual judgments. Bealer (1996) thinks they are intellectual seemings. $^{7}$

Metaphilosophical inquiries into the nature of intuition can take a variety of guises:

Metaphysical: what are intuitions?

Epistemological: what justificatory status does the intuition that p confer on the belief that $\mathrm{p}$ ?

Experimental: what intuitions do members of the lay public have about important philosophical cases?

Psychological: what module(s) of the mind issue intuitions, and what cognitive biases can interfere with these issuances?

Phenomenological: what is it like to have an intuition?

Sociological: $\quad$ how widespread are appeals to intuition in philosophy?

Methodological: what role, if any, should appeals to intuition play in philosophical theorizing?

My primary interest lies in the last category, the methodological question. However, it is impossible to give a satisfactory answer to the methodological question without engaging, at least to some extent, with the other questions. (It is, after all, difficult to adjudicate the role

\footnotetext{
${ }^{7} \mathrm{I}$ take it for granted that Kantian intuition is another thing altogether.
} 
of intuitions in philosophy without knowing what intuitions are.) Unfortunately, many of these questions are unclear and clouded by dubious background assumptions.

There is a tacit presumption in much of the literature, shared by both proponents and critics of appeals to intuition, that philosophical intuitions, once properly analyzed, constitute something like a natural kind. Intuitions may not issue from a single faculty, and the intuitions themselves may concern a heterogeneous collection of propositions, but nonetheless — so this line of thinking goes — there is something unifying about philosophical intuitions that justifies treating them monolithically. Bengson 2014 explicitly considers a heterogeneous approach to intuition but rejects it: "I myself do not accept this or any other 'family resemblance' theory of intuition" (565). Bealer 1998 asks, "Taking it for granted that phenomenal experience is a basic source [of evidence], how should we classify intuition?" (217). He doesn't entertain the possibility that different intuitions should be classified differently. The SEP entry on intuition explicitly (and without argument) presumes that a monolithic treatment is appropriate: "It is plausible (and will be assumed here) that the intuitions of interest in philosophy constitute a single epistemic and psychological kind.", Similar treatments can be found in Pust 2000, Korman 2005, Sosa 2006, and Audi 2008, among others.

This assumption infects both pro-intuition recommendations (appeals to intuition are fine-we should stop worrying about them and get on with doing philosophy) and antiintuition recommendations (appeals to intuition are fundamentally flawed-we should restrict their use in philosophical theorizing). Both recommendations rely on an ampliative

\footnotetext{
8 Pust, Joel, "Intuition", The Stanford Encyclopedia of Philosophy (Spring 2016 Edition), Edward N. Zalta (ed.), URL $=<$ http://plato.stanford.edu/archives/spr2016/entries/intuition/ $>$
} 
inference: intuitions of type $\Phi$ have feature $x$; therefore most intuitions are likely to have feature $x$. When feature $x$ is truth-conducive, we get the pro-intuition recommendation; when feature $x$ is not truth-conducive, we get the anti-intuition recommendation.

But ampliative inferences only work on unified categories situated at the appropriate level of generality. We can't run ampliative inferences on the predicate 'grue,' for example, because 'grue' is not unified in the right sort of way. Or suppose one took as one's inference base the union of one's perceptual judgments and one's probabilistic judgments. Learning that one's perceptual judgments are generally true does not license one to conclude that one's probabilistic judgments are generally true. So too, perhaps, with intuitions. If 'intuition' is not unified in the right way, then learning about intuitions of type $\Phi$ may not tell us much about intuitions of type $\Gamma$.

To determine the merit of philosophical appeals to intuition, we need some way to gauge the reliability or justificatory power of such appeals. But attempting to measure the reliability or justificatory power of intuitions immediately generates a dilemma. On the one hand, challenging the reliability or justificatory power of all intuitions leads to self-defeat, as any such challenge will necessarily rely on intuition at some point in the argument. On the other hand, restricting the challenge to a certain subset of intuitions risks a familiar sort of generality problem: what makes these intuitions unreliable or unjustified and not their counterparts in other domains?

In response to this dilemma, I argue that metaphilosophy (and by extension firstorder philosophy) would be best served abandoning intuition talk altogether. 'Intuition' picks out an overly broad and general category. When assessing the reliability of an evidence 
source, it is necessary to be fine-grained about the evidence source. (Compare trying to assess the reliability of eyewitness testimony by assessing the reliability of perception in general.) We ought not ask whether intuition as a whole is reliable; rather, we should ask whether particular kinds of intuition are reliable, leaving open the possibility that some sorts of intuitions are more trustworthy than others.

I suggest that there are three principled ways of sub-dividing intuitions in a way that pushes the metaphilosophical dialectic forward. We can individuate classes of intuition by (1) their psychological provenance, (2) the context in which they occur, and (3) the exoticism of their content. This tripartite division will allow us to better gauge the reliability and justificatory power of philosophical intuition, thus making it easier to identify which appeals to intuition are problematic without risking wholesale skepticism.

To reiterate my main claim: I think debates in metaphilosophy (and by extension first-order philosophy) would be improved by a finer-grained taxonomy of intuition. The argument for this claim is inductive, and it comprises four parts. First, in chapter two, I argue against two views (methodological particularism and descriptive intuition skepticism), which, if correct, would doom my project from the start. Next, in chapter three, I marshal evidence for the view that 'intuition' picks out a heterogeneous, gerrymandered kind. In chapter four, I show how a finer-grained intuitional taxonomy affects four popular metaphilosophical arguments (the argument from calibration, the argument from intuitional sensitivity, the argument from self-defeat, and the argument from innocence-by-association). When we stop treating intuitions monolithically, the possibility of breaking entrenched dialectical stalemate emerges. Finally, in chapter five, I propose three strategies for effecting 
a finer-grained intuitional taxonomy. This is the most speculative chapter of the monograph. It will, however, suggest fertile ground for future research.

I end this brief introductory chapter with a clarificatory note. Much of this monograph is devoted simultaneously to talking about intuitions and arguing that intuition talk is confused. There is an apparent tension in this approach, but the tension is merely that-apparent. My objection is not that the concept intuition is internally inconsistent or that the term 'intuition' lacks a referent. My objection is that metaphilosophers treat intuitions as if they constitute a unified, monolithic, natural kind. Once we distinguish a category's being disunified from a term's lacking a referent, the tension dissolves. The way philosophers-especially metaphilosophers-talk about intuitions is confused because the category 'intuition' is not unified enough to warrant the generalizations that they make. They are trying to run ampliative inferences on a gerrymandered phylum. But the fact that a category is disunified does not entail that the corresponding term lacks a referent. ${ }^{9}$ Compare: the category 'jade' is not unified because it encompasses both jadeite and nephrite, minerals united only by superficial similarities. But the term 'jade' nevertheless has a clear referent.

The problem is not that there are no intuitions. The problem is that there are too many (types of) intuitions. There is nothing approaching a consensus as to what intuitions are because intuitions are not one sort of thing. Or so I shall argue.

\footnotetext{
${ }^{9}$ I don't intend to pinpoint the exact referent of the term 'intuition' as philosophers use it. Such a task is too hard. And I certainly don't intend to deliver a full theory of intuition. Given the disunity of the subjects which fall under the header 'intuition,' no such theory is possible. Like Pust (2001: 252, fn. 1), I will assume that "the reader has some intuitive grasp of what I mean by 'intuition."”
} 


\title{
Chapter Two: Methodological Particularism and Descriptive Intuition Skepticism
}

\author{
"By and large the greatest philosophers have been the greatest, and the most self- \\ conscious, methodologists; indeed, I am tempted to regard this fact as primarily \\ accounting for their greatness as philosophers." \\ -H.P. Grice, "Reply to Richards," in R. Grandy and R. Warner (eds), Philosophical \\ Grounds of Rationality: Intentions, Categories, Ends (Oxford: Clarendon Press, 1986), p. 66
}

\section{INTRODUCTION}

This chapter is devoted to clearing the ground for the main arguments to come in chapters three, four, and five. The ground-clearing exercise comprises two parts. In the first part I argue against a position I call 'methodological particularism,' the view that there are no useful general principles to guide philosophical practice. It is necessary to refute this view because the thesis of this monograph is a methodological recommendation (stop talking about intuitions). But according to particularists, methodological recommendations are misplaced in philosophy - attempts to articulate rules of good philosophical practice which rise above the platitudinous are doomed to failure. In response, I argue that much of metaphilosophy has direct and unavoidable methodological import. The mere intelligibility of certain paradigmatic metaphilosophical questions entails that there exist useful, general principles to guide the practice of doing philosophy well. Given that we have good reason to think at least some of these questions are intelligible, it follows that metaphilosophers can—and should—dispense methodological advice.

In the second part I argue against a position I call 'descriptive intuition skepticism,' the view that intuitions are not appealed to as evidence in philosophical arguments. It is necessary to refute this view because the central claim of this monograph is that appeals to intuition, as they are currently employed, cannot play the argumentative role that 
philosophers want them to play. A finer-grained taxonomy, I claim, is needed. But descriptive skeptics maintain that intuitions do not feature as premises in philosophical arguments, nor are they the evidential bases of such premises. Hence, a new intuition taxonomy, however emended, cannot improve the argumentative role that (non-skeptics think) intuitions play. In response, I first criticize the case studies approach to investigating this question. Then I evaluate two arguments of a more general nature which purport to support the descriptive skepticism: the argument from anomalous inadmissibility and the argument from insufficiency. I find both arguments wanting. I next consider responses to the most obvious argument against descriptive skepticism, the argument from absence of alternatives. Along the way, I show how one can accommodate the data uncovered by the case studies approach without establishing the skeptical conclusion that certain defenders of the case studies approach wish to establish.

\section{Against Methodological Particularism}

\subsection{Methodological Particularism and Methodological Generalism}

Methodological particularism is the view that there are no useful general principles to guide the practice of doing philosophy well. ${ }^{10}$ The methodological particularist believes that "there are no rules of good philosophical practice" and thus that "there isn't much to say about how to do philosophy well" (Dever 2016). ${ }^{11}$ According to the particularist, doing

\footnotetext{
10 Strictly speaking, the view should be called philosophical methodology particularism because it is a view that concerns philosophical methodology, not methodology in any other discipline or methodology in general (whatever that would mean). I leave the 'philosophical' portion of the name implicit throughout.

11 Similar claims are sometimes put forward in the sciences. See especially Paul Feyerabend's (1975) Against Method and his (1978) Science in a Free Society.
} 
philosophy well doesn't require adherence to any particular set of general principles or usefully specific rules. ${ }^{12}$

Methodological particularism is a tolerant view, but it is not relativism. The particularist is not committed to the claim that all methodologies are equally appropriate. But when a methodology is inappropriate, it is not inappropriate in virtue of violating some set of principles. The particularist may well be able to separate those philosophers doing philosophy well from those philosophers not doing philosophy well. But she will not be able to effect this separation by methodological principles alone.

The particularist believes that skilled philosophers will be sensitive to philosophical evidence when they encounter it (whatever form that evidence might take). And she believes that skilled philosophers will be sensitive to methodological procedures which conduce to the accumulation of philosophical evidence (whatever those procedures might be). As such, she believes that skilled philosophers will be more likely to hold justified philosophical beliefs than unskilled philosophers. But conforming to some set of methodological principles is neither a sufficient nor a necessary condition on being a skilled philosopher.

Methodological particularism is opposed by methodological generalism. According to the generalist, doing philosophy well requires respecting a set of general principles. Furthermore, the content of these principles is precise enough to guide actual philosophical practice. Given the diversity of philosophical methodologies currently employed in the

\footnotetext{
12 We can distinguish a weaker version of methodological particularism according to which doing good philosophy doesn't require being able to explicitly formulate any general methodological principles (though it still may require implicit adherence to such principles). I won't consider such a view here.
} 
discipline by philosophers with the same philosophical goals, the generalist is committed to the claim that some professional philosophers are doing philosophy poorly merely by virtue of their methodology. ${ }^{13}$

The generalist is not committed to the existence of absolute methodological principles. That is, she is not committed to the claim that adhering to some principle $\Phi$ is a necessary (much less sufficient) condition on doing philosophy well. Rather, the generalist is only committed to contributory methodological principles. These principles specify considerations that always count as evidence of doing philosophy well, even if circumstances occasionally require the principle to be flouted. The generalist is committed to there being some set of usefully specific principles whose dictates philosophers always have some reason to obey, even if countervailing reasons sometimes make it rational to disregard those principles. $^{14}$ In contrast, the particularist denies that there is any set of principles which universally offers even prima facie methodological justification.

In what follows I argue against methodological particularism. $\$ 2.2$ contains a brief note on terminology. In $\$ 2.3$ I expound a view of philosophical methodology important to the main argument. According to that argument, which appears in $\$ 2.4$, the intelligibility of certain paradigmatic metaphilosophical questions entails that there exist useful, general principles to guide the practice of doing philosophy well. Given that we have good reason

\footnotetext{
13 Of course, the generalist need not be able to distinguish which set of methodological principles conduces to doing philosophy well. Moreover, generalism is silent regarding the ease by which such principles can be distinguished. As such, although the generalist is committed to the claim that some philosophers are in fact doing philosophy poorly merely by virtue of their methodology, she is not committed to thinking that any philosopher is unjustified in adopting the methodology that she does.

14 One might find a useful comparison with W.D. Ross's prima facie duties. Ross 1930: chapter two.
} 
to think at least some of these questions are intelligible, it follows that methodological particularism is probably false.

\subsection{A Note on Terminology}

There is, rather unhelpfully, already a metaphilosophical position which goes by the name 'particularism.' In The Problem of the Criterion (1973), Roderick Chisholm highlights the role that reflective equilibrium plays in philosophical theorizing. He distinguishes two methodological points of emphasis (15). The philosophical particularist believes that one ought to privilege case judgments over general principles when engaging in reflective equilibrium. The philosophical methodist believes one ought to privilege general principles over case judgments when engaging in reflective equilibrium. ${ }^{15}$ According to my terminology, both Chisholm's philosophical particularist and his philosophical methodist count as methodological generalists because both provide a general principle which guides how one ought to engage in reflective equilibrium.

The present terminology is parasitic not on Chisholm's distinction but on the type of moral particularism that Jonathan Dancy propagated in the 1980s and 90s and the debates that such a view generated. ${ }^{16}$ Moral particularism is the view (roughly) that "moral judgment can get along perfectly well without any appeal to principles" (Dancy 2004: 1). Moral particularism stands opposed to moral generalism, the view that "the very possibility of moral thought and judgment depends on the provision of a suitable supply of moral principles" (7). Analogous positions can be constructed, inter alia, in epistemology, semantics,

\footnotetext{
15 Chisholm cites Locke as a methodist and Reid as a particularist (15-19).

16 See, e.g., Dancy 1983, Dancy 1993, Dancy 2004.
} 
etiology, and, importantly for our purposes, philosophical methodology. ${ }^{17}$

\subsection{What Is Philosophical Methodology?}

We can distinguish the normative study of philosophical methodology from the descriptive study of philosophical methodology. The normative study of philosophical methodology is, in the broadest sense, the study of how to do philosophy well. The descriptive study of philosophical methodology is the study of what philosophers actually do when they do philosophy. The normative study of philosophical methodology is itself a branch of philosophy; the descriptive study of philosophical methodology is more akin to the sociology of philosophy. ${ }^{18}$ The debate between methodological particularists and methodological generalists is most closely associated with normative philosophical methodology, though there is a sense in which the debate is meta-methodological.

To know how to do philosophy well, one needs to know what the goal of doing philosophy is. Debates within philosophical methodology need not definitively settle this issue. Indeed, these debates need not even settle whether there is a single goal or multiple goals. Instead, the methodologist might simply map logical space: given goal $\Gamma$, adopt procedure $\Phi$. It is compatible with generalism that there are multiple appropriate but incompatible philosophical methodologies, so long as these methodological differences are generated by acceptably different philosophical goals.

\footnotetext{
${ }^{17}$ Granted, it is a terminological cost to employ an old word in a new way, but the gain in accuracy is, I think, worth the price. One might, for example, be tempted to apply the terms 'methodological pluralism' and 'methodological monism' to the views I will consider, but given the way that 'methodology' is defined below, it is compatible with methodological generalism that one endorse a plurality of philosophical methodologies. For readers familiar with Dancy's work and the opposing literature that it spawned, the term is also a reminder to analogize, which may prove another benefit.

18 Which is not to say that the empirical information the descriptive project delivers is irrelevant to the normative project. If the descriptive claims of (e.g.,) Cappelen 2012 or Deutsch 2015 regarding intuition turn out to be accurate, then some of the questions which have hitherto been central to the normative question will have to be abandoned.
} 
Not all answers to the question 'How does one do philosophy well?' fall under the purview of philosophical methodology. Doing philosophy well requires a certain clarity of thought, and, as embodied creatures, the clarity of our thought depends in part on the condition of our bodies. But the methodologist should not be expected to have anything to say about which diet/exercise regimen most conduces to doing philosophy well. Such considerations are outside the scope of philosophy. But ruling out such answers while preserving the answers that pre-theoretically look to fall under the purview of philosophical methodology is not easy.

One rough way to effect such a separation is to consider which elements of doing philosophy are unique to philosophy and which elements are common to other disciplines. ${ }^{19}$ Thinking clearly conduces to doing philosophy well, but it also is helpful in many other areas. Thus, those studying philosophical methodology ought not concern themselves with the subject. Unfortunately, there may not be any element of doing philosophy wholly unique to philosophy. ${ }^{20}$ A priori reasoning is common to both philosophy and mathematics. Thought experimentation is common to both philosophy and physics. Close reading and exegesis ${ }^{21}$ is common to both philosophy and history. And so on. ${ }^{22}$

To home in further, one could distinguish the content of our thought processes from the background conditions which enable those thought processes to run efficiently.

\footnotetext{
19 To make this distinction one must be able to (roughly) separate philosophy from other disciplines. Lest our metaphilosophical digressions come to overshadow our present topic, I'll set that difficulty aside.

20 This is to say that philosophy is distinguished by its content, not by its methods.

${ }^{21}$ By which I include something like the epistemic importance of historical sources, which can be contrasted with disciplines that are fervently ahistorical, like math. (Admittedly, some would like to see philosophy similarly ahistorical.)

22 Of course, there may be no other discipline which employs precisely this combination of elements, but if philosophical methodology were restricted to treating methods that lie within the unique intersection of these elements, it would be an overly-specialized (and thus practically useless) field.
} 
One might think that philosophical methodology pertains to the contents of our metaphilosophical beliefs, not the manner in which those beliefs are generated. Thus, whether philosophical arguments can overthrow commonsense convictions is an appropriate issue to be investigated under the banner of philosophical methodology, but whether drinking coffee after 2:00 pm produces better or worse philosophical theorizing is not. Unfortunately, this approach won't work either, for two reasons. One: some metaphilosophical beliefs might influence philosophical efficacy without falling under the purview of philosophical methodology. Thinking that doing philosophy is easy, for example, might make one a better philosopher (or vice versa). But this is a question for psychology, not philosophy. More importantly, two: philosophical methodology is not interested merely in metaphilosophical beliefs; it's also interested in metaphilosophical practices.

The best way to delineate the subject matter of philosophical methodology requires taking a substantive stand on the nature of philosophical methodology itself, in a way which bears, as we'll see below, on the debate between methodological particularists and methodological generalists. On this construal, the normative study of philosophical methodology is really just the epistemology of philosophical inquiry. At its heart, philosophical methodology seeks to answer two questions: (1) What would count as evidence for a philosophical theory? and (2) How, if it is possible, can we obtain that sort of evidence?. Or, alternatively: (1') In virtue of what is one justified in believing a philosophical theory? and (2') How, if at all, can one attain such justification ? $^{23}$ This approach preserves the dual focus on beliefs (the first question) and practices (the second question). The approach also excludes irrelevant questions of

\footnotetext{
23 Of course, this approach is only helpful if one already has a handle on what makes something a philosophical theory. Again, I'll set this difficulty aside.
} 
psychology and physiology. ${ }^{24}$ Finally, this approach matches the actual topics which are promoted under the epithet 'philosophical methodology. ${ }^{25}$

Two objections to this conception bear considering. ${ }^{26}$ The first objection is that there is nothing uniquely philosophical about philosophical methodology, understood in this epistemic sense. According to this objection, there is nothing epistemically distinctive about coming to have philosophical knowledge or justification. Coming to justifiably endorse a philosophical theory might require a priori reasoning, thought experimentation, or exegetical interpretation, but, as noted above, these methods are employed by other disciplines as well. So philosophical methodology is not merely a branch of epistemology; it simply collapses to epistemology more generally. ${ }^{27}$

Even granting that there is nothing epistemically distinctive about coming to have philosophical knowledge, this objection is misguided because it fails to recognize that many branches of philosophy are distinguished by their contents, not by their methods. Philosophy of time is a branch of metaphysics, but it doesn't collapse to metaphysics. The philosophical significance of these content-distinguished branches plays a role in the way the taxonomy is carved. Philosophy of board games is not properly called a branch of philosophy, not because we couldn't pursue it, but because board games are not particularly philosophically interesting. The epistemology of philosophical inquiry is at least prima facie

\footnotetext{
24 Admittedly, this exclusion is parasitic on such questions falling outside the purview of epistemology more generally. How this exclusion is effected is not entirely clear.

25 Not perfectly, but close enough. It's of course compatible with this approach that some philosophers misuse the label 'philosophical methodology.'

26 Both objections derive from Dever 2016.

${ }^{27}$ Here is as good a place as any to mention that methodological particularism does not entail epistemic particularism, the view that there are no general epistemic principles.
} 
philosophically interesting because it is potentially relevant to each and every branch of philosophy. ${ }^{28}$

A second objection is that the epistemological conception of philosophical methodology deviates too far from standard methodological talk. ${ }^{29}$ Sometimes criticism of the aims and objectives of contemporary Anglo-American philosophy is couched in methodological terms, as when feminists (justifiably) complain that analytic philosophy is disconnected from real world concerns. Sometimes pragmatic considerations of theory selection are touted as methodological principles, as when a theory is adopted as one's working theory in virtue of its parsimony, not because parsimony is truth-conducive but because simpler theories are easier to work with. Sometimes substantive pre-theoretic assumptions are advertised as mere methodological doctrines, as when physicalism or materialism is assumed without argument. There is not much to be said here except that sometimes the term 'methodological' gets misused. The goals of philosophy are theoretically prior to the methods of philosophy. Respecting certain pragmatic considerations of theory selection may help us do philosophy better, but these considerations are closer in kind to the physiological and psychological considerations dismissed above than they are to genuine methodological principles. And of course it's possible to try to hide one's substantive pretheoretic commitments beneath an innocuous veneer of methodology, but this strategy is, at best, periphrastic.

\footnotetext{
28 It might turn out that at the end of the day, there are no philosophically interesting methodological questions, but working this out will require treating philosophical methodology as a unique branch of philosophy.

29 See Dever 2016 for supporting quotes.
} 


\subsection{Argument Against Methodological Particularism}

Having defined the relevant sense of 'particularism' and 'methodological,' I turn now to arguing against methodological particularism. But first a strawman worry and a quicktoo quick-argument.

It might be said that methodological particularism is an obviously false view, hardly worth considering, much less disproving. After all, here are some methodological principles. Don't beg the question against your dialectical opponent. Don't commit the 'affirming the consequent' fallacy. Don't engage in ad hominem attacks. The particularist is ostensibly committed to the possibility that these principles ought sometimes to be completely ignored. But clearly these principles ought never to be completely ignored. So particularism is obviously false and thus uninteresting.

This quick argument misses the nature of methodological particularism. Recall that methodological particularism is the view that there are no useful, general, methodological principles. Those three terms deserve some overdue attention. A principle qualifies as methodological (in our sense) just in case the principle tell us what counts (or doesn't count) as evidence for (or against) a philosophical theory and/or how to obtain such evidence. A methodological principle qualifies as general just in case the principle specifies considerations that always count as evidence of doing philosophy well (or poorly), even if circumstances occasionally require the principle to be flouted. A general methodological principle qualifies as useful just in case the principle is specific enough to parse practicing philosophers into two non-empty groups: those that endorse ${ }^{30}$ the principle as argumentatively essential and those

\footnotetext{
30 Or, upon learning that they follow this principle, would endorse
} 
that don't. The principle don't beg the question against your dialectical opponent (and its like) is not a useful methodological principle because no practicing philosopher self-consciously rejects it. So the quick argument doesn't go through.

But the quick argument does suggest a generic argumentative structure. Consider the following three paradigmatic methodological questions:

INTUITION. Does the intuition that $\mathrm{p}$ (prima facie) justify the belief that $\mathrm{p}$ ? If so, how/when? If not, why not?31

THEORETICAL VIRTUE. Are so-called theoretical virtues (e.g., parsimony/simplicity) truth-conducive? If so, how/when? If not, why not?32

COMMON SENSE. Can philosophical arguments ever justifiably overthrow our commonsense convictions? If so, how/when? If not, why not?33

Given these three questions, we can formulate an argument for generalism:

\section{Argument for Generalism}

(1) If there is an intelligible answer to either INTUITION, THEORETICAL VIRTUE, or COMMON SENSE, then there is at least one useful general methodological principle.

(2) There is an intelligible answer to either INTUITION, THEORETICAL VIRTUE, or COMMON SENSE.

(3) So there is at least one useful general methodological principle.

(4) If there is at least one useful general methodological principle, then methodological particularism is false.

$\therefore$

(c) So methodological particularism is false.

I'll defend the premises in reverse order and then consider a big picture worry about the argumentative structure. Premise (4) follows from the definition of particularism, and premise (3) is the logical consequence of premises (1) and (2). We begin, then, with premise (2).

\footnotetext{
31 See, inter alia, Bealer 1996, Bengson 2013, Chudnoff 2011, Hales 2012, Hintikka 1999, Sosa 2006.

32 See, inter alia, Baker 2003, Klein \& Warfield 1994, Sober 2002, Swinburne 1997, Weatherson 2003.

33 See, inter alia, Gupta 2006, Lemos 2004, Lycan 2001, Kelly 2008, Rinard 2013.
} 
It is by no means obvious that INTUITION, THEORETICAL VIRTUE, and COMMON SENSE represent well-formed questions. For example, it may turn out-as this monograph argues - that the category picked out by 'intuition' is hopelessly over-broad, ambiguous, vague, or otherwise confused. In that case, there would be no general justificatory or evidential role for intuitions because there would exist no unified, monolithic mental state picked out by 'intuition.' Nor would such a state of affairs imply that none of the mental states hitherto regarded as intuitions ever play a justificatory or evidential role. It may be that some of the mental states which are currently called 'intuitions' play a justificatory role and others do not. We might very well be led to a species of particularism about the justificatory role of the heterogeneous category 'intuition.' Mutatis mutandis for THEORETICAL VIRTUE and COMMON SENSE.

There is, I'm afraid, not much to be said in the abstract about such worries. Indeed, I am sympathetic to difficulties in adjudicating the extension of concepts like 'intuition,' 'theoretical virtue,' and 'common sense.' It should be noted, however, that in order for the particularist to succeed in rejecting premise (2), it must be the case that all three paradigmatic questions are confused. Other paradigmatic questions which lead to methodological principles and thus can be substituted into premise (2) must also be confused. There seems to be no unifying feature shared by INTUITION, THEORETICAL VIRTUE, and COMMON SENSE (aside from falling under the methodological banner), so it's hard to see how a single argument could be jointly marshaled against the intelligibility of the questions. So it appears the particularist will have to employ a piecemeal strategy, arguing on grounds unique to each question that the question is mistaken. Given the number of intelligent philosophers 
investigating these questions, philosophers who would be sensitive to arguments against the intelligibility of the questions if such arguments existed, it seems unlikely that such a strategy would succeed in every case. On the basis of such considerations, it seems the burden of proof is on the particularist to show that premise (2) is false.

Conceding premise (2), the particularist might still reject premise (1). The particularist may grant that 'intuition' is a perfectly well-defined category and that there are intelligible answers to the question 'Does the intuition that $\mathrm{p}$ justify the belief that p?', but deny that this commits her to methodological generalism. Three answers to the question 'Does the intuition that $\mathrm{p}$ justify the belief that p?' present themselves:

(a) The intuition that $\mathrm{p}$ always justifies the belief that $\mathrm{p}$.

(b) The intuition that $\mathrm{p}$ never justifies the belief that $\mathrm{p}$.

(c) The intuition that $\mathrm{p}$ sometimes justifies the belief that $\mathrm{p}$.

The particularist may concede that answers (a) and (b), if true, would generate normatively binding methodological principles, but so long as there is a third intelligible option, premise (1) is false. By endorsing (c), the particularist avoids the slide to generalism. The particularist claims that in some cases intuitions are good evidence and in others not, but there are no principles governing the difference. Sometimes the intuition that $\mathrm{p}$ justifies the belief that $\mathrm{p}$ and sometimes the intuition that $\mathrm{p}$ does not justify the belief that $\mathrm{p}$. So sometimes intuitions should be ignored and sometimes they should not be ignored. It depends on the particular case.

This reaction to premise (1) mischaracterizes the nature of the paradigmatic questions. (c) is not, in fact, an intelligible answer to INTUITION. In effect, the particularist here treats the question 'Does the intuition that $\mathrm{p}$ justify the belief that $\mathrm{p}$ ?' as akin to the 
question 'Does the clock's reading 9:59 justify the belief that the meeting will start soon?'. Of course, in some circumstances the clock's reading 9:59, together with other background beliefs, will justify the belief that the meeting will start soon and in other circumstances the clock's reading 9:59 will not justify such a belief. But the first question is really asking 'Does the intuition that $\mathrm{p}$ by itself justify the belief that p?'. There is nothing in the essence of clocks which justifies beliefs about meetings, but there may be something special about intuitions such that the intuition that $\mathrm{p}$ always provides some level of justification for the belief that p. Nobody believes anything about meetings on the basis of information about clocks alone. But philosophers do sometimes believe that $\mathrm{p}$ solely on the basis of the intuition that p. (c) is not the correct answer to INTUITION because it implies that, even bolding all the case facts constant, sometimes intuition is a source of justification and sometimes it is not. Such a view is borderline inconsistent. But particularists are already committed to the falsity of (a) and (b). And if (a), (b), and (c) are all false, it means that there is no possible answer to INTUITION and hence that the question is ill-formed. Thus the particularist is thrown back to denying premise (2).

To make the above point clearer, let's consider a case which might motivate answer (c). Suppose one takes a pill which produces an intuition that $\mathrm{p}$ if and only if in fact $\neg \mathrm{p}$ (and one knows one has taken such a pill). In this example, says the particularist, the intuition that $\mathrm{p}$ does not even prima facie justify the belief that $\mathrm{p}$. But the thought experiment doesn't rule out the possibility that in normal cases the intuition that $\mathrm{p}$ does justify the belief that $\mathrm{p}$, so answer (c) looks not only intelligible but imminently plausible. 
The generalist responds in one of two ways. Either the intuition that $\mathrm{p}$ never justifies the belief that $\mathrm{p}$ (in which case we should go in for answer (b)), or in the thought experiment the intuition that $\mathrm{p}$ does prima facie justify the belief that $\mathrm{p}$, but this justification is immediately undermined by one's knowledge of having taken the pill (in which case we should go in for answer (a)). In the thought experiment the intuition that p plays two roles: (1) its natural, evidentiary role in favor of $\mathrm{p}$, and (2) a secondary role as a proxy indicator for $\neg$ p. But we're only interested in the role of intuitions qua intuitions. Compare: a reliable source informs you that she will arrange to have your horoscope read 'a person will mow your lawn' just in case she intends to mow your lawn. Does this mean that your horoscope's prediction that $\mathrm{p}$ is good evidence that $\mathrm{p}$ ? In a sense, yes. Knowing what you do about the reliable source, if you read in your horoscope that someone will mow your lawn, you will be justified in believing that someone will mow your lawn. But this justification is totally parasitic on the justification that reliable testimony delivers. In isolation, the horoscope does not justify the belief. Your horoscope is a proxy indicator for the future state of your lawn, but qua horoscope it offers no evidence regarding the future state of your lawn. Mutatis mutandis for the intuition case.

If premises (1) and (2) are true in the above sense, then there exists at least one useful, general, methodological principle. Examples, I hope, are obvious. If it's true that the intuition that $\mathrm{p}$ justifies the belief that $\mathrm{p}$, then we have the methodological principle the intuition that $p$ is evidence that $p .^{34}$ If theoretical virtues are not truth-conducive, then we have the methodological principle don't appeal to simplicity when defending the truth of your theory. If

\footnotetext{
${ }^{34}$ I assume here that evidence is sometimes misleading. If you're a Williamsonian about evidence, the principle will have to be slightly modified.
} 
philosophical arguments cannot justifiably overthrow commonsense convictions, then we have the methodological principle commonsense beliefs ought to be preserved in the course of philosophical theorizing. And so on.

But perhaps the argument begets too many principles. The big picture worry is that the argumentative structure radically overgenerates methodological principles and thus cuts no ice against methodological particularism. According to this objection, more or less every substantive philosophical question yields methodological principles. Consider, for instance, the debate between intuitionist logicians and classical logicians about the validity of doublenegation elimination. ${ }^{35}$ Suppose there is an intelligible way to settle this debate and that the intuitionists are right: double-negation elimination is an invalid rule. Thus we have a methodological principle: don't utilize the double-negation elimination rule in your arguments. But methodologists should not be expected to have anything to say about the validity of doublenegation; that's an issue for the logicians. Furthermore, there's nothing special about the debate between the intuitionist logicians and classical logicians. Debates in, inter alia, semantics, mereology, philosophy of mind, and metaethics will also yield substantive methodological principles. But if methodological particularism is false merely in virtue of there being an intelligible answer to any philosophical question, then methodological particularism is nothing more than a hollow strawman. But given that methodological generalism is not merely trivially true, it follows that there must be something wrong with my argumentative structure.

\footnotetext{
35 Thanks to Josh Dever for this example.
} 
This objection brings us full-circle because it once again misunderstands the nature of methodological particularism. Recall (for the final time) that methodological particularism is the view that there are no useful, general, methodological principles. Recall as well that a general methodological principle qualifies as useful just in case the principle is specific enough to parse practicing philosophers into two non-empty groups: those that endorse the principle as argumentatively essential and those that don't. Given this definition, we can see that debates about intuition properly fall within philosophical methodology while debates about double-negation do not. Appeals to intuition are significantly more common and argumentatively essential than appeals to double-negation, so the methodological principle don't appeal to intuition counts as useful but the methodological principle don't appeal to doublenegation does not. This distinction may strike readers as ad hoc, but given the conception of philosophical methodology defended above, it should come as no surprise. Philosophical methodology is a field individuated by its content, not by its methods. Appeals to intuition occupy a central role in the methodology of contemporary philosophers; appeals to doublenegation do not. Thus the objection fails. Methodological particularism is false, but it is not trivially false.

\section{Against Descriptive INTUition SKePticism}

\subsection{Normative vs. Descriptive Intuition Skepticism}

The orthodox view is that intuitions play a central role in philosophical theorizing; that these intuitions function directly as evidence in philosophical arguments or, no less importantly, indirectly as a source of evidence; and that this is an appropriate role for intuitions to play. The orthodox view has both normative and descriptive components. The 
normative component is that intuitions appropriately feature as (a source of) evidence in philosophical arguments. Depending on one's view of evidence, that means variously that the intuition that $\mathrm{p}$ offers prima facie justification for the belief that $\mathrm{p}$, that the intuition that $\mathrm{p}$ reliably (but fallibly) tracks the truth that $\mathrm{p}$, or that the intuition that $\mathrm{p}$ offers a defeasible (epistemic) reason to believe that $\mathrm{p}$. The normative component has been under attack since at least the $1990 \mathrm{~s}^{36}$ and continues to come under fire today. ${ }^{37}$ The descriptive component of the orthodox view is that intuitions in fact play a central evidential role in philosophical theorizing and argumentation, whether or not this is an appropriate role for them to play. ${ }^{38}$ Criticism of the descriptive component of the orthodox view is much more recent. ${ }^{39}$

We can thus distinguish two varieties of intuition skepticism: normative intuition skepticism and descriptive intuition skepticism. Normative intuition skepticism appears under a number of guises - the intuition that $\mathrm{p}$ does not justify the belief that $\mathrm{p}$, the intuition that $\mathrm{p}$ does not reliably track the truth that $\mathrm{p}$, the intuition that $\mathrm{p}$ is not a reason to believe that $\mathrm{p}$-but the basic point is the same: intuitions ought not play the role they are commonly taken to play in philosophical argumentation. Descriptive intuition skepticism is different. According to the descriptive intuition skeptic, whether or not intuitions should play the role they are commonly taken to play in philosophical argumentation, as a matter of sociological fact, intuitions do not play such a role. Our self-conception of contemporary philosophical

\footnotetext{
36 See Stich 1990, Goldman 1992, Cummins 1998, Hintikka 1999.

37 See Machery et al. 2004; Alexander \& Weinberg 2007; Swain, Alexander, \& Weinberg 2008; Weinberg et al. 2012.

38 We can distinguish something's playing an evidential role from something's being evidence. The entrails of sacrificed sheep were treated as evidence by ancient Roman haruspices but were not in fact evidence for the propositions the haruspices claimed they were evidence for. In contrast, stellar parallax has always been evidence for the heliocentric model of the solar system, even though it has only played an evidential role since the mid-19 $9^{\text {th }}$ century.

39 See Williamson 2007; Deutsch 2009, 2010, 2015; Cappelen 2012; Molyneux 2014.
} 
practice is mistaken. By and large, intuitions are not offered as premises in philosophical arguments, nor are they presented as the source for premises in philosophical arguments. Where intuitions appear at all in philosophy, they are argumentatively inessential (though, as we'll see below, they may play other important roles). In short, according to the descriptive intuition skeptic the orthodox view vastly overestimates the degree to which intuitions play a role in contemporary analytic philosophy. ${ }^{40}$

The descriptive skeptic ${ }^{41}$ is not committed to the claim that intuitions play no role in philosophy. Indeed, it is compatible with descriptive skepticism that intuitions play a large part in the philosophical enterprise, broadly conceived. However, it's important for the descriptive skeptic to separate the context of justification from the context of discovery and the context of explanation. The descriptive skeptic claims that intuitions play no role in the context of justification; that is, intuitions are not treated as evidence or sources of evidence. The descriptive skeptic can leave open the possibility that intuitions play a major role in the context of discovery (as, say, inspiration) or the context of explanation (as, say, pedagogical tool for effectively communicating one's position). The descriptive skeptic can even leave open the possibility that intuitions are what license valid deductive inferences, without committing to the claim that intuitions are used as evidence in philosophical arguments. ${ }^{42}$

\footnotetext{
40 There is a third view in the vicinity which ought to be distinguished from both normative and descriptive intuition skepticism: intuition nibilism. Intuition nihilism is the view that there are no such things as intuitions. 'Intuition' is akin to 'phlogiston:' a term without extension. Intuition nihilism is distinct from but entails descriptive skepticism. (One can't appeal to what does not exist.) Intuition nihilism is a position that is rarely defended explicitly, although sympathy towards (if not outright endorsement of) the view may underpin at least some of the motivation for descriptive skepticism.

41 In what follows I'll allow 'intuition' to remain implicit.

42 If intuitions license valid deductive inferences by being evidence for various propositions (e.g., the proposition modus ponens is valid) then we would be stuck in a familiar Lewis Carroll style regress, so if intuitions license inferences, they must do so non-evidentially. Molyneux (2014: 450-452) seems to believe this usage of
} 
In what follows I argue against descriptive skepticism. The section proceeds in three main parts. In $\$ 3.2 \mathrm{I}$ identify two broad strategies by which to argue for descriptive skepticism, the case studies approach and the methodological principles approach. I criticize the case studies approach and offer reasons to prefer the methodological principles approach. In \$3.3 I evaluate two arguments in favor of descriptive skepticism: the argument from anomalous inadmissibility and the argument from insufficiency. After rebutting each argument, in $\$ 3.4 \mathrm{I}$ consider responses to the most obvious argument against descriptive skepticism, the argument from absence of alternatives. Along the way I show how one can accommodate the data uncovered by the case studies approach without establishing the skeptical conclusion that certain defenders of the case studies approach wish to establish. §3.5 concludes.

\subsection{The Argument from Case Studies}

There are two main ways to argue for descriptive skepticism. The first and to-date most popular is careful analysis of cases where intuitions allegedly feature as evidence in philosophical arguments. In Max Deutsch's (2015) book-length defense of descriptive skepticism, he pays special attention to Gettier's counterexamples to the JTB theory of knowledge and Kripke's counterexamples to the descriptivist theory of reference. He notes approvingly that neither Gettier nor Kripke mention anything about intuitions when presenting and discussing their thought experiments and argues persuasively that Gettier's and Kripke's arguments are often misrepresented as explicitly relying on intuition. In

intuition is grounds for thinking intuitions are never treated as evidence. But pretty clearly this (non-evidential) usage of intuition is compatible with the (evidential) orthodox view. 
Herman Cappelen's (2012) own book-length defense of descriptive skepticism, ${ }^{43}$ he also discusses Gettier and Kripke and adds to the investigation ten or so other specimens. ${ }^{44} \mathrm{He}$ finds a similar absence of explicit appeals to intuition and a similar misrepresentation of the arguments in popular philosophical mythos.

The goal of this exegesis is to debunk the claim that intuitions are appealed to in these cases (or, if they are appealed to, the goal is to show that they are argumentative thirdwheels). Strategies of this form typically adopt the following generic structure:

(1) Appeals to intuitions, if they existed, would exhibit features $F_{1} \ldots F_{n}$.

(2) But nothing in our actual philosophical practice exhibits features $F_{1} \ldots F_{n}$. $\therefore$

(c) So philosophers don't appeal to intuitions.

For example, although according to Cappelen "the notion of the intuitive is obscure" (2014: 580), he identifies several features that intuition theorists standardly take to characterize intuition (2012: 112-113). Intuitions exhibit or are accompanied by a special "seems true" phenomenology. Intuitions enjoy "default justificatory status" (that is, they justify but don't require justification). Intuitions are non-inferential and non-experiential. Intuitions are based solely on conceptual competence. After a careful analysis of his case studies, Cappelen concludes that none of the alleged paradigms of the intuitive exhibit the features we would expect if they were, in fact, appeals to intuition. Descriptive skepticism is presented as a promising alternative.

Deutsch's and Cappelen's case studies represent important and exciting work. It is undeniable that all too often these stock examples get re-constructed in the

\footnotetext{
43 Neither book, I should note, is exhausted by case studies. There is lots of other interesting material.

44 Including, inter alia, Burge's arthritis case, Thomson's violinist, Lehrer's Mr. Truetemp, and Chalmers on phenomenal zombies
} 
metaphilosophical literature in a way that elides their original presentation. It is refreshing to return to the primary texts to see how these famous cases were meant to figure in their authors' broader arguments. Intuitions, it seems, were far from the forefront.

Nonetheless, there are some pretty serious limitations to the case studies approach. The first is pragmatic: exegesis is hard. Even though Gettier does not mention intuition in the presentation of his cases, it does not follow that he did not rely on intuition in evaluating the cases and did not expect his audience to do the same. Discerning Gettier's intentions requires much more than superficial textual analysis. Kripke's Naming and Necessity is an even more difficult exegetical target. There are, for example, whole passages in which it is unclear if Kripke is being satirical, and one's reading of these passages may color the rest of the book. ${ }^{45}$ Cappelen and Deutsch recognize this challenge. They concede that the absence of explicit intuition talk in their case studies offers at best weak evidence in favor of descriptive skepticism. The real goal of the argument from case studies is to identify diagnostic features of appeals to intuition and then examine actual philosophical practice to see if those features are present. This is the right goal to have, but we shouldn't be blind to the fact that this is exactly the sort of exegetical work which naturally lends itself to multiple legitimate interpretations. $^{46}$

The second difficulty is that the case studies approach requires an ampliative inference if it is going to demonstrate that the orthodox view is mistaken. From the fact that ten philosophical arguments do not treat intuitions as evidence it does not follow directly

\footnotetext{
45 I have in mind passages like (64), "It really is a nice theory. The only defect I think it has is probably common to all philosophical theories. It's wrong. You may suspect me of proposing another theory in its place; but I hope not, because I'm sure it's wrong too if it is a theory."

46 See, for instance, Bengson 2014 \$4 for an alternate analysis of Kripke’s Gödel case.
} 
that intuitions are never (or even rarely) treated as evidence. The ten cases must somehow be paradigmatic or representative. Establishing the needed extra premise will be particularly challenging, but without it, opponents of descriptive skepticism will always have an easy out. Cappelen (130-131) explicitly acknowledges this limitation, but as he says, one has to start somewhere and descriptive skepticism is a nascent position. Moreover, the cases he analyzes are precisely those cases defenders of the orthodoxy put forward as the best evidence that intuitions feature in philosophical arguments. Thus, these case studies are an appropriate first word in favor of descriptive skepticism, and perhaps they even shift the burden of proof to defenders of the orthodox view. But as a final word on descriptive skepticism, the case studies approach is relatively weak. John Bengson (2014: 562, fn.13) has enumerated at least nine additional examples, not cited or discussed by Cappelen, in which philosophers allegedly clearly appeal to intuition. It's not obvious to me whether Bengson's list shifts the burden of proof back to Cappelen, but without criteria to distinguish a representative sample of case studies from a non-representative sample, it's clear the back-and-forth could continue for some time.

The third reason to worry about the case studies approach is that its conclusion will always be contingent and time-indexed. Demonstrating that certain philosophers do not appeal to intuition as (a source of) evidence in their arguments does not establish that philosophers couldn't appeal to intuitions if they so desired. ${ }^{47}$ And it does not establish that philosophers never have or never will appeal to intuitions in their arguments. All that the case

\footnotetext{
47 The exact modality of this 'could' is difficult to pin down. Defenders of the case studies approach probably don't want to argue that it is metaphysically impossible to appeal to intuitions (unless the argument for this position goes by way of intuition nihilism; see fn. 33 above). The relevant reading of 'could' is something like 'could, relative to the achievement of the actual aims of actual philosophers.'
} 
studies approach can establish is that during some smaller or greater (depending on the representativeness of the cases) interval of time, philosophers did not appeal to intuitions in their arguments. The case studies approach is thus an ongoing project.

The alternative to the case studies approach is to find some more general, less contingent, less exegetical argument for descriptive skepticism. In the next section, I identify two such arguments: the argument from anomalous inadmissibility and the argument from insufficiency. (These arguments appear explicitly in Molyneux 2014.) I call the strategy of adopting one or more of these types of arguments the 'methodological principles approach.' The goal of the methodological principles approach is to find some principle of philosophical methodology, inherent in the nature of philosophy itself, which prohibits appeals to intuition.

\subsection{Arguments from Methodological Principles}

The methodological principles approach is necessarily more ambitious than the case studies approach. To some, this characteristic might look more bug than feature. Perhaps all that is wanted is the modest, contingent, time-indexed conclusion that the case studies approach purportedly establishes. Nevertheless, there are at least two reasons to privilege an exploration of the methodological principles approach. First, if one or more of the arguments that fall under the methodological principles banner succeeds, the descriptive skeptic will have a much cleaner, much more robust route to descriptive skepticism. Second, although there is much to say in response to the descriptive skeptic's interpretation of the case studies, the best argument (to my mind) against descriptive skepticism itself appeals to something like methodological principles. Hence an investigation into the methodological 
principles approach may give some insight into the differing methodological principles held by descriptive skeptics and defenders of the orthodoxy. These revealed differences may, in turn, help resolve (or dissolve) entrenched dialectical stalemates in descriptive philosophical methodology.

\subsubsection{Argument from Anomalous Inadmissibility}

The argument from anomalous inadmissibility begins with the observation that sometimes intuitions cut very little ice in philosophical dialectics. Bernard Molyneux (2014: 454-456) presents Max Black's (1954) version of the problem of induction, ${ }^{48}$ then asks why the following "glib response" doesn't solve the problem:

(i) Intuitively, induction is an epistemically virtuous principle of reasoning, whereas counterinduction is not.

(ii) Therefore induction is an epistemically virtuous principle of reasoning, whereas counterinduction is not.

The reason can't be that the intuition appealed to in (i) is weak. As Molyneux notes, the “intuition favoring induction is as powerful and as widely held as any intuition in ethics, epistemology, or metaphysics" (455). Such examples could be multiplied many-fold. ${ }^{49}$ For instance, one wonders why mereological nihilism (endorsed by such heavyweights as Unger 1979, van Inwagen 1990, Dorr \& Rosen 2002, and Sider 2013) isn't destroyed by the strong and widespread intuition that there exists such things as clock-towers and television sets and that these things are composite objects. The argument from anomalous inadmissibility is thus a simple modus tollens. "If intuitions were standardly used as evidence, then our strong

\footnotetext{
48 Counterinduction is the principle that the future will not resemble the past. Black shows that, prima facie, counterinduction enjoys the same level of epistemic support as induction.

${ }^{49}$ Molyneux also references Goodman's (1955) “new riddle” of induction, Quine's (1964) indeterminacy of translation thesis, and Kripke's (1982) quaddition worries.
} 
intuitions should have settled these matters long ago" (456). But our strong intuitions did not settle these matters long ago. So intuitions must not be standardly used as evidence.

Of course, Molyneux concedes that sometimes it seems as if our intuitions decisively settle some philosophical dispute. According to received philosophical wisdom, the widespread and strong intuition that Gettier's subjects had justified true beliefs but not knowledge decisively overturned the JTB theory of knowledge. And so a defender of the orthodoxy might retreat to the position that intuitions sometimes feature as evidence and sometimes do not. But if intuitions are sometimes treated as evidence and sometimes not, then, according to Molyneux, "we are owed an account of why we use them as evidence when we do, and why we don't when we don't"' (456). Molyneux judges the prospects of developing such an account to be grim. He writes, "On the face of it, such an account is difficult to provide" (ibid.), adding "What's the relevant difference between, say, the Gettier case, where most [defenders of the orthodoxy] think that intuitions are used as evidence, and the case of induction, where it plainly seems they are not?" (ibid.).

Below is an attempt to provide such an account. But first we should note that there is an easy method for distinguishing the cases in which it would be pragmatically appropriate to appeal to intuitions from cases in which it would be pragmatically inappropriate to appeal to intuitions. One need only examine the dialectical status of the intuitions. It would be, for example, dialectically ineffective to cite cases involving clock-towers and flat-screen televisions in an attempt to convince the mereological nihilist that she is mistaken. Such cases arrive too late. The nihilist is well aware of the unintuitive consequences of her theory and will not be persuaded simply by being reminded of them. In contrast, Gettier's 
interlocutors had never considered cases like his and thus were unaware that the JTB theory of knowledge delivered such a counterintuitive verdict. Nevertheless, one must not confuse persuasiveness with decisiveness. ${ }^{50}$ One can offer a decisive (in the normative sense of the word) piece of evidence even if one's interlocutors are too stubborn to be persuaded by it.

A more sensible answer to the question invokes P.F. Strawson's (1959) distinction between "descriptive metaphysics" and "revisionary metaphysics." The basic distinction is one of ambition. Descriptive metaphysicians do not attempt to modify or amend the way we ordinarily think and deploy concepts; they aim merely to systematically describe it. Revisionary metaphysicians, on the other hand, seek an almost total overhaul. If we wish to adequately represent the world, they counsel us, we must systematically revise our conceptual schema. On this view, epistemologists investigating the nature of knowledge are pursuing a program in descriptive metaphysics. Therefore common-sense intuitive reactions to cases must play a central role in their theorizing. When, on the other hand, ontologists investigate the (alleged) existence of composite objects, they are engaged in revisionary metaphysics. Therefore common-sense intuitive reactions to cases ought not to play a central role in their theorizing.

The basic insight comes from Uriah Kriegel (2013: 8):

[W] hile intuitions about what object or scenario falls under what concept certainly constitute evidence for theories about metaphysics implicit in our conceptual scheme (i.e., descriptive-metaphysical theories) it is unclear how they could constitute evidence for theories about the conceptual-scheme-independent structure of the world (revisionary-metaphysical theories).

\footnotetext{
50 See Williamson 2007 (especially chapter seven) for a critique of the so-called "dialectical conception of evidence."
} 
He adds that the reason ontologists are justified in ignoring mereological intuitions is that in doing revisionary metaphysics, in contrast to descriptive metaphysics, we are

not concerned with the structure of our concepts or our conceptions of reality, but with the structure of reality itself. Insofar as it studies the concept of existence, for instance, its target is not the concept we have but the concept we ought to have; not the folk concept, but the philosophical concept. (9)

Descriptive metaphysicians investigate folk concepts. Revisionary metaphysicians investigate philosophical concepts. Respecting intuitive judgments about cases helps us understand folk concepts but not philosophical concepts. So if we are doing descriptive metaphysics when analyzing knowledge and revisionary metaphysics when investigating composite objects, we should respect intuitive judgments in the former but not the latter.

Now I don't actually want to endorse Kriegel's account. Maybe he’s on to something; maybe not. But the point is that it's not a prima facie crazy view. To my ear, it even has the ring of plausibility. And if anything like Kriegel's account is right, then the argument from anomalous inadmissibility doesn't go through because the inadmissibility that Molyneux identifies, when placed in the appropriate metaphilosophical context, simply isn't anomalous.

There is a second, and, I think, more powerful response to the argument from anomalous inadmissibility. According to this response, the reason we find the problem of induction so vexing, and the reason that it cannot be solved by appeal to intuition, is precisely because the problem of induction generates a conflict of intuition. Similarly, the reason why some ontologists find mereological nihilism so compelling is precisely because it captures many strong and powerful intuitions that ordinary object ontology misses. So philosophers do appeal to intuition, but when there are counterbalancing intuitions on the other side, the intuitions don't count for much. 
Consider the induction case. On the best interpretation, the problem of induction is a paradox. Induction seems to be a justified method for drawing conclusions about the world. But if induction is justified, it must be justified either deductively or inductively. ${ }^{51}$ It cannot be justified deductively because only necessary truths can be justified deductively, and the principle that the future will resemble the past is contingent. And it cannot be justified inductively because that would beg the question by assuming what we have set out to justify. And so we have a paradox: induction seems, in fact, to be justified, but seems not, in principle, to be justifiable. ${ }^{52}$ Now, there is a sense in which intuition plays a decisive evidential role in this debate. Intuition delivers, as a datum, that induction is justified. The problem of induction is the problem of making sense of and explaining that datum. Further appeals to intuition, it turns out, do not help us explain why the intuition is right.

A similar story can be told for the mereology case. ${ }^{53}$ Yes, it's common sense that there exists clock-towers and television sets, but even philosophers who respect common sense need not think it is infallible. ${ }^{54}$ A plausible argument for mereological nihilism begins with the intuition that physical entities can't have vague boundaries. ${ }^{55}$ Ordinary object ontology cannot accommodate this intuition, and so it is reasonable to search for alternatives. Defenders of nihilism then marshal additional intuitions to support the view,

\footnotetext{
51 I here construe 'deduction' and 'induction' broadly so that deduction and induction exhaust possible types of reasoning.

${ }^{52}$ Let me just flag that I realize this is a very cartoonish picture of the problem. A more careful presentation of the problem would be much more subtle and nuanced. But the details don't affect the point I'm making here.

53 Indeed, Michael Rea (1995) explicitly presents the problem of material constitution as a conflict of intuition between five individually plausible but jointly incompatible assumptions.

54 After all, it's also common sense (in at least a loose understanding of the phrase) that the bricks that make up the clock-tower are not composed primarily of empty space. But atoms are composed primarily of empty space, and the bricks are composed of atoms, so this piece of common sense is false.

55 Alternatively, this claim is supported by the counterintuitive consequences that result from allowing vague objects. Either way, the argument begins with intuition.
} 
such as the intuition that ideological parsimony is truth-conducive. Once again, it's not true that intuitions are inadmissible in arguments against the nihilist. The nihilist simply believes that, after a process of reflective equilibrium, the common sense which underpins ordinary object ontology isn't sustainable.

So much for the argument from anomalous inadmissibility. In the next section I consider the argument from insufficiency.

\subsubsection{Argument from Insufficiency}

According to Molyneux's argument from insufficiency (446-50), "the propositions that intuition putatively supports are treated as having a degree and kind of certainty and justification that they could not have got from being intuited" (446). The argument proceeds by examining an "obviously true" (446) philosophical principle allegedly known only via intuition. He calls the principle under consideration the possibility principle (PP):

(PP): $p$ is possible only if $\neg p$ is not necessary.

He then attempts to derive a contradiction from the assumption that philosophers treat intuition as evidence and the only evidence for PP. The allegedly inconsistent set is as follows (where “(I)PP” represents the proposition that one intuits that PP):

(i) I(PP) is treated as evidence for PP.

(ii) Nothing except I(PP) is treated as evidence for PP.

(iii) The justification for PP is not undermined by assaults on I(PP).

(iv) $\mathrm{PP}$ is treated as being more certain and justified than $\mathrm{I}(\mathrm{PP})$.

(v) PP is treated as justified a priori.

According to Molyneux, (i) and (ii) suggest the negation of (iii)-(v). If (i) and (ii) are true, then insofar as we come to doubt I(PP) we should correspondingly doubt PP, hence the tension with (iii). Similarly, if I(PP) is our only evidence for PP, we should never be more 
certain about PP than we are about I(PP), hence the tension with (iv). And if intuition is a mental state which we access via a posteriori introspection, and $\mathrm{I}(\mathrm{PP})$ is our only evidence for PP, we shouldn't treat PP as justified a priori, hence the tension with (v). Thus, according to Molyneux, we have two choices: reject (i) and (ii) or reject (iii)-(v). He recommends the former. I'll argue instead that we ought to reject (iii) and (iv) and that (v) is not incompatible with (i) and (ii).

I begin with a brief discussion of (v), which essentially amounts to terminological haggling over the appropriate way to apply the predicate 'a priori.' There is, unfortunately, no standard account of a priori reasoning. A first pass characterization is something like 'reasoning without the aid of experience.' But care must be taken to distinguish both the inputs of a priori reasoning and the background conditions of a priori reasoning from the a priori reasoning process itself. Mathematics is an a priori discipline if anything is, but learning calculus requires the aid of all kinds of experience. One must use one's ears to hear one's instructor and use one's eyes to read one's textbook. Similarly, one can reason a priori using inputs learned a posteriori. It is an empirical, contingent fact that the Gateway Arch in St. Louis is a catenary curve, a fact known only with the aid of experience. Nevertheless, determining the area under the Gateway Arch is an a priori exercise.

Whether or not introspection is a type of experience is a vexed question, but even granting that introspection is a species of a posteriori reasoning, it doesn't follow that the propositions introspected are justified a posteriori. Seeing the truth of PP is independent of introspection in the same way that the area under a given catenary curve is independent of the architecture of the Gateway Arch. An analogy to water is perhaps helpful. It's a 
contingent, empirical fact that the clear, liquid stuff in our streams and lakes is (mostly) $\mathrm{H}_{2} \mathrm{O}$. But although we know the chemical composition of water only through a posteriori reasoning, it doesn't follow that we don't know the modal fact, that water is necessarily $\mathrm{H}_{2} \mathrm{O}$, through a priori reasoning.

The broader point is this: the first-pass characterization of a priori reasoning is not a full theory. It's not even close. Intuition is standardly taken to be a paradigm form of a priori reasoning. Perhaps, as Molyneux believes, this is a mistake. But if it's a mistake it doesn't tell against the claim that intuitions figure in philosophical arguments; it tells against a naïve theory of a priori reasoning. There is at least $a$ sense in which PP's being justified a priori is compatible with PP's being known through intuition. And if this sense doesn't survive sustained scrutiny then we will have learned, it seems to me, something interesting about a priori reasoning, not anything new about intuition.

I turn now to more substantive discussion of (iii) and (iv). Regarding (iii) Molyneux writes,

To see why (iii) is hard to deny, note how attacks on I(PP) leave PP unchallenged. For example, the classical Platonist might argue that we don't intuit PP; rather, we recall it. And the contemporary nativist, similarly, may suppose that PP is not intuited but abstracted from our native beliefs. An empiricist might argue that PP, rather than being intuited, is extracted from lessons learned via past experience, in which it was implicit. And the attitude eliminativist, meanwhile, might even claim that there are no such mental states as intuitions. On any of these views, I(PP) would be false. But such considerations would not undermine PP in the slightest. (447)

This argument is question-begging. If the Platonist, the nativist, the empiricist, or the eliminativist is right, then (ii) is false-intuition isn't treated as our only source of evidence for PP. So if (ii) is a tenet of the orthodox view, then Platonism, nativism, empiricism, and 
eliminativism presuppose that the orthodox view is false. Perhaps this shows that the orthodox view is not as widespread as one might have thought. ${ }^{56}$ But it cuts exactly no dialectical ice to show how four views which presuppose the falsity of the orthodox view are incompatible with the orthodox view. To put the point another way, (iii) is only hard to deny if one has already denied (ii). To properly defend (iii), Molyneux would have to offer reasons to support (iii) independent of the truth or falsity of (ii). But this he cannot do. If intuition is our only possible source of evidence for PP, then if we were to lose access to that evidence, the defender of the orthodoxy is happy to admit that we would also lose our justification for endorsing PP.

Molyneux defends (iv) in a similar fashion. No philosopher seriously doubts PP. But the Platonist, the nativist, the empiricist, and the eliminativist all doubt (I)PP. ${ }^{57}$ So PP is treated as more certain than I(PP). Again, though, the defense of (iv) is really just a veiled assault on (ii). Molyneux seems to assume that all philosophical positions must be in principle compatible with the orthodox view. Any incompatibility is treated as evidence that the orthodox view is mistaken. This is a strange strategy. Of course on the assumption that there are no such things as intuition we have good reason to reject the orthodox view. ${ }^{58}$ But demonstrating incompatibility shows nothing about how to resolve said incompatibility. Molyneux is trying to run a reductio here, but reductios only succeed if they are generated from premises one's opponent already accepts or at least is tempted to accept.

\footnotetext{
56 Alternatively, it shows that Molyneux has picked a bad example because PP is not taken to be known exclusively through intuition.

${ }^{57} \mathrm{My}$ considered view is that only the eliminativist actually doubts (I)PP. The other three just have different theories of intuition. But I'll concede the point for the sake of argument.

58 I'll note again how I think that Platonism, nativism, and empiricism are compatible with the orthodox view, although eliminativism plainly isn't.
} 
Besides the charge of circularity, there's also a positive case to be made for rejecting (iv). I find it very natural to think something along the lines, "I'm not certain that PP is true, but I am certain that PP seems true" in a vein similar to "I'm not certain there's a mug on the desk (for all I know I'm a brain in a vat), but I am certain that there seems to be a mug on the desk." Thus, if some logician or metaphysician offered an ingenious argument against PP, one could concede that one's credence in PP had been reduced, without conceding that one's credence in (I)PP had been similarly reduced. The only way PP is more certain than (I)PP is under the question-begging assumption that (ii) is false.

There is, perhaps, a more charitable reading of Molyneux's argument. Clearly, a defender of the orthodoxy does not think the view that there are no intuitions (intuition nihilism) is a live option, and it would be uncharitable to attribute this attribution to Molyneux. Perhaps, though, Molyneux's point is that although a defender of the orthodoxy rejects intuition nihilism, she is more certain that $\mathrm{PP}$ is true than that nihilism is false. This is a plausible claim, but it is false. It's a bit like saying that one is more certain that one has hands than that external world skepticism is false. After all, the argument against external world skepticism contains multiple premises and logical transitions, each of which opens one up to the possibility of error, whereas knowing that one has hands merely requires looking down. But it would be absurd to be more certain that one has hands than that external world skepticism is false. ${ }^{59}$ That one has hands just straightforwardly entails that external world skepticism is false.

\footnotetext{
59 There may be certain exotic epistemic contexts in which we are less certain that external world skepticism is false than we are certain that we have hands in ordinary contexts. My claim is that it would be absurd to be more certain that one has hands than that external world skepticism is false in the same context. And of course,
} 


\subsection{Argument from Absence of Alternatives}

So much for arguments in favor of descriptive skepticism. I turn now to the most obvious argument against the view. I'll call it the 'argument from absence of alternatives. ${ }^{, 60}$ The argument from absence of alternatives begins with the empirical observation that philosophers standardly take themselves to offer evidence for the philosophical claims they defend. ${ }^{61}$ Descriptive skeptics contend that intuitions are not offered as evidence (nor are they utilized as sources of evidence). Given descriptive skepticism, it follows either that philosophers are mistaken about offering evidence for the philosophical claims they defend or that the evidence they offer is of a non-intuitive nature. Below I consider six possible alternatives to intuition and argue that none of them could succeed in replacing intuition as evidence in philosophy. This suggests that intuitions are argumentatively indispensable. But if intuitions are argumentatively indispensable and descriptive skepticism is true, then it follows that philosophy is a largely non-evidential enterprise. But philosophy is not a largely non-evidential enterprise. So descriptive skepticism is false.

It should be noted that the argument from absence of alternatives is not meant to be a defense of the common refrain that philosophical arguments 'bottom out in intuition.' That is, the argument from absence of alternatives does not rely on the claim that chains of justification must terminate, on pain of infinite regress, with intuitions. The argument from

it's fine to be more certain that one has the perception as of having hands than that external world skepticism is false.

${ }^{60}$ Nado 2015 calls a similar argument the “Argument from Lack of Other Obvious Options." I don't see why the other options must be obvious, so I have not adopted her terminology. Elsewhere (Ichikawa 2013) it's been called the "What else?" argument.

61 This is a generic about standard philosophical practice. Of course sometimes philosophers just list what they believe without offering any evidence. But even in this case philosophers standardly take themselves to have (epistemic) reason to believe the philosophical claims they endorse. 
absence of alternatives is officially neutral on how chains of justification must terminate. So, too, are many versions of descriptive skepticism. ${ }^{62}$ The argument from absence of alternatives merely claims that philosophers standardly take themselves to offer pieces of evidence to their philosophical interlocutors during philosophical exchanges and that the evidentiary nature of standard philosophical dialectics (which often go deep without quite reaching rock-bottom) would be greatly undermined if philosophers did not treat intuitions as evidence.

The six intuition alternatives I will consider are: arguments, non-psychological propositions, empirical data, theoretical virtues, common sense, and self-evident propositions. We need not think that any one of these categories will perfectly replace appeals to intuition, but together they ought to be able to perform the evidential work defenders of the orthodox view traditionally ascribe to intuition. This list is not, of course, exhaustive, but it does, I think, encompass the most plausible candidates. The failure of the six candidates to adequately replace intuition in philosophical practice forms a strong inductive base to motivate the conclusion that intuitions are argumentatively indispensable in philosophy.

\subsubsection{Arguments}

I begin with the suggestion that philosophers marshal arguments, not intuitions, to support their claims. Here's Deutsch (2015) introducing his book-length defense of descriptive skepticism: "Analytic philosophy is chock-full of hypothetical examples and thought experiments... but analytic philosophers argue for their claims about what is or is

\footnotetext{
${ }^{62}$ See, e.g., Cappelen 2012: 196.
} 
not true in these cases and thought experiments. It is these arguments, not intuitions, that are, and should be, treated as evidence for the claims" (xv). On the face of it, this is a puzzling claim for two reasons. First, all philosophical disputes are adjudicated—or rather, ought to be adjudicated-by argument. To do otherwise is to leave the philosophical domain. And an appeal to intuition is a type of argument. It may not be a good argument, and it may not be a very common argument, but it is an argument nonetheless. ${ }^{63}$ So arguments are not true alternatives to intuitions. Moreover (and this is the second reason), calling an argument with conclusion $\mathrm{p}$ evidence for $\mathrm{p}$ is a category mistake. It is the premises of the argument which constitute the evidence for $\mathrm{p}$, not the argument itself. ${ }^{64}$ The question at hand is what sorts of premises feature in our arguments. The defender of the orthodox view believes that intuitions feature in our arguments; she does not thereby commit to the claim that philosophers who appeal to intuition do not argue for their views.

There is, however, a more charitable reading of Deutsch's assertion. When he says that "instead of appealing to intuitions, analytic philosophers argue for their claims" (ibid.), what he means is that the arguments that philosophers give don't rely on intuition (at least in an evidential sense). The real contrast is not between arguments and intuitions. The contrast is between arguments on both sides: arguments that feature intuitions on the one hand and arguments that do not feature intuitions on the other. But if intuitions do not typically feature in philosophical arguments, what does?

${ }^{63}$ Here it is schematized:

(1) I have an intuition that $\mathrm{p}$.

(2) If I have an intuition that $\mathrm{p}$, then (probably) $\mathrm{p}$.

$\therefore$

(c) So (probably) p.

${ }^{64}$ We would have an unacceptable type of epistemic double-dipping if both the premises of the argument and the argument itself counted as evidence. 


\subsubsection{Non-psychological Propositions}

One popular suggestion is that the non-psychological contents of our intuitions feature as evidence in philosophical arguments. Thus, it is not the intuition that the Gettier subject has justified true belief but not knowledge that refutes the JTB theory of knowledge. After all, the JTB theory of knowledge is compatible with one's having all sorts of mental states. Rather, it is the non-psychological fact that the Gettier subject has justified true belief but not knowledge which refutes the JTB theory of knowledge. Timothy Williamson (2007: chapter seven) assembles a compelling case against the tendency to psychologize evidence in philosophy. However, for the purposes of assessing the merits of descriptive skepticism, this argument is largely beside the point. One can accept, with Williamson, that intuition reports can't, by themselves, overturn a long-standing theory in epistemology. But such a concession hardly entails that intuitions are evidentially inert. To see why, we must distinguish one's evidence from one's source(s) of evidence, which in turn requires us to say a little something more about intuitions and evidence more generally.

One can be a propositionalist or a non-propositionalist about both intuitions and evidence. The standard propositional view of intuitions is that intuitions are beliefs or judgments of a certain kind. ${ }^{65}$ The standard non-propositional view is that intuitions are a type of sui generis intellectual seeming. ${ }^{66}$ For evidence, the most influential propositional account is Williamson's own (2000) thesis that one's evidence consists of all and only the

\footnotetext{
65 See, inter alia, Devitt 2006, Gopnik and Schwitzgebel 1998, Kornblith 1998, Lewis 1983. The view that intuitions are dispositions to believe is sometimes lumped into this group, though, of course, dispositions are non-propositional.

66 See, inter alia, Bealer 1998, Pust 2000, Huemer 2001.
} 
propositions one knows. In contrast, many other views allow for one's private feelings and experiences to qualify as evidence. ${ }^{67}$

The first point to observe is that if one is a non-propositionalist about intuitions (e.g., intuitions are intellectual seemings, à la Bealer) and a propositionalist about evidence (e.g., one's evidence is all and only what one knows, à la Williamson), then intuitions, by definition, cannot be offered directly as evidence because intuitions are metaphysically unfit to be evidence. ${ }^{68}$ But even if non-propositionalism about intuitions and propositionalism about evidence is the correct combination of views, descriptive skepticism doesn't follow by fiat. Descriptive skepticism is the view that intuitions play no evidential role in philosophy, either direct or indirect. But the combination of non-propositionalism about intuitions and propositionalism about evidence leaves open the possibility that intuition is a source of evidence. ${ }^{69}$ Thus, we can agree with Williamson that it is the non-psychological contents of our (purported) intuitions which feature as premises in philosophical arguments, but this point of agreement doesn't resolve the question of how we come to know those propositions. If descriptive skepticism is right, we don't know those propositions via intuition. How else could we know them?

\subsubsection{Empirical Data}

Williamson suggests that much of what we utilize as evidence in philosophy is known via the same faculties that enable us to successfully navigate the non-philosophical world. After presenting a real-life Gettier case to an audience, Williamson (2005: 12) writes,

\footnotetext{
67 See (e.g.) Connee and Feldman 2004.

68 This point comes from Nado 2016: 790.

${ }^{69}$ Compare perception. The right account of perception is probably non-propositional, but it doesn't follow from this that according to Williamson perception cannot be a source of evidence.
} 
"My judgment that the audience had justified true belief without knowledge is not based on intuition in any sense that would distinguish it from other judgments. It is just an ordinary $a$ posteriori judgment, philosophical only in the use I make of it." Perhaps, then, mundane empirical data is the source of many of our philosophical beliefs.

To be sure, I don't deny that philosophers sometimes, and perhaps often, appeal to empirical data to support the theories they defend. Some areas of philosophy seem especially receptive to the influence of empirical data. Philosophers working in the philosophy of biology or philosophy of physics or philosophy of mind or philosophy of time-not to mention any type of applied philosophy — all engage with empirical data in an indispensable way. However, even in these fields, empirical data does not exhaust the evidence types to which philosophers appeal. After all, if a philosopher of biology utilizes all and only the evidence that biologists utilize, she is probably not doing philosophy of biology, just biology proper.

More importantly, there are wide swaths of philosophy which are either immune to the influence of empirical data or massively underdetermined by the empirical data. Debates in philosophy of math (e.g., nominalism versus platonism), the metaphysics of modality (e.g., concretism versus ersatzism), and property theory (e.g., universals versus tropes) are unlikely to be settled or substantially advanced by appeals to empirical data. Even views which assert, "There are no protons or galaxies or houses of cards" (Rosen and Dorr 2002: 152), are taken to be empirically adequate. Mereological nihilists like Rosen and Dorr contend that such theories can't be refuted "just by looking" or other "straightforward empirical means" (155) because 
once the possibility of doing without composition has been drawn to our attention, it does not require any great expertise in science for us to introduce new theories which differ from the old ones in being neutral on questions of composition. A team of scientifically-inclined compositional nihilists would have no trouble with the job. (162)

Rosen and Dorr rhetorically invite their readers to "wheel out your stethoscope, your electron microscope, your MRI, your Geiger counter," concluding that "experiments of this sort are beside the point" (155).

Of course, from the fact that mereological nihilists don't appeal to empirical data it doesn't follow that they must appeal to intuitions. Indeed, mereological nihilism is often accused of being spectacularly counterintuitive, so intuition seems like a particularly ill-suited type of evidence for the nihilist to appeal to. Instead, most nihilists tend to tout the theoretical virtues of nihilism, especially its parsimony. I turn next, then, to appeals to theoretical virtues and vices. ${ }^{70}$

\subsubsection{Theoretical Virtues}

Appeal to theoretical virtues is a common argumentative strategy in much of the contemporary philosophical literature. David Lewis writes, "Why believe in a plurality of worlds? - Because the hypothesis is serviceable, and that is a reason to think that it is true" (1986: 3). ${ }^{71}$ Brian Weatherson writes, "One reason I prefer the JTB analysis to its modern rivals is its brevity" (17). ${ }^{72}$ In discussing the relationship between knowledge and the

\footnotetext{
${ }^{70}$ For brevity's sake, I will often leave off the second conjunct. Additionally, my analysis focuses primarily on theoretical virtues rather than theoretical vices. I hope it is obvious that my arguments generalize to both virtues and vices.

${ }^{71} \mathrm{He}$ adds, "Modal realism is fruitful; that gives us good reason to believe that it is true" (4). It's unclear if serviceability and fruitfulness are meant to be distinct virtues.

${ }^{72}$ Notice how slippery the language is here. Weatherson makes the ostensibly innocuous claim that he prefers the JTB analysis for its brevity. There are, of course, a multitude of reasons to prefer a simpler theory to its more complicated rivals. Simpler theories are, ceteris paribus, easier to work with, after all. However, in order 
reference relation, Williamson writes, "We take such assignments of reference to be incorrect because we take them to be gerrymandered, unnatural, insensitive to the underlying similarities and differences, not cutting at the joints" (2007: 268). ${ }^{73}$ Debates between nominalists and Platonists often turn on matters of elegance and simplicity. Debates between realists and anti-realists often center on questions of explanatory power. Debates between nihilists, universalists, and so-called commonsense ontologists often hinge on the issue of parsimony. And whenever a philosopher criticizes her opponent on grounds of internal inconsistency, she is appealing to the cardinal theoretical vice.

What is less common is for first-order philosophers to explain why we are justified in believing their favorite theoretical virtues reliably track the truth. That they do so is usually just assumed, more out of habit and professional custom than because there is an implicit story lurking somewhere in the background. Indeed, it seems to me that the only plausible story which could justify our appeals to theoretical virtues ultimately rests on the intuition that theoretical features like parsimony, brevity, naturalness, elegance and so on are truthconducive. Thus, if theoretical virtues feature as evidence in philosophical arguments, so too must intuitions.

To see how the story goes, it will be helpful to examine a paradigmatic example of the theoretical virtues, simplicity. Appeals to simplicity date back at least as far as Aristotle's Posterior Analytics, where he writes, "We may assume the superiority ceteris paribus of the

for Weatherson's argument to go through, he must not be using 'preference' in this harmless pragmatic sense. Rather, 'reason to prefer' must be synonymous with 'reason to think true.'

73 Again, it is somewhat unclear whether being gerrymandered, being unnatural, being insensitive to underlying similarities and differences, and not cutting at the joints are meant to be distinct theoretical vices. 
demonstration which derives from fewer postulates or hypotheses" (I.25, 86a 33-36). ${ }^{74}$ The claim that simplicity is evidence of truth could be justified either empirically or a priori. Empirical justifications typically appeal to patterns of theory acceptance and rejection in the sciences. Setting aside the obvious difficulty of translating scientific methodology into its philosophic equivalent, it seems to me that this type of justification often rests on a naïve and shallow understanding of the history of science.

For instance, it is sometimes claimed that the simplicity of the Copernican system was a reason to endorse the heliocentric model of the universe in the $16^{\text {th }}$ century. However, there are many obvious respects in which the Copernican model was not simpler than the competing Ptolemaic model. (The two systems use roughly the same number of epicycles, for example.) And while the Copernican model could more simply explain phenomena such as retrograde motion and the positions of Venus and Mercury relative to the sun, it could not easily reconcile the postulated rotation/revolution of the earth with our phenomenological experience as of a motionless planet. (The Ptolemaic model had a very simple explanation - the earth was stationary.) It wasn't until the Keplerian system that we truly got a simpler model of the solar system. But the Keplerian system was also better at making predictions than the old Ptolemaic model, so it is unclear that it was accepted on theoretical simplicity grounds, as opposed to empirical adequacy.

A priori justifications for the truth-conduciveness of simplicity typically appeal to statistical/probabilistic principles. This approach has a number of problems. First note that the following probabilistic strategy won't work. Suppose we have two competing theories.

\footnotetext{
${ }^{74}$ This is an oft-cited passage, but it seems to me Aristotle probably takes simplicity to be a mere pragmatic virtue in this passage.
} 
The content of theory A is that grass is green and Santa Claus exists. The content of theory $\mathrm{B}$ is merely that grass is green. Because theory A entails theory B, we conclude that theory B is more probable, and thus simplicity is vindicated.

Not so fast. This line of reasoning only gets us to agnosticism about Santa Claus. But what we want is atheism about Santa Claus, and this strategy cannot deliver that. There is no relationship of logical entailment between "grass is green and Santa Claus exists" and "grass is green and Santa Claus doesn't exist," so logic can't tell which theory is more probable. In general, there is no simple relationship between a theory's ontological simplicity and a theory's likelihood to be true, and so the easy probabilistic argument for ontological simplicity fails. There are, of course, more sophisticated probabilistic models, but even when these models are applied to toy cases, they often yield conflicting and/or counterintuitive results. ${ }^{75}$

What's worse, it's not even clear what simplicity is. We can identify two broad kinds of simplicity: syntactic simplicity and ontological simplicity. ${ }^{76}$ Syntactic simplicity is a tally of a theory's foundational principles. Ontological simplicity is a tally of the kinds of entities postulated by a theory. These two types of simplicity sometimes pull in opposite directions, as when a theory becomes easier to state by postulating additional entities. Thus it is ambiguous to say merely that theory $A$ is simpler than theory $B$.

\footnotetext{
75 See Sober 2002.

${ }^{76}$ We should also distinguish psychological complexity from what we might call metaphysical complexity. There is a sense in which our credences in long proofs should be lower than our credences in short proofs. Human beings are, after all, fallible reasoners, and every additional step of a proof is a new opportunity for error to creep in. An ideally rational agent, however, for whom the possibility of logical error does not exist, would not adjust her credences in response to length of proof.
} 
Philosophers sometimes take themselves to have a good instinctual grasp on the nature of simplicity. Consider, for example, two curves:

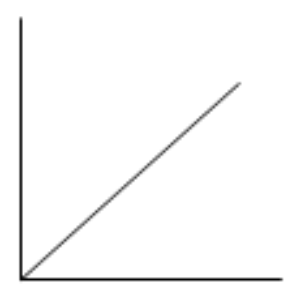

(a)

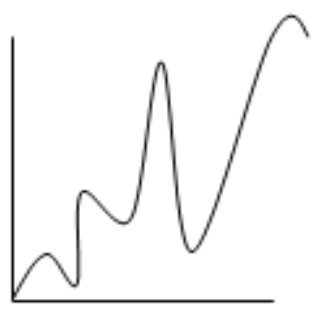

(b)

There is, I suspect, widespread agreement that curve (a) is simpler than curve (b). If pressed to explain their judgments, philosophers might claim that linear curves are simpler than, say, parabolic curves because linear curves have fewer adjustable parameters:

(LIN) (PAR)

$$
\begin{aligned}
& y=a+b x \\
& y=a+b x+c x^{2}
\end{aligned}
$$

But notice that (LIN) is just a special case of $(\mathrm{PAR})$ when $\mathrm{c}=0$. So if simplicity involves minimizing assumptions, that's reason to think (PAR) is simpler than (LIN).

There is, of course, much more to say about the matter. But it appears to me that appeals to simplicity rest on, and can only be justified by, intuitions about simplicity. Some philosophers are remarkably explicit about this connection. For instance, in defending the theoretical virtues of nominalism, especially its parsimony, Nelson Goodman and W.V.O. Quine (1947: 105) write, "Why do we refuse to admit the abstract objects that mathematics needs? Fundamentally this refusal is based on a philosophical intuition that cannot be justified by appeal to anything more ultimate." 
Perhaps, though, we shouldn't take Goodman and Quine at their word. Perhaps what they call "intuition" is really just an appeal to philosophical common ground. Perhaps much of what counts as evidence in philosophy is common sense.

\subsubsection{Common Sense}

At first glance, it may seem like appeals to common sense are ill-suited to replace appeals to intuition in philosophical arguments. After all, many philosophical views (e.g., mereological nihilism, eliminative materialism, external world skepticism) are said to offend against common sense. But this first-pass dismissal is too quick. Consider, for instance, the argument for indiscernibility knowledge skepticism. The argument rests on two simple assumptions: ${ }^{77}$

1) To know that $\mathrm{p}$ we must have grounds for $\mathrm{p}$

2) These grounds must be discriminating

Although these assumptions entail rejecting much of what we commonsensically take ourselves to know, one could construct a plausible case that the assumptions are themselves tacit bits of common sense. Our collective set of commonsense beliefs is almost certainly inconsistent. Perhaps it falls to the philosopher to systematize this collection. In the process of making the set consistent, some commonsense beliefs must be tossed aside.

To evaluate whether appeals to common sense can play the same role as appeals to intuition, it will be helpful to review the extant philosophical literature on common sense. Here are some things common sense isn't, according to the dialectic. Common sense isn't infallible: "Common-sense beliefs can be corrected, even trashed entirely, by careful empirical investigation and scientific theorizing" (Lycan 2001: 40). Common sense isn't

\footnotetext{
${ }^{77}$ See Luper 2003: xi-xii.
} 
irresistible: "If the only thing to be said in favor of our common sense beliefs is that they are irresistible, why should we not view them the way we view bad habits, such as smoking or overeating, that we continue to engage in even when reason convinces us that they should be given up? [...] What makes it reasonable to take such things as data is that they are known or justified, rather than being irresistible" (Lemos 2004: 19-21). And common sense isn't relative: "Whatever their ultimate epistemic status, the convictions targeted by such theories are hardly local dogmas. Even if much of what passes for common sense is relative to time and place, there is, it seems, a Hard Core that is not relative in this way" (Kelly 2008: 54).

One might be tempted to regard common sense as some sort of consensus, either reflective or unreflective, but this too, according to the dialectic, would be a mistake. Susanna Rinard (2013: 191) tells us that that the earth orbits the sun is not common sense, so reflective consensus is not sufficient to establish a claim as common sense. She also tells us (ibid.) that that the earth is flat is common sense, so reflective consensus is not a necessary condition on a claim's being common sense. Appeals to unreflective consensus won't help either, for Rinard (194) also tells us that that testimony is a legitimate way to acquire justified belief is not common sense. Although non-philosophers might not phrase their beliefreport in this language, such a claim is about as pre-theoretic as things ever get in philosophy.

At this point one might be excused for wondering if there is an informative concept picked out by 'common sense' at all. And yet there is robust debate about the role of common sense in philosophy. The central question of the debate is this: Can philosophical arguments ever justifiably overthrow our commonsense convictions? Here's Anil Gupta (2006: 1778) 
representing the 'no' camp: “Any theory that would wage war against common sense had better come loaded with some powerful ammunition. Philosophy is incapable of providing such ammunition." And Rinard (2013: 212) representing the 'yes' camp: "Philosophical argument is perfectly capable of undermining our ordinary, pre-theoretic view of the world."

The best way to get a handle on the difference between common sense and its contrary $^{78}$ is to think about the distinction in methodological terms. According to Thomas Kelly (2005: 203), "the methodological commitment incurred [by the defender of common sense] is that there are some particular judgments inconsistency with which suffices to undermine the credibility of a general principle to the point that it is reasonable to reject that principle." Once the debate is recast in a methodological light, the real question becomes whether and when to be (in the terminology of Chisholm 1973) a philosophical particularist or a philosophical methodist. ${ }^{79}$ Recall that Chisholmian particularism is the view that case judgments ought to be privileged over general principles when engaging in reflective equilibrium and that Chisholmian methodism is the view that general principles ought to be privileged over case judgments when engaging in reflective equilibrium. ${ }^{80}$ On this interpretation, the defender of common sense privileges case judgments while her opponent privileges general principles.

The problem is that this metaphilosophical debate has nothing to do with common sense. There are some case judgments, like the judgment that phenomenal zombies are possible or

\footnotetext{
78 Just what common sense is meant to be distinguished from is sometimes unclear. In much of the extant literature, the appropriate contrast is something like 'speculative philosophical principles.' But presumably the descriptive skeptic will not like this contrast class.

79 See $\$ 2.2$.

80 This is not a binary distinction. The extent to which one is a particularist or a methodist admits of degrees, with hyper-particularism (the view that general principles should be afforded no weight) at one end of the spectrum and hyper-methodism (the view that case judgments should be afforded no weight) at the other.
} 
that the China-brain lacks consciousness, which are far removed from common sense. On the other hand, there are a great many common sense principles-just pick your favorite logical axiom, like the reflexivity of identity. Which is not to say that the debate is vacuous. It's important to know when to privilege case judgments over principles (and vice versa), and this is a difficult question. If we are to engage in reflective equilibrium, we can't just rate general principles solely on the extent to which they match case judgments; otherwise gerrymandered principles will always come out best. ${ }^{81}$ Similarly, we can't rate the trustworthiness of particular case judgments solely by the extent to which they conform to some general principle; otherwise we will always throw out those judgments which conflict with our principle. ${ }^{82}$ What we want is to weight our judgments and principles in the way such that our overall web of beliefs hangs together the best. And so we must appeal to theoretical virtues like coherence and simplicity.

In summary: the debate over whether philosophy can overturn common sense is just the debate over whether to be philosophical particularists or philosophical methodists. But in order to decide when to be philosophical particularists and when to be philosophical methodists, we must appeal to theoretical virtues. So appeals to common sense ultimately collapse to appeals to theoretical virtues. As argued above, appeals to theoretical virtues collapse to appeals to intuition. By the transitivity of 'collapse,' appeals to common sense collapse to (and thus cannot replace) appeals to intuition.

Again, this is not to say that philosophical arguments necessarily bottom out in intuition. I've said nothing about how chains of justification must terminate. In the course

\footnotetext{
81 This is the hyper-particularist position. See fn. above.

82 This is hyper-methodism.
} 
of a normal philosophical dialectic, it's perfectly natural for one interlocutor to appeal to common sense to support a portion of her theory, for a second interlocutor to reject this piece of common sense, for the first interlocutor to criticize this rejection on grounds of some theoretical virtue, and for the second interlocutor to question the relevance of this theoretical virtue. It's here where intuition enters. Notice that we are nowhere near 'rockbottom.' There's still much more to be said. After all, intuitions come in varying strengths. And so the second interlocutor might appeal to a stronger intuition. Or she might appeal to a pair of intuitions equal in strength to the first interlocutor's intuition. And so on. So although we might reasonably think of some appeals to intuition as nothing more than tacit appeals to common sense, appeals to common sense, even when supplemented with other evidentiary appeals, cannot effect a complete replacement of appeals to intuition.

\subsubsection{Self-Evident Propositions}

One final replacement candidate deserves consideration. Molyneux (2014: 445) contends that "the best analysis of standard practice may be that we treat intuition as revealing, but not justifying, self-evident propositions," where "such propositions are intrinsically justified and neither need nor get support from their being intuited." Intuition thus plays a role in the context of discovery but not in the context of justification. Appeals to intuition are argumentatively inert because the self-evident propositions which intuition delivers already contain all that is needed to justify them.

A few initial clarificatory remarks are in order. First, not all propositions which might appropriately be called 'self-evident' are fit to be delivered by intuition. There is a sense in which it is self-evident that there is a mug on my desk, but plainly this is not the 
sense of 'self-evident' with which Molyneux is concerned. Intuition doesn't deliver, much less justify, the proposition 'there is a mug on the desk.' So we ought to restrict our attention to what we might vaguely call 'intellectually self-evident propositions. ${ }^{83}$

Second, one might legitimately worry whether propositions typically taken to be justified by intuition, such as the proposition that parsimony is truth-conducive or that the fat man ought not to be pushed, are sufficiently self-evident. But one must take care not to confuse self-evidence with obviousness. Obviousness is a psychological property relating a proposition to an agent. Self-evidence is a property that propositions either have or lack, irrespective of how obvious they seem to agents. The important feature of self-evident propositions is that they are, in some sense, self-justifying - not that they are obvious. ${ }^{84}$

Third, the fact that intuition reveals self-evident propositions which are then used as evidence in philosophical arguments isn't meant to entail that intuition is a source of evidence, at least in the normative sense with which we've been using the term. For Williamson, the perception as of a mug on the desk isn't evidence for anything-perceptions aren't propositional and so aren't metaphysically suited to be evidence. But the perception as of a mug on the desk is a source of evidence for the proposition that there is a mug on the desk. Moreover, I am justified in believing that there is a mug on the desk precisely because I have had the perception as of a mug on the desk. In contrast, for Molyneux, the fact that a selfevident proposition was intuited is totally irrelevant to one's justification for believing that proposition. It's something of a psychological accident that intuition, rather than some

\footnotetext{
83 This appellation is deliberately vague so as to leave open the question of whether self-evident propositions must be analytic or even a priori.

84 Audi (2008: 488) observes that the proposition 'first cousins share a pair of grandparents' is self-evident, even though the sentence may not seem obviously true upon first reading it.
} 
other mechanism, reveals these self-evident propositions, just as it is something of a psychological accident that neurons $\mathrm{N}_{1} \ldots \mathrm{N}_{\mathrm{n}}$ light up when I have the perception as of a mug on the desk rather than some other set of neurons. Intuition thus plays a causal, not a justifying, role.

There is, nevertheless, a reason to think that appeals to self-evident propositions can't replace appeals to intuition, and the objection strikes at the heart of descriptive skepticism. The worry is simply that appeals to self-evident propositions look too much like appeals to intuition. The degree of resemblance is so high that, given the amorphous nature of the descriptive skeptic's target, there's reason to think that when defenders of the orthodoxy talk about appeals to intuition they just are talking about appeals to self-evident propositions. Molyneux hasn't advanced an alternative to intuition; he's simply given us a novel theory of intuition.

To see why this is so I turn to Robert Audi's (2008) account of self-evident propositions, which I take to be paradigmatic of the literature. In the paper Audi details "how an adequate understanding of a self-evident proposition can enable us to see its truth by virtue of apprehending conceptual relations" (486). Later he notes, "An adequate understanding of a self-evident proposition, $p$, does imply (at least in a rational person) a disposition to believe it, indeed, one strong enough so that there should be an explanation for non-belief given comprehending consideration of $p^{\prime \prime}(488) .{ }^{85}$ In $\$ 3.2$ I laid out the features that Cappelen (2012: 112-113) took to characterize appeals to intuition. There were four:

\footnotetext{
$85 \mathrm{He}$ adds, "On this account, self-evident propositions are conceived as truths such that (a) adequately understanding them is sufficient for justification for believing them (which does not entail that all who adequately understand them do believe them), and (b) believing them on the basis of adequately understanding them entails knowing them" (478).
} 
(1) Intuitions exhibit "seems true" phenomenology.

(2) Intuitions enjoy default justificatory status.

(3) Intuitions are non-inferential/non-experiential.

(4) Intuitions are based on conceptual competence.

If understanding a self-evident proposition enables us to see its truth by apprehending its conceptual relations, giving us a non-experiential disposition to believe it which is intrinsically justified, then I see no reason to distinguish appeals to self-evident propositions from appeals to intuition.

But one might object that appeals to intuition somehow involve the psychological faculties of intuiting agents, whereas appeals to self-evidence do not. After all, self-evidence is a feature of propositions, while being intuited is a relationship between a proposition and an intuiter. Given these differences, one ought not, perhaps, conflate the two. Reflection on mathematical practice strengthens the objection. ${ }^{86}$ Legitimate mathematical proofs are sometimes said to bottom out in self-evident axioms. Whether or not any mathematician has intuited anything is irrelevant to the soundness of the proof. Mutatis mutandis, so the objection goes, for philosophy.

I'm happy to endorse this particular analogy between math and philosophy, but the objection still misses its mark. Descriptive skepticism is a view about what sorts of things philosophers offer as evidence for their theories - it is not a view about what makes an argument sound. At issue then is how philosophers (and mathematicians, if we want to carry the comparison forward) justify their beliefs. If one wants to understand how some philosopher or mathematician came to justifiably believe the conclusion of some argument,

\footnotetext{
86 Thanks to Cory Juhl for this example.
} 
one would want to know (among other things) what justified the philosopher/mathematician in classifying some premise as self-evident.

Some might complain that this is a causal/psychological question which has nothing to do with epistemology, but this complaint would be mistaken. Williamson is right that in general psychological reports such as ' $\mathrm{I}$ have the intuition that $\mathrm{p}$ ' do not figure directly as premises in philosophical arguments, but it does not follow from this that psychological reports are irrelevant to justification. Compare the perception the case. If pressed to justify the claim that there is a mug on the desk, it would be wholly appropriate to resort to the psychological report

(0) I am having the perception as of a mug on the desk.

Perception is a source of evidence, and not merely a causal source. The perception as of a mug on the desk, even if it is not itself evidence, justifies the belief that there is a mug on the desk.

The same sort of thing happens in philosophy. If pressed to justify the claim that the Gettier subject has a justified true belief that $\mathrm{p}$ but does not know that $\mathrm{p}$, one might respond in one of two ways:

(1) I have an intuition that the Gettier subject does not know that $\mathrm{p}$.

(2) It is self-evident that the Gettier subject does not know that $\mathrm{p}$. (1), like (0) and unlike (2), is a psychological report. Psychological reports like (0) and (1) are justified by introspection. It is dialectically inappropriate to demand further justification of claims which can only be justified by introspection (which is not to say that introspection is infallible). But the claim 'it is self-evident that the Gettier subject does not know' is a claim about the status of a particular proposition. It is dialectically appropriate to demand that this 
claim be justified. Note that we're here talking about what is and is not dialectically appropriate. If it's true that it is self-evident that the Gettier subject does not know that p, then the proposition 'the Gettier subject does not know that p' justifies itself. But merely claiming that a proposition is self-evident cannot be a dialectical firewall against further demands for justification. ${ }^{87}$

So there is a further question that can legitimately be asked, namely 'Why think that it is self-evident that the Gettier subject does not know?' to which the appropriate response is something like the following psychological report:

(3) I see that it is self-evident by apprehending the conceptual relations between justification, truth, belief, and knowledge.

But here's what the faculty ${ }^{88}$ of intuition does, according to many philosophers of intuition: it apprehends relationships between concepts. Intuition does not merely reveal self-evident propositions, it justifies our taking them to be self-evident. So even though the intuition that the Gettier subject does not know is not evidence against JTB, intuition is still the source of the evidence against JTB. And it's a source in exactly the same way as perception is the source for the claim that there's a mug on my desk. To put the same point another way: even if the intuition that $\mathrm{p}$ doesn't propositionally justify the belief that $\mathrm{p}$ (because $\mathrm{p}$ is selfevident), having the intuition that $\mathrm{p}$ is still required in order for the agent to be doxastically justified in believing that p. Appeals to self-evident propositions cannot replace appeals to intuition because appeals to self-evident propositions just are appeals to intuition. Perhaps

\footnotetext{
87 Consider: "What is your argument for mind-body dualism?" "It is self-evident that mind-body dualism is true." Even if mind-body dualism is self-evident, merely saying that is so is a poor strategy for winning converts.

${ }^{88}$ Speaking loosely. We need not commit to any single mental module performing this task.
} 
the term 'intuition' is overused and overly vague, but an appeal by any other name smells just as sweet.

\subsection{Conclusion}

In this section I've argued against descriptive intuition skepticism, the view that intuitions aren't used as evidence in contemporary philosophical arguments. I've distinguished two different ways of supporting descriptive skepticism: the case studies approach and the methodological principles approach. Although the methodological principles approach is the superior strategy, the best two arguments thus far offered in this vein fall flat. I've also considered and rebutted possible responses to the best argument against descriptive skepticism, the argument from absence of alternatives. The upshot of all this is that I can admit, in keeping with the case studies approach, that arguments do not bottom out in intuition as quickly as is sometimes supposed, that thought experiments are not always presented as decisive, that intuition is not always appealed to explicitly. Nonetheless, if the argument from absence of alternatives is successful, then although the case studies approach establishes an important and interesting methodological fact, it does not (indeed, could not) demonstrate that descriptive skepticism is true. 


\section{Chapter Three: The Heterogeneity of Intuition ${ }^{89}$}

"I have no desire to describe the way the word 'intuition' is used in detailwhy describe a mess in detail?"

-Timothy Williamson, quoted in Herman Cappelen's Philosophy Without Intuitions, p. 84 fn. 24

\section{INTRODUCTION}

In this chapter, I marshal evidence for the view that 'intuition' picks out a heterogeneous, gerrymandered category. Of course, there's probably no such thing as heterogeneity simplicter —only heterogeneity relative to some standard. The standard I will adopt is the one imposed by the metaphilosophical goals RELIABILITY and JUSTIFICATION introduced in chapter one. Thus, the aim is to show that intuitions do not constitute the unified kind that many metaphilosophers require in order to run their ampliative inferences. (In chapter four I show how these arguments change once the assumption that intuitions form a unified kind is dropped.) Below I present four sources of disunity: ambiguities in the way the term 'intuition' is used $(\$ 2)$, distinct varieties of intuition $(\$ 3)$, diverse contents of intuitions ( $(4)$, and unclear generality $(\$ 5)$. Finally, in $\$ 6$ I consider four objections.

\section{Ambiguities}

In this section I sketch some important ambiguities in the way the term 'intuition' gets used by philosophers. These ambiguities break down into two broad categories: content ambiguities and context ambiguities. A failure to disambiguate the features outlined below often results in dialectical confusion or stalemate, but more importantly for present purposes, the ambiguities contribute to a false sense that intuitions constitute a unified category. Of course, the existence of these ambiguities is not decisive evidence against the view that intuitions constitute a unified category. Nonetheless, getting a handle on these

${ }^{89}$ Portions of this chapter appeared in my 2016 article "Carving Intuition at Its Joints," Metaphilosophy, Volume 47, Issue 3, pages 326-352 
ambiguities is an important first step in appreciating just how complex philosophical intuition talk really is. And the more complicated our intuition talk turns out to be, the less plausible it will be that the subject of that talk is appropriately unified. In short, equivocation in the way 'intuition' gets used risks glossing over some important, fundamental differences among the things philosophers take to be intuitions.

\subsection{Content Ambiguity}

The most widely cited intuition ambiguity is the state/content ambiguity. The term 'intuition' is ambiguous between the psychological state of intuiting that $\mathrm{p}$ and the contents of that state, namely p. ${ }^{90}$ Hence, the phrase 'the intuition that p' may refer to a particular mental attitude, which might be distinguished by certain characteristic psychological features, such as a special quasi-perceptual phenomenology or a feeling of certitude or an ease of retrieval. $^{91}$ Alternatively, the phrase may refer merely to proposition $\mathrm{p}$, without any psychological implications. This ambiguity is familiar from other propositional attitudes, like belief and desire.

Additionally, we might distinguish the act of intuiting that $\mathrm{p}$ from the state of intuition that the act gives rise to. It might be the case that the intuition that $\mathrm{p}$ is always preceded by the act of intuiting that p. But perhaps not. If some intuitions are innate, we might just find ourselves saddled with the intuition that $\mathrm{p}$ without ever having actively intuited that $\mathrm{p}$. (There is, of course, the act of reporting that one has the intuition that $\mathrm{p}$, but that's another thing altogether.) Indeed, if intuitions are merely dispositions to believe, it might not make

\footnotetext{
90 See Deutsch 2015: 35-39 for more detail on this ambiguity.

91 In $\int 6$ I consider whether there might be some characteristic(s) of the state of intuition which serves to unify the category. That is, even if intuitions feature wildly different contents and are produced by diverse psychological faculties, if they all exhibit (say) a special 'seems-true' phenomenology, that might be a reason for treating them monolithically.
} 
sense to talk of the act of intuiting that $\mathrm{p}$ at all, any more than it makes sense to talk of the act of forming a disposition to believe that $\mathrm{p}$.

The act/state ambiguity is important for distinguishing implicit intuitions from explicit intuitions. For example, if intuitions are (a certain subset of) dispositions-to-believe, we might appropriately say that epistemologists had the tacit intuition that it's possible to have a justified true belief that $\mathrm{p}$ without knowing that $\mathrm{p}$, although it took Edmund Gettier to make that intuition explicit. But some metaphilosophers deny that implicit intuitions are a category of intuition we ought to recognize. George Bealer and John Bengson, for example, believe that intuitions are conscious mental states best modeled on perception. Just as it doesn't make sense to talk of 'tacit perceptions,' so too is talk of implicit intuitions confused. There are true counterfactuals about what one would come to intuit given certain conditions, but these counterfactuals should not be confused with intuitions proper. Still, there is a sense in which one can truly report that David Chalmers has the intuition that phenomenal zombies are possible, even if Chalmers happens to be asleep at the time the report was made. Thus, at the very least intuition talk is often ambiguous between an occurent and non-occurent understanding of intuition.

Finally, sometimes when an author claims that intuition is a source of evidence, what she means is that there is a faculty of intuition akin (in some way) to vision or hearing or (more loosely) memory, and that the outputs of this faculty are beliefs which are justified in virtue of being produced by the faculty. Notice how the analogy to other propositional attitudes like belief breaks down at this point. Like intuition, there is the act of believing, the state of belief, and the contents of one's belief. But nobody thinks that there is a faculty of 
belief. A better analogy is to perception. There is the act of perceiving that $\mathrm{p}$, the (occurent) state of perceiving that $\mathrm{p}$, the contents of the perception that $\mathrm{p}$, and the various faculties of perception. 'Intuition' is ambiguous among all four.

It is important to carefully distinguish the state, act, and faculty-readings of 'the intuition that p' from the content-reading of 'the intuition that p.' When the meaning is left ambiguous questions of the evidential worth of intuitions are clouded. When an author asserts that the intuition that the fat man ought not to be pushed is evidence that utilitarianism is false, it's unclear exactly what she means. She might mean that being in a certain psychological state is evidence that utilitarianism is false, in the same way that being in a certain psychological state might be evidence that one has been brain-washed. Or she might mean that it's true that one ought not to push the fat man off the bridge and that this fact is incompatible with utilitarianism. Even granting the second interpretation, there is a further ambiguity. We might wonder what justifies one in thinking that the fat man ought not to be pushed. In particular, does the psychological act of intuiting that the fat man ought not be pushed justify the belief that the fat man ought not be pushed, in the same way that the psychological act of remembering that the meeting starts at 9:00 justifies the belief that the meeting starts at 9:00? Or is the psychological act of intuiting that the fat man ought not to be pushed merely the causal trigger for a belief that gets justified by other means, in the same way that a politician's soaring rhetoric might cause one to believe that $\mathrm{p}$ without justifying the belief that $\mathrm{p}$ ? Without proper disambiguation, these questions are difficult to answer. 


\subsection{Context Ambiguity}

The last question of $\$ 2.1$ raises an ambiguity of context. When an author asserts that she believes that $\mathrm{p}$ because of an intuition that $\mathrm{p}$, she might mean that the intuition causes the belief or that the intuition justifies the belief (or both). Most of the metaphilosophical discussion of intuitions concerns their role in the context of justification. Normative intuition skeptics deny (to one degree or another) that the intuition that $\mathrm{p}$ justifies the belief that p. Descriptive intuition skeptics deny that philosophers utilize the intuition that $\mathrm{p}$ to justify the belief that p. Defenders of the orthodox metaphilosophical view hold that philosophers do utilize the intuition that $\mathrm{p}$ to justify the belief that $\mathrm{p}$ and that the intuition that $\mathrm{p}$ does (prima facie) justify the belief that $\mathrm{p}$.

But intuitions and intuition-discourse can also be employed in other contexts. Intuitions might be used in the context of discovery. An insight which ultimately gets defended in other ways might be first revealed by intuition. Intuitions might be used in the context of explanation. An author might present a thought experiment which elicits strong intuitive reactions in order to better frame and elucidate her point, without thinking that the intuitions generated by the thought experiment justify the point. ${ }^{92}$ The language of intuition might be used in rhetorical contexts. An author might assert that $\mathrm{p}$ is intuitive merely to signal that $\mathrm{p}$ will go undefended or to predict that $\mathrm{p}$ will go unchallenged.

Context ambiguity is especially salient when philosophers employ the adjectival and adverbial form of 'intuition.' In addition to discussing intuitions, philosophers also make

\footnotetext{
${ }^{92}$ Ned Block's (1978) China-brain case might be one such example.
} 
free use of the adjective 'intuitive' and the adverb 'intuitively. ${ }^{93}$ For the most part, these terms are used to modify judgments, thoughts, or propositions, as in 'the intuitive judgment that p' and 'intuitively, p.' Of particular importance is the negative form of these terms: 'counterintuitive' and 'counter-intuitively.' In slight contrast to 'intuitive,' 'counterintuitive' is often used to describe theories or consequences of theories, as in 'mereological nihilism is a counterintuitive theory' or 'mereological nihilism has counterintuitive consequences.' The exact content of the claim ' $\mathrm{x}$ is counterintuitive' is unclear. It might mean that one has no intuitions with respect to $\mathrm{x}$ or the consequences of $\mathrm{x}$. Or it might mean that one has the intuition that $\neg \mathrm{x}$ or that one has the intuition that $\neg \mathrm{p}$, where $\mathrm{p}$ is a consequence of $\mathrm{x}$.

Presumably it is the latter reading which is intended when one claims that mereological nihilism is counterintuitive. But this reading is not unproblematic. Mereological nihilism entails that there are no clock-towers or mountains or television sets, and it is this consequence that its opponents (and some of its proponents) find counterintuitive. This seems to suggest that we have an intuition with the content 'there exists television sets.' But it is a contingent fact-if it is a fact at all-that television sets exist. How could intuition deliver knowledge that there exists television sets? Surely, it would be inappropriate to use intuition to infer the existence of any particular television set. It takes hard empirical data to determine if your neighbor does or does not own a TV. Alternatively, the content of the relevant intuition might be 'when such-and-such atoms are arranged so-and-so, they necessarily form a composite object known colloquially as a

\footnotetext{
93 See Cappelen 2012: 30-36 for an overview of 'intuitive' and 'intuitively' in non-philosophical English.
} 
television set.' But I find it hard to believe that people legitimately have an intuition with this content.

I suspect that often ' $\mathrm{x}$ is counterintuitive' can be reformulated to avoid reference to intuition altogether and that the mereological nihilism example illustrates this phenomenon. Thus ' $\mathrm{x}$ is counterintuitive' might simply mean that $\mathrm{x}$ is false. (We have non-intuitive access to the fact that television sets exist, and this fact is incompatible with mereological nihilism.) Alternatively, ' $\mathrm{x}$ is counterintuitive' might mean that $\mathrm{x}$ is surprising. (Most people naively believe that there exist such things as television sets, but mereological nihilism teaches us otherwise.) Similarly, 'intuitive' and 'intuitively' might be used to flag pre-theoretic commitments or shared background assumptions, without thereby implying that the pretheoretic commitments or shared background assumptions depend on a particular type of mental state.

When I argue that we need a finer-grained taxonomy of intuition, I mean that we need a finer-grained taxonomy of the justificatory uses of intuition. It might be interesting to know more about the ways intuition gets used in other contexts, but the metaphilosophical conclusions I find problematic all concern the context of justification. Thus, I will tend to prioritize the noun 'intuition' over its adjectival and adverbial counterparts. However, it's important not to ignore 'intuitive' and 'intuitively' entirely. 'Intuitive' and 'intuitively' are straightforwardly gradable in a way that 'intuition' is not. A proposition can be more or less intuitive, whereas having an intuition appears to be binary: one either has the intuition or one does not. Of course, one can talk about stronger and weaker intuitions and (more generally) intuitions of strength $\mathrm{n}$, but the awkwardness of this language might explain why 
some authors employ the adjectival and adverbial forms of 'intuition.' When I do cite instances of 'intuitive' or 'intuitively' it will always be with the assumption that the occurrences essentially refer to intuitions and can be paraphrased to language which utilizes only the noun 'intuition.'

\section{VARIETIES OF INTUITION}

In this section I sketch three fundamental dimensions along which intuitions can vary: a priori/a posteriori, general/particular, and de re/de dicto. ${ }^{94}$ This classification gives us a three-dimensional taxonomic space. Intuitions in different regions of the taxonomic space exhibit different properties. Some metaphilosophers target the entirety of this taxonomic space in their intuition analyses. Others target proper sub-regions of the space, though not all metaphilosophers focus on the same sub-region.

Again, the fact that there are varieties of intuition is not decisive evidence against the view that intuitions should be treated monolithically. What's important for our purposes is the possibility that, for principled reasons, intuitions in some regions of the taxonomic space might be more or less reliable (or confer a greater or lesser evidential weight) than intuitions in other regions. Treating intuitions monolithically ignores this possibility.

\subsection{A Priori vs. A Posteriori}

When rationalist-inclined philosophers talk about intuitions, the propositions which are allegedly intuited (or intuitive) are usually thought to be necessary or a priori or analytic or all three. In contrast, when psychologists and empirically-inclined philosophers investigate intuitions, they are happy to admit of contingent, a posteriori, synthetic intuitions.

\footnotetext{
94 The a prior/a posteriori and de re/de dicto dimensions are binary. The general/particular dimension is gradable.
} 
David Sosa (2006) writes, "Pre-philosophically, intuition appears to be a sui generis faculty delivering a priori knowledge" (633, emphasis added). In contrast, Jennifer Nagel (2012) writes, "When we read the emotions of others in their facial expressions-to take an example of an uncontroversial case of intuitive judgment-neurotypical adults are remarkably accurate at detecting and decoding the minute shifts in brow position and nostril contour that distinguish emotions such as surprise and fear" (498, emphasis added). It's understandable that sophisticated philosophical reasoning might lead two philosophers to different accounts of intuition. What's surprising is how far apart Sosa and Nagel start. Sosa thinks that our pre-theoretical conception of intuition restricts its domain to the a priori. Nagel gives as exemplar of an uncontroversial instance of intuition an empirical judgment.

The Sosa quote above is indicative of the typical attitude of rationalist philosophers, while the Nagel quote is more closely representative of the psychologists' camp. Concerning this distinction, two proposals deserve attention. The first is that a priori intuitions are a different sort of thing than what psychologists (typically) study. When non-philosophers talk about intuition, they are literally talking about something else. ${ }^{95}$ The second proposal is that a priori intuitions are a mere subset of intuitions more generally, distinguished not in kind but in emphasis from other intuitions. The features of the world that philosophers study are normally modally robust, and so it is no surprise that the intuitions which motivate philosophical theories usually exhibit that same modal robustness. ${ }^{96}$

\footnotetext{
95 This is a bit too strong. Mathematicians, for example, might appeal to the same sort of intuitions as philosophers do.

${ }^{96}$ I take for granted that there is a close relationship between a priority and necessity, though the relationship isn't identity.
} 
Bealer seemingly endorses the first proposal. In his 1999 he is explicit that his analysis targets a priori intuitions: "In our context when we speak of intuition, we mean 'rational intuition' or 'a priori intuition.' This is distinguished from what physicists call 'physical intuition"' (30). He is explicit about what separates a priori intuitions from physical intuitions: "We have a physical intuition that, when a house is undermined, it will fall. This does not count as a rational intuition, for it does not present itself as necessary" (ibid.). And he is explicit that the results from studies of physical intuitions do not generalize to a priori intuitions: "I should note, finally, that the work of cognitive psychologists such as Wason, Johnson-Laird, Nisbett, Kahneman and Tversky tells us little about intuitions in our sense; these researchers have simply not been concerned with them" (31). ${ }^{97}$

For Bealer, the difference in modal presentational phenomenology between a priori and a posteriori intuitions is deep, so deep that the two types of intuitions are best considered distinct, unrelated categories of mental states. But other authors, opting for proposal two, deny that this presentational difference is so profound. Fischer and Engelhardt 2016 take intuitions to be judgments delivered by cognitive processes which are "effortless (the key property) as well as unconscious, non-intentional, and autonomous" (68). ${ }^{98}$ Nagel 2012 believes that the "crucial characteristic of intuition is that its workings are not exposed to us at the moment of judgment" (495). In this, a priori and a posteriori

\footnotetext{
${ }^{97}$ In his 1996, Bealer goes further: “The very idea of an empirical test for [intuition's] eventual tie to the truth is misconceived... The thesis that intuitions have the indicated strong modal tie to the truth is a philosophical (conceptual) thesis not open to empirical confirmation or refutation" (7).

98 Where a process is effortless "to the extent to which it is independent from working memory," unconscious "to the extent to which the subject is unable to report its course," non-intentional "to the extent to which its initiation is insensitive to the aims or goals" of the subject, and autonomous "to the extent to which the subject is unable to end the process, once initiated" (ibid.).
} 
intuitions are united. Hence, the work of cognitive psychologists may well be relevant to the project of evaluating a priori intuitions.

Neither proposal has been established definitively. Thus, it would be a mistake to assume that a priori intuitions are so different from a posteriori intuitions that metaphilosophers can ignore the latter. Likewise, it would be a mistake to assume that the (un)reliability of a posteriori intuitions guarantees the (un)reliability of a priori intuitions. What's needed is a taxonomy of intuitions which clearly recognizes both categories so that these questions can be better explored. If there is good evidence that (some) a priori intuitions issue from (some of) the same mental module(s) as (some) a posteriori intuitions, then we'll have a principled method for evaluating the reliability of (those) a priori intuitions. Similarly, we may be able to learn something about a priori intuitions by examining the ways in which our a posteriori intuitions go wrong. Our a posteriori intuitions seem to be pretty good at predicting the behavior of middle-sized objects moving at medium speeds. Presumably, this reliability has an evolutionary explanation: we evolved in an environment of middle-sized objects moving at medium speeds. If, on the other hand, our a posteriori intuitions are pressed to make predictions about very large or very small objects moving very fast or very slowly, they often go very wrong. Analogously, it may be the case that our a priori intuitions about thought experiments which don't deviate too far from ordinary circumstances are far more reliable than a priori intuitions about exotic thought experiments.

\subsection{Case Judgments vs. General Principles}

Sometimes intuitions are elicited in response to particular (usually hypothetical)

cases. For instance, one might be presented a story about a doctor who, without permission, 
removes the organs from a healthy patient (thereby killing her) in order to save the lives of five patients in need of various organ transplants. ${ }^{99}$ The story elicits the intuition that the doctor's actions are morally impermissible. But according to act utilitarianism (at least the crudest version), the doctor's actions are not only permissible but obligatory. And so the intuition elicited by the story is evidence that (the crude version of) act utilitarianism is false.

But there is another class of intuitions which does not rely on reactions to specific cases. These are the so-called 'general' or 'theoretical' intuitions. Thus, an ethicist might appeal to the intuition that correct moral reasoning must be agent-neutral (i.e., everyone's pleasures and pains_-or whatever else generates moral reasons_-must be counted equally). A skeptical epistemologist might appeal to the intuition that to know that $\mathrm{p}$ we must have discriminating grounds for $\mathrm{p}$. Or a mereologist might appeal to the intuition that parthood is a reflexive, transitive, antisymmetric relation. And, of course, theoretical intuitions are ostensibly indispensable to math and logic, where axioms are frequently said to be known via intuition.

Granting that case judgments and general principles can both be accurately described as intuitions, we might wonder if one type of intuition is more important than the other. For example, are our case judgment intuitions really just the product of a tacit application of some general principle? Or are our theoretical intuitions really just tacit amalgamations of case judgments? Even if the two are unrelated in this way, we might still wonder if one type of intuition is more reliable than the other or if one has more justificatory force than the other.

\footnotetext{
99 Adapted from Thomson 1976: 206. I should note that Thomson's primary interest in presenting the story was not refuting act utilitarianism.
} 
Bealer emphasizes the primacy of case judgment intuitions over theoretical intuitions, asserting that "it is intuitions about concrete cases that are accorded primary evidential weight by our standard justificatory procedure; theoretical intuitions are by comparison given far less evidential weight" (1996: 4). ${ }^{100}$ In contrast, Laurence BonJour emphasizes what he calls "rational insight," a type of intuition which typically delivers general principles. ${ }^{101}$ More generally, Roderick Chisholm (1973) distinguishes two methodological points of emphasis. The philosophical particularist believes that one ought to privilege cases judgments over general principles when engaging in reflective equilibrium. The philosophical methodist believes one ought to privilege general principles over case judgments when engaging in reflective equilibrium. Chisholm himself held that "we can deal with the problem [of choosing between particularism and methodism] only by begging the question" (37).

Because different types of philosophical arguments appeal to different types of intuition, RELIABILITY and JUSTIFICATION demand that we recognize the possibility of a difference in reliability or justificatory force between case intuitions and theoretical intuitions. Again what's needed is a fine-grained taxonomy that doesn't assume without argument that case intuitions are cut from the same cloth as theoretical intuitions.

\subsection{De Dicto vs. De Re}

One final varietal distinction merits attention. Most metaphilosophers believe that propositions are the proper target of intuitions. It's common to report intuitions using thatclauses. I have the intuition that the Gettier subject doesn't know. My intuition is that the

\footnotetext{
100 Nonetheless, Bealer's own arguments rely to a significant degree on theoretical intuitions. 101 See (e.g.) his 1998: 15-16.
} 
China-brain lacks consciousness. The locution 'intuition that p'-where 'p' can only be filled by propositions - is nearly ubiquitous. Philosophers who think that intuitions are a species of judgment are most at home with this formulation. But even philosophers who model intuitions as dispositions or seemings are happy to make use of the phrase. Marcu McGahhey and Neil Van Leeuwen (forthcoming) call the position that intuitions have determinate propositional content "Mainstream Propositionalism."102

But there is a secondary, non-propositional use of the term. ${ }^{103}$ According to this usage, abstract objects, not propositions, are the target of intuitions. Thus we can distinguish de dicto intuitions from de re intuitions. ${ }^{104}$ When one has a de re intuition, one gains understanding, not belief. If this understanding rises to the level of knowledge, it is knowledge by acquaintance, not propositional knowledge. According to this usage, one uses intuition to (e.g.) recollect a Platonic form, recognize a universal, grasp a property, or apprehend a concept.

De re intuitions are sometimes taken to be particularly salient to the philosophy of mathematics, in part due to Kurt Gödel's famous 1964 claim that "despite their remoteness from sense experience, we do have something like a perception also of the objects of set theory," which he subsequently labelled "mathematical intuition" (1983: 483-4). ${ }^{105}$ Most

\footnotetext{
102 McGahhey and Van Leeuwen's own view is that intuitions do not have contents (though they may have valences). On this view, intuitions are more akin to "twinges, internal promptings, [or] urgings."

103 I suspect (but will not argue) that this secondary usage is older than what we now take to be the primary use. Kant, Locke, Descartes, and Plato all seem to employ intuition in this sense.

104 Audi (2008: 476) marks the same distinction with the terms "cognitive intuitions" (de dicto) and "objectual intuitions" (de re). Bengson (2015: 709) also calls de re intuitions "objectual intuitions," though he does not adopt the other half of Audi's terminology.

105 I nurse doubts, however, as to whether Gödel actually meant to be employing 'intuition' in the de re sense just described. A closer reading of the text reveals that the target of Gödel's special mathematical perception is not numbers or sets, but the (propositional) axioms of set theory.
} 
metaphilosophers, either implicitly or explicitly, take de dicto intuitions to be the appropriate targets of their intuition analyses. But the grounds for this exclusion are often unclear. Perhaps a faculty of de re intuition sounds too mysterious. Or perhaps de re intuitions are thought to play a less important role in philosophical theorizing. Or perhaps de re intuitions, if they exist at all, are a completely different type of mental state from de dicto intuitions. Once again, the fact that two sets of dissimilar mental states both get called 'intuitions' is some evidence that 'intuition' doesn't pick out a unified category. In any event, the exact relationship between de re intuition and de dicto intuition deserves to be explored, and this exploration can only be accomplished with a suitably fine-grained taxonomy in hand.

\section{THE Diversity OF INTUITION CONTENTS}

Appeals to intuition-both implicit and explicit—are rife in analytic philosophy as it is practiced today. These appeals come in a variety of forms. Intuitions are mustered to support judgments of conceptual applicability, theoretical simplicity, metaphysical possibility, moral duty, epistemic blameworthiness, dialectical burden, and myriad others. Among the most conspicuous types of appeal to intuition are thought experiments. Derek Parfit invites his readers to imagine beings who reproduce by both fission and fusion, fusing every autumn and dividing every spring. ${ }^{106}$ Frank Jackson asks his readers to consider a brilliant neuroscientist forced to investigate the world via a black and white monitor in a black and white room. ${ }^{107}$ Donald Davidson invites his readers to imagine a lightning strike in a swamp which reduces his body to its basic elements while transforming a nearby dead tree into an

\footnotetext{
106 1971: 22
}

107 1982: 130 
exact facsimile of him. ${ }^{108}$ David Chalmers asks his readers to consider a physical duplicate of a normal human being, but lacking all conscious experience. ${ }^{109}$ More recently, Jack Lyons bids his audience to study a fable involving a "Grand Interworld Station" housing not only “terrestrial humans of all eras," but also "centaurs, unicorns, Norse deities, sentient teapots, talking lions, inhabitants of Mars, Alpha Centauri, and Twin Earth, and more” (2013: 14). Philosophical thought experiments are as wide-ranging as they are unusual.

Thought experiments receive an outsized portion of metaphilosophical attention, especially within the nascent experimental philosophy movement, but it's important to note that appeals to intuition need not be so dramatic. More quotidian appeals to intuition are just as varied as their flashier cousins. There are, for instance, appeals to nomological intuitions: "We have a strong intuition that the laws of nature are contingent and a strong intuition that the existence of sparse properties is contingent also" (Bird 2004: 271), semantic intuitions: "Intuitively, there was a gradual undetected shift in the semantic value associated with Americans' use of the term 'corn"' (Schroeter \& Schroeter 2014: 16), justice intuitions: "Intuitively, the most obvious injustice of the system of natural liberty is that it permits distributive shares to be improperly influenced by these factors so arbitrary from a moral point of view" (Rawls 1971: 72.), parsimony intuitions: "Why do we refuse to admit the abstract objects that mathematics needs? Fundamentally this refusal is based on a philosophical intuition that cannot be justified by appeal to anything more ultimate" (Goodman \& Quine 1947: 105), biological intuitions: "Intuitively, representations that see selection as acting at other levels get the causal structure wrong” (Sterelny \& Kitcher 1988:

\footnotetext{
108 1987: 443-444
}

109 1996: 94 
359), and even metaphilosophical intuitions: "Intuitively, these intuitions are evidentially as basic as evidence gets" (Bealer 1996: 11). Such examples could be multiplied many-fold.

For their part, metaphilosophers are happy to acknowledge the diversity of intuitions. Sosa 2006 cites mathematical, logical, modal, and spatial intuitions in the same breath. Bealer 1998 mentions much the same list, but supplements it with moral, aesthetic, and mereological intuitions. Others, such as Malmgren 2011, add epistemic and semantic intuitions to the group. Notwithstanding this diversity, there is a tendency to treat intuition monolithically. This tendency does not comport with our two metaphilosophical goals, RELIABILITY and JUSTIFICATION. When investigating a source of evidence, the narrower the alleged domain of expertise, the easier it is to evaluate the reliability of the source. A monolithic treatment of intuition misses the possibility that we might be justified in relying on some intuitions but not others. Because the contents of intuitions cut across so many diverse domains, we must be sensitive to the hypothesis that appeals to intuition are more suited to some areas than to others.

For example, arguments for wholescale normative intuition skepticism might be selfdefeating because they rely on certain epistemic intuitions. There might not be a way to argue that the intuition that $\mathrm{p}$ never justifies the belief that $\mathrm{p}$ without at some point employing an intuition about the nature of justification. This fact might give us good reason to regard certain intuitions as self-justifying. Intuitions about the nature of justification, say, might be epistemic bedrock: there might be no way to question them in a way which does not undermine the project of questioning them. But even if this is so, it's not clear how this conclusion ought to affect our confidence in other types of intuition. We can grant that 
certain epistemic intuitions are self-justifying while still worrying that our moral intuitions systematically co-vary with non-evidential factors or that our modal intuitions misrepresent the space of possible worlds.

A similar rush to generalize is observable amongst some empirically-minded intuition critics. An opponent of appeals to intuition might cite the unreliability of mathematical, logical, or probabilistic judgments as the basis for general intuition skepticism. But like epistemic intuitions, the justificatory status of probabilistic intuitions does not straightforwardly generalize to other types of intuition. Even if most human beings are terrible at the type of abstract reasoning required for doing mathematics, they might be quite competent employing concepts like 'knowledge,' 'goodness,' or 'possibility.' No single experimental study can give us good cause to doubt the reliability of all intuitions. Even taking the entire $\mathrm{x}$-phi corpus as a whole (and granting that the various methodological problems that have been identified can be rectified), we would be wrong to think that the studies cast doubt on all and every intuition. The domain of intuitions is just too large. Compare: scientists of one stripe or another have described one hundred distinct situations in which our perceptual beliefs are liable to go astray. Should we come to think that every (or even most) perceptual beliefs are unjustified? Of course not. The experimental philosophy movement can, of course, describe specific intuitions which the data suggest are unreliable, and these circumscribed results might be surprising and useful. But in terms of a generally applicable lesson, the best x-phi can show is that when deploying intuitions, one 
ought to be careful. ${ }^{110}$ This is hardly a surprising result. ${ }^{111}$ Philosophical practice of all varieties demands patience, rigor, and, of course, much care.

\section{The Particularity of Intuitions}

Metaphilosophers want to know whether the evidence that figures in philosophical arguments is reliable and/or whether we are justified in relying on that evidence. To most metaphilosophers, investigating philosophical intuitions is the most promising way of evaluating these questions. But there is no way to make these assessments without taking particular intuitions to be instances of some more general type. And that raises the issue of how to pick out the appropriate type from amongst the numerous possibilities.

Relying on intuition is a kind of belief-altering process. ${ }^{112}$ Every belief-altering process token is an instance of some belief-altering process type. ${ }^{113}$ But to evaluate the merits of relying on intuition, we need to determine the relevant process type. In this case, the relevant process type will be the process type that best serves our two metaphilosophical goals, RELIABILITY and JUSTIFICATION. It's important to note that the search for the appropriate process type is a pragmatic, not metaphysical, endeavor. Even if intuitions constitute a natural kind, there may still be practical reasons to consider a more fine- or coarse-grained treatment.

\footnotetext{
${ }^{110}$ For instance, if using a thought experiment to elicit an intuitive judgment, try out a number of similar cases with minor variations and see if your intuitions change. Then put the cases (in a number of different orders) to lots of your friends and colleagues and see what they think. Even if this process confirms your initial hunch, be modest about what the thought experiment proves.

111 Which is not to say that it's not an important lesson. One can easily find papers whose authors would have done well to better heed this advice.

112 Belief-altering, rather than belief-forming, because in addition to generating beliefs, intuition may strengthen or weaken beliefs.

113 See Conee \& Feldman 1998
} 
When evaluating the merits of relying on some source of evidence, it's crucial not to concentrate too broadly or too narrowly. If one focuses too narrowly, one ends up with a taxonomy which is too finely-grained, with too many process types to effectively evaluate them all. On the other hand, if one focuses too broadly, one ends up with too few process types, and one risks glossing over important differences. In the metaphilosophical literature, the tendency has been to focus too broadly.

There is no reason to think that the reliability of intuitions-whatever intuitions turn out to be-is not as fine-grained as the reliability of, say, testimony or perception. Testimony is a generally reliable source of evidence, but the testimony of pathological liars is not. Perception is a generally reliable source of evidence, but perception after taking hallucinogenic drugs is not. We ought to be (and usually are) discriminating about our sources of evidence. Our guiding metaphilosophical goals suggest that, absent some special feature which would serve to unify the category (see objections below), our metaphilosophical practice would be improved if we ceased to investigate intuitions tout court and instead conducted research (whether a priori or empirical) into the reliability and justificatory power of specific subsets of intuitions. ${ }^{114}$

An analogy is helpful. Imagine trying to evaluate the merits of relying on eyewitness testimony in the courtroom by examining the general virtues of testimony or perception. Not only would it be hopeless, it would be pointless. Notwithstanding the general reliability of testimony and perception, there still may be special reason to discount the value of

\footnotetext{
114 In chapter five I speculate on three features of intuitions which might be helpful in dividing them more finely for further study.
} 
eyewitness testimony in a court of law. ${ }^{115}$ Similarly, 'intuition' as a general category may well prove to be epistemically virtuous, while an important subset of intuitions which figures prominently in philosophical argumentation turns out to be problematic. ${ }^{116}$

Results from experimental philosophy suggest that intuition, considered broadly, is too general to serve our metaphilosophical goals. Many experimental studies allegedly demonstrate that intuition reports systematically co-vary with non-evidential factors. For instance, socioeconomic status affects folk judgments about free will (Nichols \& Knobe 2007), political orientation affects folk judgments about the permissibility of civilian casualties (Uhlmann et al. 2009), gender affects folk judgments about knowledge and reference (Buckwalter \& Stich 2014), language of presentation affects folk judgments about moral obligation (Costa et al. 2014), to name just a few. Importantly, recent research suggests that professional philosophers are prone to the same sort of cognitive biases and heuristics which lead the folk astray (Schwitzgebel \& Cushman 2015).

Notwithstanding the sometimes exaggerated claims of the experimental philosophers, these studies, even if methodologically sound, do not entail that intuition is generally unreliable or that we are generally unjustified in relying on intuition. ${ }^{117}$ It is no easy step to move from a few problem cases to a pronouncement about a whole domain. After all, nobody claims that intuition is infallible, and the existence of optical illusions doesn't motivate the absurd position that perception is therefore unreliable. Ernest Sosa captures

\footnotetext{
115 See Stambor 2006.

116 The analogy comes from Jennifer Nado who writes, "A court cannot dismiss the possibility of myopiainduced error in a witness's long-distance identification of a suspect by simply appealing to the on-balance reliability of vision. Mutatis mutandis for the intuition case" (2014: 24).

117 Weinberg, Nichols, and Stich, in their seminal 2001 paper which launched the experimental philosophy movement, recognize this point. They restrict their conclusions to epistemic intuitions of a certain kind.
} 
this point nicely when he summarizes his take on the results from experimental philosophy: "The upshot is that we have to be careful in how we use intuition, not that intuition is useless" (2007: 105).

Although Sosa does well to resist the ampliative inference that the experimentalists press, he does less well in respecting the important metaphilosophical issues that the experimentalists do raise. Sosa, like almost all metaphilosophers, treats intuition at a level that is too general. But the only way to be careful in the way we use intuitions is to be more discriminating in the types of intuition that we recognize. That is, we must be more finegrained in the way we carve up intuitions so that we can distinguish the problematic intuitions from the unproblematic ones.

\section{OBJECTIONS}

In this section I consider four objects to the case for heterogeneity presented above. The first objection attempts to undercut the argument by suggesting that other propositional attitudes, such as belief and desire, are just as heterogeneous as intuition and that other sources of evidence, such as memory and testimony, deliver contents just as diverse. On the assumption that philosophers appropriately treat belief/desire and memory/testimony as unified kinds, it follows that my argument that intuition is heterogeneous is mistaken. The second and third objections concede that I have identified heterogeneous features of the category 'intuition' but argue that these aspects of intuition are outweighed by unifying features: phenomenology, in the one case, and cognitive faculty, in the second. The final objection argues that in response to the heterogeneity of intuition, rather than adopt a finergrained taxonomy, we ought to adopt a so-called 'no-theory' theory of intuition. 
To respond fully to these objections would require a second (or even third) dissertation. Here I merely sketch some initial reactions. It's important to emphasize at the outset, however, that the ultimate point I'm trying to make is relatively modest: if treating intuitions monolithically doesn't conduce to the metaphilosophical goals RELIABILITY and JUSTIFICATION, then we ought to adopt a different metaphilosophical treatment of intuition. Thus, in many instances, the metaphysics of intuition and the exact nature of intuitive justification can be set to one side. Because the goal of the project is pragmatic, these questions need not be definitively settled in advance.

\subsection{Other Attitudes and Sources of Evidence}

One might naturally worry that the prima facie evidence I've marshalled against the homogeneity of intuition could just as easily be marshalled against other propositional attitudes, in particular belief and desire, or other sources of evidence, in particular memory and testimony. 'Belief' and 'memory' both admit of many of the same ambiguities that plague 'intuition.' We might speak of distinct varieties of belief and memory. The contents of beliefs and memories are at least as diverse as the contents of intuitions. But, so the objection goes, it would be wrong to conclude that 'belief' and 'memory' don't pick out fairly unified kinds. Thus, the ambiguity, variety, and diversity of intuitions cannot be used to argue that 'intuition' picks out a gerrymandered or disjunctive category.

The problem with this objection is twofold. First, as we will see in subsequent chapters, from the point of view of RELIABILITY and JUSTIFICATION, it does make sense to parse intuitions more finely, just as it sometimes makes sense to parse beliefs and memory more finely. When investigating the reliability of courtroom testimony, it would be foolish 
to appeal to the general reliability of testimony to assuage genuine concerns about, say, confabulation. $^{118}$

Second, and more important for present purposes, the natural unity of belief cannot, by analogy, undergird the natural unity of intuition because there is a crucial difference between the two. Beliefs are actually more diverse than intuition. A belief report of the form 'S believes that p' is well-formed no matter what proposition replaces the variable 'p.' Not so with intuitions. As we have seen, there are additional constraints on intuitions. For rationalist-inclined metaphilosophers, the proposition intuited must be necessary or analytic or a priori (or whatever it takes to rule out hunches, guesses, and anything with empirical content). For empirically-inclined metaphilosophers, the process which leads to the intuition must be subconscious or uncritical. These restrictions undermine the naturalness of intuition and weaken the analogy to belief. ${ }^{119}$

\subsection{Phenomenology}

John Pollock 1974 claims that "logically intuiting something is a phenomenologically unique experience" (321). Alvin Plantinga 1993 writes that propositions known through the "cognitive module" of intuition are accompanied by "that peculiar sort of phenomenology with which we are all well acquainted, but which I can't describe in any way other than the phenomenology that goes with seeing that such a proposition is true" (106). Earl Conee 1998 adds, "Seeing the truth is analogous to visual perception in that the object of the seeing

\footnotetext{
118 A confabulated memory is a plausible but infelicitous pseudo-memory which is unconsciously and unintentionally generated to fill gaps in what is remembered. Confabulated memories are phenomenologically indiscriminable from genuine memories.

119 Other propositional attitudes, such as desire and fear, may appear to be similarly restricted, but they are not. It would certainly be strange to fear that the number 7 will cease to be prime, but it's not metaphysically impossible in the way that intuiting an empirical proposition is (according to some metaphilosophers) supposed to be.
} 
is apprehended by experiencing phenomenal qualities" (848). ${ }^{120}$ According to some, intuitions constitute a unified kind in virtue of their phenomenology.

Unfortunately, the phenomenology of intuition is not easy to nail down with much precision. In describing the phenomenology, metaphilosophers repeatedly make use of locutions like 'being struck by p' (Sosa), 'seeming that p' (Bealer), or 'just seeing the truth of p' (Plantinga). Phenomenological claims such as these often lead to dialectical stalemate. Herman Cappelen (2012: 117) reports that "by introspection I cannot, even with the best of will, discern a special feeling that accompanies my contemplation of the naïve comprehension axiom, Gettier cases and other alleged paradigms of the intuitive." Of course, Cappelen may just be phenomenologically deficient. ${ }^{121}$ But even granting that there is some sort of unique phenomenology which accompanies intuition, difficult though it is to identify, it's still not clear that this phenomenology can justify treating intuitions monolithically.

According to the most popular phenomenological view of intuitions, intuitions are seemings, where a seeming is understood to be a type of 'assertive' mental state in which the contents of the seeming are 'presented as true."122 Of course 'seemings' is far too broad a category to be of much metaphilosophical use. After all, there are visual seemings, but the reliability of perception does not guarantee the reliability of intuition. Intuitions, then, aren't just any old seemings. Intuitions are intellectual seemings. It's not at all clear what makes a seeming 'intellectual,' but a first stab is that it is a seeming unaccompanied by perceptual

\footnotetext{
120 Even Jonathan Weinberg, a critic of appeals to intuition, notes that intuitions "frequently stand out with great psychological salience" (2007: 318).

121 Though if he is, many others, myself included, are too.

122 This literature is rife with metaphors, most of which I find unhelpful.
} 
qualia. This initial characterization does not stand up to much scrutiny, however, because if it were true, blindsight would count as a type of intuition. ${ }^{123}$ A better characterization has it that an intellectual seeming is a seeming unaccompanied by perceptual qualia which does not depend on the sense modalities. ${ }^{124}$

One prima facie reason to be attracted to the phenomenological view of intuition is that the view could help explain the justificatory power of intuitions. We are already familiar with the justificatory force of visual seemings; if intuitions are just another type of seeming, the explanation of their justificatory power might proceed along similar lines. Indeed, there might even be a unifying story which explains both the justificatory power of perception and the justificatory power of intuition.

Michael Huemer famously advances just such a theory. He calls it phenomenal conservatism (PC):

PC "If it seems to $S$ that $p$, then, in the absence of defeaters, $S$ thereby has at least some degree of justification for believing that $p$ " (2007: 30).

Setting aside the truth-value of PC, Huemer's theory is unlikely to help us pursue the metaphilosophical goals outlined in chapter one, not even JUSTIFICATION. There are two problems. The first problem is that PC is very modest. PC doesn't say that the seeming that $\mathrm{p}$ justifies, even prima facie, the belief that $\mathrm{p} .{ }^{125}$ Rather, PC merely tells us that the seeming that $\mathrm{p}$ confers some level of justification on the belief that $\mathrm{p}$. It's consistent with PC that

123 (Ernest) Sosa (2014: 49, fn 11) finds this result "surprising but perhaps acceptable."

124 This characterization, too, faces difficulties. One must be careful about 'depends.' After all, reading the thought experiment which generates an intuitive response depends on the use of your eyes. A better characterization might somehow distinguish background/enabling conditions for using intuition from intuition itself.

125 Huemer does endorse this stronger version of PC in his 2001. He explicitly retracts this version and replaces it with the version cited above in his 2007. 
seemings confer a very small degree of justification and that the seeming that $\mathrm{p}$ never, by itself, justifies the belief that p. As metaphilosophers, we want to know what counts as good evidence in philosophy. But even if intuitions are a type of seeming, PC doesn't tell us that they are thereby good evidence.

Compare another modest view, testimonial conservatism (TC):

TC If some speaker $S$ testifies that $p$ to some hearer $H$, then, in the absence of defeaters, $H$ thereby has at least some degree of justification for believing that $p$.

TC doesn't help us parse good testimony from bad testimony. It's not going to help us in a court of law; it's not going to help us decide which politicians to believe; it's not going to help us decide which of our friends are reliable. TC, like PC, is practically useless. Even if PC were true, the best way to do philosophy might be to ignore intuitions-perhaps the justification they provide is too minimal to ever make a difference-in the same way that in researching some domains (especially, say, introspective domains, like what you want to eat) it's appropriate to ignore testimony.

The second problem is that phenomenology is cheap. As various forms of synesthesia demonstrate, the phenomenology of an experience is a largely contingent matter. Consider some person, call him Brian, who has a hunch about the sex of the unborn child his two-months-pregnant wife is carrying. Brian might be 'struck' by the conviction that his wife is carrying a girl. It might just 'seem' to Brian that his wife is carrying a girl. Brian might just 'see' that his wife is carrying a girl. I maintain that-absent some metaphysical theory which prohibits this description of events-such an experience could be 
indistinguishable from an intuition experience. But metaphilosophers generally want to deny the status of intuition to such empirical hunches. For example, Bealer writes,

"There are significant restrictions on the propositions concerning which one can have intuitions; by contrast, there are virtually no restrictions on the propositions concerning which one can make a judgment or a guess or have a hunch" (1996: 124). If any hunch, guess, suspicion, or premonition could rise to the justificatory level of intuition, then it would be epistemically inappropriate for philosophers to appeal to intuitions.

The natural response to this counterexample is to hold that intuitional phenomenology is a necessary but not sufficient condition on one's having an intuition. It's the presentational phenomenology in the right kind of cases that delivers intuitions. Perhaps the proposition under consideration must be necessary, analytic, or involve abstracta. Brian's hunch about the (contingent, synthetic, concrete) gender of his unborn child doesn't qualify, and thus it does not pose a threat to the view that intuitions should be treated monolithically.

Nonetheless, there is a worry here. The only way to support this revised criterion of intuition is by appeal to some metaphysical theory of intuition. But invoking PC to defend some metaphysical theory of intuition is, in this context, question-begging. That many of our intuitions are justified is a premise in the argument for PC. For example, Huemer writes,

For those who agree with such judgments as that sensory experiences provide justification for external-world beliefs, that intuitions provide justification for a priori beliefs, and that memories provide justification for beliefs about the past, there is an obvious challenges of accounting for the justificatory force of all these experiences. [...] PC holds out the promise of a simple and unified account of the justification of our beliefs about the external world, about the past, about the future, about values, and so on. It is otherwise very difficult, perhaps impossible, to account for all these justified beliefs, let alone to do so in such a simple manner. It 
therefore seems to me that this is a powerful argument in favor of some form of phenomenal conservatism. (2013: 346/9)

Metaphysical theories of intuition—at least current theories—take it as an unargued datum that intuitions should be treated monolithically. Consequently, these theories cannot justify this treatment. And as David Sosa—himself a proponent of the single-capacity, monolithic treatment of intuition—writes, "there is dubious philosophical virtue in devising a view that makes impossible what one finds threatening" (2011: 477).

\subsection{Faculty}

A separate attempt to unify intuitions goes by way of etiology. If intuitions issue from the same faculty, then-perhaps-there is sufficient reason to treat them monolithically. This is a plausible approach, but it's important to note that the etiology of intuition is an empirical question. That intuitions issue from the same faculty cannot be established from the armchair. I'm not sure how to adjudicate where the dialectical burden of proof initially lay in this particular dispute. (The diversity of intuitions seems to tell in favor of a multiple-capacity view, but, then again, one might think that there is similar diversity in visual perceptions.) In any event, as we'll see in chapter five, psychological research from the last two decades has clearly shifted the burden to the monolithic camp.

There is mounting empirical evidence that the human mind is modular in one form or another. ${ }^{126}$ For example, Dehaene \& Cohen 1997 report on two patients: one, impaired in subtraction but not multiplication; the other, impaired in multiplication but not subtraction. This research suggests that there is a mental module dedicated to multiplication which is

\footnotetext{
126 See Carruthers 2006 for a defense of the view that the mind is massively modular. For the purposes of this section, I need only assume that the mind is modestly modular.
} 
functionally distinct from the module dedicated to subtraction. Waltz et al. 1999 report similar modularity in the logical domain, and moral psychologists have long known that utilitarian preferences are governed by a different part of the brain than deontic preferences. $^{127}$ For these reasons, psychologists and neuroscientists no longer make sweeping generalizations about inferential processes. For instance, due to the fact that "inferential procedures are carried out by many different modules using a variety of procedures," Mercier and Sperber 2009 argue that "it is pointless to ask how inference in general is performed or to try to generalise from the properties of inference in a given domain to all inferential processes" (153). On the plausible assumption that different types of intuitions might issue from different mental modules, the lesson applies equally well to metaphilosophy: sweeping generalizations about (e.g.) the reliability of intuition are unwarranted. Thus, the sameness-of-origins thesis can no longer be justifiably assumed. And as far as I'm aware, there are no articles or books which purport to give a positive, empirical argument for the single-faculty approach.

\section{4 'No-Theory' Theory}

A final objection has it that the central questions of metaphilosophy, including RELIABILITY and JUSTIFICATION, can be asked and answered without any serious taxonomy of intuition, much less the fine-grained taxonomy I insist is necessary. According to this objection, metaphilosophy can suffice with a few loosely grouped paradigmatic examples which together constitute a so-called 'no-theory' theory of intuition. The best representative of this view (and the source of the terminology) is Max Deutsch. He claims that

\footnotetext{
127 See Greene \& Haidt 2002.
} 
"developing a theory of the nature of intuitions is not necessary for understanding their role in philosophical argument," adding that the "issue of the state's role and evidential status can be discussed, and perhaps settled, well in advance of settling... questions concerning categorization" (2015: 28-29). That the methodological role of intuitions can be investigated without fully understanding the nature of intuitions is good news, according to Deutsch, because "the project of developing such a theory is fraught with difficulties anyway" (ibid.). In place of such a theory, Deutsch "trust[s] that the reader will be able to recognize an intuitive judgment when he or she encounters one” (ibid.).

Deutsch's desire to sidestep difficult theoretical and taxonomic questions is understandable. We've already seen metaphilosophers disagree about the phenomenology of intuitions, the evidential status of intuitions, the extent to which philosophical arguments depend on intuitions, whether the contents of intuitions must be a priori, and whether to privilege case judgment intuitions over general principle intuitions. In the face of such fundamental and pre-theoretic disagreement, the prospects of arriving at a neutral yet informative definition of intuition seem dim. Instead, Deutsch opts to follow Anna-Sara Malmgren and characterize an intuitive judgment as "any judgment relevantly similar to certain paradigms" (2011: 268). This indirect specification, Malmgren and Deutsch maintain, is the only option that can serve as an unbiased starting point. If other judgments are relevantly similar-where 'relevantly similar' is left to be spelled out-we can call those judgments intuitions. 
But how are we to adjudicate which judgments fit the bill? We could try enumerating examples (paradigms of the paradigmatic, if you will) and see how far that gets us. Here's one such example:

Suppose an individual consults a wristwatch she has every reason to believe is reliable. The watch reads 11:00, and, in fact, the time is 11:00. However, unbeknownst to the subject, the watch stopped at 11:00 the previous evening. Does such a person know that the time is 11:00?

However one responds, we might label that judgment an intuition. We might add that Ned Block's 'China-brain' case, Alvin Goldman's 'fake barn country' case, David Chalmers' 'phenomenal zombie' case, and Tyler Burge's and Hilary Putnam's 'twin earth' cases all elicit relevantly similar judgments.

The trouble with this approach, as we've already seen in chapter two, is that some philosophers explicitly deny that these cases represent paradigms of the intuitive. Williamson and Cappelen don't think we rely on intuition (at least in the traditional sense) when evaluating Gettier cases (or any other of the alleged paradigms). We could simply dismiss this minority opinion — after all, no treatment of any philosophically interesting topic will be so minimal as to escape all dissent—but that would, I think, be a mistake. Cappelen and Williamson are not exactly small figures in the field, and their views deserve a fair hearing.

More importantly, as we'll see repeatedly in chapter four, the success or failure of many of today's most popular metaphilosophical arguments crucially depends on an accurate categorization of intuition. Although such a categorization is difficult to establish, without a fine-grained taxonomy of intuition, metaphilosophers risk drawing unjustified general 
inferences, missing important methodological possibilities, and simply talking past one another. In short, the details matter. It is to those details I turn next. 


\section{Chapter Four: Metaphilosophical Arguments ${ }^{128}$}

"Arguments seldom work on men of wit and learning when they have once engaged themselves in a contrary opinion."

- Thomas Hobbes, letter of 1645

\section{INTRODUCTION}

In this chapter, I examine four popular metaphilosophical arguments, two from the anti-intuition camp - the argument from calibration $(\$ 2)$ and the argument from intuitional sensitivity (\$3) — and two from the pro-intuition camp—-the argument from self-defeat $(\$ 4)$ and the argument from innocence-by-association $(\$ 5)$. I show how dropping the assumption that intuitions constitute a homogeneous, unified kind significantly alters the arguments, undermining premises in some cases, revealing new dialectical avenues in others.

\section{Calibration}

Calibration is the procedure by which the accuracy of a process of belief-alteration is tested within some range and, if necessary, corrected. Calibration proceeds by means of verifiable comparison to some standard or standards. The calibration objection against intuitional methodology charges that philosophical intuition, construed as an instrument, cannot be verified against any independent standard. Hence, the accuracy of philosophical intuition can be neither tested nor (should such be necessary) corrected. Thus, we should jettison appeals to intuition from our philosophical toolkit.

Below, I examine the argument from (lack of) calibration. ${ }^{129}$ First, in $₫ 2.1$, I motivate the argument. Next, \$2.2 I explain in more detail what calibration is. Finally, in $\$ 2.3 \mathrm{I}$

\footnotetext{
128 Portions of this chapter appeared in my 2016 article "Carving Intuition at Its Joints," Metaphilosophy, Volume 47, Issue 3, pages 326-352

129 I drop the parenthetical in what follows.
} 
demonstrate where the argument assumes that a monolithic treatment of intuition is appropriate and show the consequences of this erroneous assumption.

\subsection{Motivating the Argument from Calibration}

Recently, the reliability of philosophical intuition has come under attack. ${ }^{130}$ These authors question whether the intuition that $\mathrm{p}$ reliably tracks the truth that $\mathrm{p}$. Call this the reliability challenge for philosophical intuition. In the sciences, when the reliability of an instrument is doubted, standard practice is to attempt calibration of the instrument in question. Within the empirical disciplines, calibration has been called "essential" and is said to "play a major role" in "providing grounds for belief in experimental results" (Franklin 1997: 76). If philosophical intuitions were to be successfully calibrated, the reliability challenge would be met. ${ }^{131}$

The reliability challenge for philosophical intuition emanates from two empirical considerations. The first is general. Well-trod psychological research demonstrates that human beings are significantly more reliable when reasoning with concrete and familiar terms than they are when reasoning with abstract and unfamiliar terms. ${ }^{132}$ Nearly a century of empirical study has confirmed this fact. For example, success in algebraic reasoning drops off markedly when the customary $x$ and $y$ are replaced by the unfamiliar $b_{1}$ and $b_{2}{ }^{133}$ Reasoning about percentages is notoriously difficult, while structurally analogous questions

\footnotetext{
130 See, inter alia, Cummins 1998, Hintikka 1999, Hales 2000, Weinberg 2007, Gendler 2007, Maclaurin \& Dyke 2012, Baz 2012, Kriegel 2013, and Silva 2013.

131 Successful calibration is a sufficient condition on meeting the reliability challenge, but it is not a necessary condition.

132 See Tamar Szabó Gendler 2007 \$2 for a nice overview and potential explanation of this phenomenon.

133 See E.L. Thorndike 1922 for the first of many such studies.
} 
about populations are answered much more easily. ${ }^{134}$ Performance on the Wason selection $\operatorname{task}^{135}$ is generally miserable but improves drastically when numbers and letters are replaced with beverages and ages. ${ }^{136}$ Contemporary research indicates that the gulf in reliability between familiar and unfamiliar reasoning is deep and surprisingly resistant to correction. ${ }^{137}$ These results should concern working philosophers because the thought experiments deployed while investigating the philosophical domain are, often of necessity, so alien to everyday life. According to these considerations, "the sorts of cases philosophers are wont to deploy in their arguments will have a tendency to be of a sort where ordinary sources of reliability would be expected to break down” (Weinberg et al. 2012: 269).

The second consideration is more particular. The first decade and a half of the twenty-first century has witnessed the rise of the experimental philosophy movement. Experimental philosophers generally contend that philosophically irrelevant differences of personal biography and experimental set-up influence intuitions in surprising and unsettling ways. A series of empirical studies originating in the experimental philosophy movement allege that folk intuitions about important philosophical cases are subject to systematic gender, socioeconomic, and cultural differences and that these intuitions are unduly sensitive to various psychological biases and heuristics. ${ }^{138}$ If intuitions regarding philosophical thought experiments are malleable in a way that philosophical facts are not supposed to be, the utility of these thought experiments would be severely undermined.

\footnotetext{
134 See Tversky and Khaneman 1983, pp. 308-309.

135 The Wason selection task is a logical puzzle in which subjects must apply the rules of the material conditional.

136 See Jonathan Evans 1998 for an overview of this literature.

137 See Kahneman 2011 for an accessible introduction to this literature.

138 See, inter alia, Weinberg, Nichols, \& Stich 2001; Machery et al. 2004; Gendler \& Hawthorne 2005; Nichols \& Knobe 2007; Swain, Alexander, \& Weinberg 2008, Uhlmann et al. 2009; and Buckwalter \& Stich 2014.
} 
These considerations do not, of course, prove that philosophical intuitions are unreliable. In fact, there may be a lurking incoherence in supposing that all philosophical intuitions are unreliable. Nevertheless, these considerations do raise methodological doubts about the effectiveness of a certain class of recherché thought experiments. These doubts should not go unanswered. If traditional philosophical methodology is going to survive intact, defenders of the orthodoxy must either undermine the force of the reliability challenge or else meet the challenge head-on. If philosophical intuitions could be calibrated, the challenge would indeed be met, but this is precisely what proponents of the argument from calibration believe to be impossible.

Robert Cummins (1998) presents the most canonical formulation of the calibration objection. Cummins argues that "even if philosophical intuition can be calibrated, it never is calibrated, because philosophers could have no possible use for intuition in a context in which the relevant theory was well enough settled to form the basis of a credible calibration test" (118). If philosophers could establish an independent, non-intuitive method for learning the truth-value of propositions hitherto only accessible via intuition, then those intuitions could be calibrated. If after calibrating the intuitions we found them to be reliable, we would be justified in appealing to those intuitions. But, argues Cummins, if we had a non-intuitive route to the truth of intuitions, we would have no need of appeals to intuition. Cummins concludes, "Philosophical intuition, therefore, is epistemically useless, since it can be calibrated only when it is not needed" (ibid.). ${ }^{139}$

\footnotetext{
139 Cummins ignores the possibility that appeals to intuition might be less costly (temporally, cognitively, or financially) than the non-intuitive route.
} 
When calibration is possible, we can correct and fine-tune our intuitive judgments. In these cases, the fallibility of intuition is no cause for alarm. Indeed, it may be that intuition is unproblematic across a rather wide swath of domains. Just as the existence of optical illusions does not give us reason to doubt the general reliability of visual perception, neither does the fallibility of intuition give us reason to doubt intuition's general reliability. The worry, though, is that some philosophical arguments might appeal to intuitions which fall outside the normal range of reliability. When we enter the carnival's House of Mirrors, we should not trust our visual perception, notwithstanding its general reliability. If the intuitions elicited by, say, exotic philosophical thought experiments cannot be calibrated, we must confront the possibility that doing philosophy based on these thought experiments is like doing science in the House of Mirrors.

\subsection{What Is Calibration?}

A process of belief-generation can be calibrated only if it is possible to have certain justified subjunctive beliefs correlating the inputs of the process to the outputs. ${ }^{140}$ Calibratability comes in a variety of strengths, depending on the modal strength with which one interprets the 'possible' of the preceding sentence. The more narrowly we restrict the range of possible worlds encompassed by the scope of the 'possible,' the correspondingly more narrowly we will restrict the range of belief-generation processes available for calibration. In general, the closer the possible world in which we come to justifiably believe the relevant subjunctives, the more informative the claim of calibratibility will be in the

\footnotetext{
140 This is a necessary but not sufficient condition because the process inputs might be in some way constitutive of the process outputs, as in the way our humor-judgments are in some way constitutive of what jokes are funny. Such trivial subjunctive correlation will not count as calibration for the purposes of this section.
} 
actual world. We can distinguish two broad families of calibration, what I'll call coherentist calibration and foundationalist calibration. ${ }^{141}$

Coherentist calibration allows for the possibility that a process of belief-generation might be calibrated merely by its consistency across trials. Coherentist calibration proceeds by means of abductive inference. If an instrument of type $X$ delivers results $\Phi$ across a suitable number of trials, other instruments of type $X$ consistently deliver results $\Phi$, and the best explanation of this consistency is accurate measurement of $\Phi$, then instruments of type $X$ will be available for calibration according to the coherentist. Line up a hundred telescopes and point them at the same celestial object—if they all deliver the same result, you have the beginnings of a coherentist calibration project.

The foundationalist makes a stronger demand on calibration. She requires that calibration proceed by way of independent comparison. A necessary condition on foundationalist calibration is that we have more than one type of access to the facts that the process or instrument under evaluation purports to deliver. Mere consistency is never enough. The only way to calibrate an instrument of type $X$ is to compare its results with some other instrument of another type $Y$ for which we have independent reason to believe is capable of measuring $\Phi$-facts. ${ }^{142}$ Point a telescope at a distant mountain, then check with a local eyewitness - if the telescope and the eyewitness agree, you have the beginnings of a foundationalist calibration project.

\footnotetext{
141 The foundationalist/coherentist contrast is distinct from the exhaustive/extrapolative contrast outlined in Weinberg et al. 2012.

142 This approach is foundationalist because it must allow, on pain of vicious regress, at least one accurate standard that need not be calibrated. Perception in the most general sense cannot, perhaps, be compared with an independently known standard, but without perception the rest of our calibration attempts will fail.
} 
While my terminology is novel, the distinction between foundationalist calibration and coherentist calibration is implicit in much of the scientific literature on calibration. In most scientific investigations, foundationalist calibration is the norm. However, when scientists search for previously unobserved phenomena-especially if that search utilizes new types of experimental apparatus - coherentist calibration may be the only option. ${ }^{143}$ Intuition skeptics have generally missed the possibility of coherentist calibration. For instance, Weinberg et al. 2012 write, "Given the problem at hand - how to calibrate intuitions, given that the practice of appeal to intuitions is now in a state of challenge - this cycle cannot stop at simply more intuitions" (273, emphasis added). I argue that the cycle can stop at more intuitions if-and only if - these intuitions form the right kind of coherent base. $^{144}$

\subsection{Calibrating the Calibration Argument}

Concern about our ability to calibrate metaphysical intuitions is not new. Cummins first voiced this worry in his 1998 paper. A crucial premise in Cummins' argument is that "the most plausible account of the origins of philosophical intuitions is that they derive from tacit theories that are very likely to be inaccurate" (125). Here Cummins assumes that philosophical intuitions derive from the same source. If intuitions issue from diverse sources, then Cummins' generalizations are unwarranted. Thus, Cummins' formulation of the calibration objection may offer evidence that some philosophical intuitions are

\footnotetext{
143 See Franklin 1997, pp. 41-49, for an example involving gravitational wave detectors. See Heilbron 2010, pp. 160-162, for an example involving early telescopes.

144 Although the foundationalist/coherentist contrast is in many ways superficial, the contrast is meant to be exhaustive. The standard by which a process type is calibrated will either be independent from the process (foundationalist) or not (coherentist). Because views will differ regarding the nature of this independence, drawing the precise line between foundationalist calibration and coherentist calibration will be contentious.
} 
epistemically useless, but he falls far short of demonstrating that all intuitions are epistemically useless.

Since the publication of Cummins' paper (and perhaps before), the calibration objection has been implicit in much of the anti-intuition literature. The concern was again made explicit in 2012 by a group of philosophers led by Jonathan Weinberg. ${ }^{145}$ Weinberg et al. improve on Cummins' reasoning in many ways, offering a more subtle and sophisticated version of the argument. However, they, too, fail to appreciate the heterogeneity and particularity of intuition. They write, "To the extent that we are going to calibrate intuitions in any sort of wholesale fashion, we are going to need to do so in large part on the basis of our best philosophical instrument, which unfortunately is intuition itself' (267, emphasis added). The point I have been trying to press is that calibrating intuition in wholesale fashion is a fool's errand. Even if calibrating intuitions as a whole were possible, it would be about as methodologically useful as calibrating belief-formation as a whole. Unless the calibration procedure yielded a result of infallibility (which of course it would not), the procedure would get us no closer to answering the specific questions of RELIABILITY and JUSTIFICATION that metaphilosophers are charged to answer.

Notwithstanding these problems, there is a useful and interesting project in the vicinity of Cummins' and Weinberg's work. Some types of intuition seem amenable to calibration in ways other types of intuition are not amenable. Intuitions about the validity of a given argument form in sentential logic (modus tollens, say) can be verified via a non-

\footnotetext{
145 Weinberg, Jonathan, Stephen Crowley, Chad Gonnerman, Ian Vandewalker, and Stacey Swain. (2012). "Intuition \& Calibration." Essays in Philosophy: Vol. 13: Iss. 1, 256-283.
} 
intuition-invoking process (by constructing a truth table, say). ${ }^{146}$ Intuitions concerning the so-called 'birthday problem' can be checked via simple probability calculations. ${ }^{147}$ Intuitions surrounding seemingly inexplicable cases of Simpson's paradox can be corrected via an understanding of basic statistical principles. ${ }^{148}$ We are thus in a relatively good position to judge the reliability of logical, probabilistic, and statistical intuitions.

While there is no straightforward ampliative inference from the (un)reliability of logical, probabilistic, or statistical intuitions to the (un)reliability of metaphysical, moral, or epistemic intuitions, calibrating one type of intuition may give us some leverage in assessing the reliability of other types of intuition. Once we have ascertained the reliability of one set of intuitions, we can start examining the relevant similarities and differences between those intuitions and intuitions in other domains. ${ }^{149}$ Fine-grained investigations of this sort are not guaranteed to bear fruit, but they are more promising, at least from the point of view of RELIABILITY and JUSTIFICATION, than investigating intuitions in wholesale fashion.

\section{INTUITIONAL SENSITIVITY}

A second anti-intuition argument derives from intuition's aforementioned alleged sensitivity to unwanted factors. Certain experimental studies allegedly demonstrate that intuitions are sensitive to evidentially irrelevant factors like gender, culture, and socioeconomic status. These findings are supposed to motivate a reconsideration of

\footnotetext{
146 Intuitions about which argument forms are valid within a given logic can be calibrated. Intuitions about which logical system reflects the way the world really is (whatever that means) cannot be calibrated.

147 The birthday problem concerns the likelihood that in a set of $n$ randomly chosen individuals, some pair will have the same birthday. The probability reaches $50 \%$ at $n=23$ and $99 \%$ at $n=57$.

148 Simpson's paradox describes a situation in which a trend that appears in two different groups of data reverses when the data is aggregated (and vice versa). For example, it's possible that baseball player $A$ can hit a higher batting average in years $n$ and $m$ than player $B$ but a lower batting average across $n+m$.

${ }^{149}$ For example, we might try to determine which mental modules issue which intuitions. See chapter five.
} 
traditional intuition-deploying practices because non-evidential sensitivity purportedly undermines positive epistemic status.

Below I examine the argument from intuitional sensitivity. In $\$ 3.1 \mathrm{I}$ present the argument in more careful detail. In $\$ 3.2 \mathrm{I}$ demonstrate how one's perception of the relevance of experimental philosophy to philosophical methodology hangs on what one takes intuitions to be. Finally, in $\$ 3.3 \mathrm{I}$ show how the debate around the argument from intuitional sensitivity could be improved by a more fine-grained taxonomy of intuition.

\subsection{The Restrictionist Challenge}

Results from the experimental philosophy movement purportedly motivate a reconsideration of our standard armchair intuition-deploying practices. One such argument has come to be known as the restrictionist challenge, ${ }^{150}$ so-named because it recommends a restriction on the extent to which intuitions are utilized when constructing philosophical theories. ${ }^{151}$ The restrictionist challenge relies in large part on what I'll call the intuitional sensitivity objection.

\section{Intuitional Sensitivity}

1) Folk intuitions about important philosophical cases are sensitive to non-evidential factors.

2) If folk intuitions about important philosophical cases are sensitive to non-evidential factors, the intuitions of professional philosophers are likely sensitive to nonevidential factors.

3) So the intuitions of professional philosophers are likely sensitive to non-evidential factors.

4) If the intuitions of professional philosophers are likely sensitive to non-evidential factors, philosophers ought to restrict their deployment of intuitions as evidence.

$\therefore$

5) So philosophers ought to restrict their deployment of intuitions as evidence.

150 Alexander \& Weinberg 2007

151 The restrictionist challenge comes in a spectrum of strengths, from those advocating modest revisions to our intuition-deploying practices to those urging complete abandonment of intuition-reliant methodologies. 
Premise (1) is ostensibly supported by the empirical data. ${ }^{152}$ Critics of experimental philosophy, such as Jennifer Nagel 2012 and Jennifer Wright 2010, contend that this data is misinterpreted or the product of sloppy methodology, while others, such as Ernest Sosa 2009, mistrust the alleged connection between reports of folk intuitions and folk intuitions themselves. Premise (2) is an ampliative inference from the intuitional sensitivity of the test subjects to the intuitional sensitivity of professional philosophers, grounded in the conviction that philosophers are prone to the same sorts of cognitive biases and contextual influences that lead the folk astray. Proponents of the so-called "expertise defense," such as Timothy Williamson (2005, 2007, 2011), maintain that philosophical training shields professional philosophers from the evidentially extraneous effects which taint the intuitions of non-philosophers. Critics of this defense, such as Weinberg et al. 2010, contend that philosophy may well be among the numerous disciplines in which "false experts" predominate. Premise (3) is the logical consequence of premises (1) and (2).

Comparatively little attention has been directed toward premise (4). Both defenders and critics of experimental philosophy have taken for granted that intuitional sensitivity to non-evidential factors would pose at least a prima facie problem for traditional armchair methodology. Joshua Alexander, a proponent of the intuitional sensitivity objection, writes, "We want our evidence to be sensitive, but we want it to be sensitive to the right kinds of things. In particular, we want our evidence to be sensitive only to those things that we think are relevant to the truth or falsity of the set of claims for which the evidence is supposed to provide evidence" (2012: 82). Sosa, a critic of the intuitional sensitivity objection, seemingly

\footnotetext{
152 Costa et al. 2014; Buckwalter \& Stich 2014; Uhlmann et al. 2009; Swain, Alexander, \& Weinberg 2008; Nichols \& Knobe 2007; Machery et al. 2004; Petrinovich \& O’Neil 1996
} 
agrees. He concedes that "the effects of priming, framing, and other such contextual factors will affect the epistemic status of intuition in general..." (2007: 105). Neither party to the debate takes seriously the position that such contextual factors are irrelevant to the epistemic status of intuition.

Experimental philosophy can tell us a great deal about how intuition reports co-vary with gender, culture, socioeconomic status, affective content, order of presentation, and the like. Psychologists can then offer plausible causal explanations of these correlations. Yet neither experimental studies nor psychological interpretations of those studies is capable of determining the justificatory status of relying on intuitions which are sensitive to nonevidential factors. For that, we must turn to the intersection of etiology and epistemology, which, as it happens, is a lively sub-discipline. ${ }^{153}$ As we’ll see in $₫ 3.2$, it cannot be assumed that sensitivity to non-evidential factors always undermines or defeats positive epistemic status.

Before turning to that issue, three brief clarificatory remarks are in order. First, we must clearly distinguish the intuitional sensitivity objection from the calibration objection. The calibration objection charges that philosophical intuition, construed as an instrument, cannot be verified against any independent standard. Hence, the accuracy of philosophical intuition can be neither tested nor (should such be necessary) corrected. Thus, we should refrain from making appeals to intuition. The intuitional sensitivity objection does not entail or straightforwardly support the calibration objection. Indeed, it is precisely because we think we have an independent handle on the truthmakers of various philosophical claims-

153 See, inter alia, Plantinga 1993, Cohen 2000, Street 2006, White 2010. 
and that ordering effects, affective content, and cultural upbringing are not among themthat the intuitional sensitivity objection gets any initial traction.

Second, the threat posed by the studies emanating from the experimental philosophy movement does not boil down to mere disagreement. We didn't need rigorous experimental research to establish that philosophers (let alone non-philosophers) occasionally disagree about the correct intuitive response to a hypothetical case. Nor does occasional disagreement pose much of a methodological challenge. There are all sorts of reasons why we might come to the wrong intuitive judgment about a particular case: the case might be underdescribed, or we might pay inadequate attention to the details, or we might let our theoretical commitments cloud our judgment, or we might simply fail to reflect deeply enough about the case.

Experimental philosophy may reveal that disagreement is more widespread than we previously appreciated, but even this claim is not enough to truly drive the restrictionist challenge. What makes the experimental philosophy studies potentially threatening is not the ubiquity of disagreement but its systematicity. Intuitions (allegedly) co-vary in a fashion that suggests they are more likely to track various non-evidential facts than the philosophical truth.

The ampliative inference from the intuitional sensitivity of the folk to the intuitional sensitivity of the apparent experts—and hence to the recommended revision of our traditional intuition-deploying practices-depends on the relative homogeneity of the philosophical community. We philosophers tend to agree about the paradigm cases, but then again, we are a profession dominated by (until relatively recently) white Anglo- 
European males. The non-truth-tracking picture of intuition predicts this consensus, and so this consensus is no indicator of reliability. As Alexander notes, "[intuitional] diversity [among the folk] is not the real story here. The real story is what intuitional diversity tells us about ourselves, namely, that our philosophical intuitions might be sensitive to things we hadn't anticipated" (2012: 77).

Finally, experimental philosophers charge that the intuitional sensitivity their studies have allegedly established is disturbing - it is both "unexpected" and "unwelcome" (Alexander 2012: 82). Ostensibly, the trouble is just that intuitions are sensitive to evidentially irrelevant influences. That is, intuitions about $\Phi$ co-vary with factors which do not epistemically bear on the truth or falsity of $\Phi$. There is indeed something unsettling about the idea that chance aspects of our personal character (race, gender, culture, socioeconomic status) or arbitrary facts about the presentation of a case (order, language, priming, affective content) might cause us to have different intuitions. And if non-evidential factors shape which intuitions we have, the justification for our standard intuition-deploying practices, so the argument goes, is undermined.

But surely this argument moves just a mite too fast. Lots of evidentially irrelevant factors play a causal role in determining which intuitions we each come to hold. Had I not made the somewhat capricious choice to study philosophy, I never would have been exposed to Gettier cases and thus never would have formed the intuition that Smith does not know. No one thinks that reflecting on this etiological fact should motivate me to doubt the reliability of my Gettier intuition. Of course, one might respond that had I never been exposed to Gettier cases, I would have had no Gettier intuition, whereas, if I had been 
exposed to Gettier cases and grown up in a different culture, I (allegedly) would have had a different Gettier intuition. So to distinguish the problematic etiological influences from the unproblematic etiological influences, we need only look at counterfactual situations in which the intuition in question isn't absent, but different.

Unfortunately, this principle doesn't generalize very far. An analogy to perception is helpful. I know that had I taken a hallucinogenic drug before viewing this tomato, I would have judged the tomato to be rainbow-colored instead of red. However, knowing this fact gives me no reason whatsoever to doubt the reliability of my normal, non-hallucinogenic perceptual experience of the red tomato. There is a correlation between drug-taking and differences in perceptual reports, but this correlation is not troubling. ${ }^{154}$

We have, I believe, a rough-and-ready ability to distinguish the problematic cases from the unproblematic cases, but this distinction is surprisingly hard to precisify. ${ }^{155}$ For our purposes, the point is simply that all of our beliefs will have epistemically irrelevant influences somewhere in their causal history. Only a small handful of these factors are even putatively problematic.

\subsection{Etiology and Intuition}

In this section I draw on recent influential work by Roger White and Adam Elga. To illustrate when the etiology of a belief does and does not affect one's justification for that belief, White offers two thought experiments, which he terms "Lucky Moore" and "Lucky Russell” (2010: 601).

\footnotetext{
154 Similarly, had I grown up in the Cult of the Tomato, I would have believed that tomatoes rule the earth from their secret garden-salad lairs, but learning this fact gives me no reason whatsoever to doubt that tomatoes do not, in fact, rule the planet.

155 See White 2010: 574.
} 
Lucky Moore: There are two doors into a room which contains either a hand or a banana (not both). If one enters through Door A there will appear to be a hand there; if one enters through Door B there will appear to be a banana. (At one of these doors stands an invisible demon who will induce a vivid hallucination as you enter). G. E. Moore enters by Door A having no idea yet what is in the room or at which door the demon is lurking. Luckily for him the demon was at Door B and Moore perceives the hand that is there. "Here is a hand!" thinks Moore. "Apparently I escaped the demon since my judgment here is correct."

Lucky Russell: There are two doors into a room which contains the premise $\mathrm{E}$ of a logic problem from which either $p$ or $\sim p$ can be derived (but not both). If you enter through Door $\mathrm{A}$ then upon calculation you will reach the conclusion $p$; if you enter through Door B you will conclude $\sim p$. (At one of these doors stands an invisible demon who will mess with reasoning capacities and lead you to a false conclusion that seems obviously correct to you). Bertrand Russell enters by Door A having no idea yet which conclusion does follow or at which door the demon is lurking. Luckily for him the demon was at Door B and by impeccable deductive steps he reaches the conclusion $p$. " $p$ " thinks Russell. "Apparently I escaped the demon since my judgment here is correct."

Both Moore and Russell confront the possibility of non-evidential factors influencing their respective beliefs. Both feel confident in their respective conclusions, but both recognize that had they chosen the other door, they would feel equally confident in the opposite conclusion. Experimental philosophers push similar worries. You may feel confident that the subject in the Gettier case does not know, but you should recognize that had you been raised in an East Asian culture, you would (allegedly) be equally confident that the subject in the Gettier case does know.

It is tempting to treat "Lucky Moore" and "Lucky Russell" on a par, but White argues persuasively that this would be a mistake. White contends that knowledge of the etiological conditions under which Moore forms his belief constitutes an undercutting defeater for his judgment that he escaped the demon; he is thus unjustified. The very same 
etiological information does not, however, undercut Russell's justification. Why not? The answer lies in the difference between perception and inferential reasoning.

Moore's evidence for the proposition here is a hand consists in the appearance as of a hand. ${ }^{156}$ Normally, the appearance as of a hand is excellent evidence for the proposition bere is a hand. But with the prospect of hallucination made salient by the etiological set-up of the case, the appearance as of a hand no more supports the proposition here is a hand than it does the proposition here is an illusion of a hand. However, to treat Russell analogously to Moore would be to suggest Russell's evidence for $p$ consists in the (intellectual) appearance that $p$. But by hypothesis, Russell's evidence for $p$ is not the appearance that $p$ but rather premise E, from which he competently deduces $p$. Moore's evidence equally well corroborates two inconsistent states of affair - the presence of a hand and the non-veridical hallucination of a hand-while Russell's evidence, by contrast, supports either $p$ or $\neg p$-but not both. Appearances, intellectual or otherwise, don't play a role in deductive reasoning, and so the etiological threat of hallucination doesn't get a toehold from which to challenge Russell's justification. ${ }^{157}$

Elga (unpublished manuscript) offers a pair of thought experiments similar in form and analysis to White's. ${ }^{158}$ I'll call them 'Lucky Scholar' and 'Lucky Perceiver.'

\footnotetext{
156 One might argue that in the veridical case, Moore's evidence is not the appearance as of a hand but a hand itself. But if Moore receives different evidence depending on whether or not the demon deceives him, then we have already drawn an important disanalogy to Russell's case, in which Russell receives the same evidence (premise E) regardless of the location of the demon.

157 Of course, Russell knows that were he to be put through a large number of trials, he would be wrong about $50 \%$ of the time. And he knows that if he were to bet at 2:1 he was right when and only when he was subjectively confident he was right (which would be every trial), he would be almost sure to lose money. White admits that this "epistemic asymmetry" is "strange," but he does not find it "intolerable" (603).

158 Elga and White offer like-minded diagnoses of the epistemology of irrelevant influences, but stake out opposed positions on the epistemology of peer disagreement. This suggests that the debate over the
} 
Lucky Perceiver: There was a coin toss while you slept last night. If the coin landed heads, nothing special happened. If the coin landed tails, your brain was put into a vat, and fed just the experiences you would have otherwise had. [The perceiver thinks to herself,] "Yes, the coin determined whether I would be envatted. So I sure was lucky to have the coin put me in the good (non-envatted) case. How lucky I am to have my senses operating veridically!"

Lucky Scholar: ${ }^{159}$ A scholar tosses a coin to determine whether to attend Harvard or Oxford. He attends Oxford, and ends up endorsing the analytic/synthetic distinction. But he finds out that if he had gone to Harvard, he would have rejected the analytic/synthetic distinction, even though he would have been exposed to the same relevant evidence... [The scholar thinks to himself,] "The arguments I accept are in perfect accord with my own standards. Or at least: The influence of graduate school gives me no special reason to think that I'm violating my own standards. So the influence of graduate school on my thinking gives me no special reason to doubt that thinking."

Again, there is a parallel to experimental philosophy: just as one does not have control over how the coin will land, one does not have control over one's race, gender, or cultural upbringing, yet these factors (allegedly) play a role in determining which intuitive reactions we have to important philosophical cases. Again, there is a temptation to treat 'Lucky Perceiver' and 'Lucky Scholar' analogously. Again, that would be a mistake.

Once more, the crucial dissimilarity lies in the difference between perceptual experience and the sort of complicated inferential reasoning one deploys to appraise a philosophical issue. Elga contends that "in the case of perceptual appearances, there is always plenty of room to take the appearances as mere inputs," whereas in the inferential reasoning case, "it is at least sometimes permissible to stand behind one's all-things-

relationship between etiology and justification doesn't collapse to a more general debate over the relationship between higher-order evidence and justification.

159 Adapted from Cohen 2000: 17-19 
considered judgments, even while being convinced that a coin flip determined the way one would make those judgments" (10). Hence, the etiology of Lucky Perceiver's belief undermines her justification while the etiology of Lucky Scholar's does not.

Learning certain etiological facts about one of your beliefs may obligate you to reassess your evidence for and against that belief, but once that reevaluation is complete, there is nothing more to be done, say White and Elga, except to believe whatever it is your evidence supports. Of course, you might be wrong and not realize it, but that is the chance you take whenever you believe anything, regardless of etiology. In the 'Lucky Moore' and 'Lucky Perceiver' cases, the possibility of deception is made salient, and thus what the evidence supports changes. ${ }^{160}$ In the 'Lucky Russell' and 'Lucky Scholar' cases, the possibility of deception does not change what the evidence supports because what the evidence supports, in these cases, cannot change. If premise E entails $\mathrm{p}$ then it necessarily entails p. Of course, the (intellectual) appearance that E entails p no longer supports $\mathrm{p}$, because the specter of deception has been raised, but appearances don't play a role in deductive reasoning. ${ }^{161}$

There is, obviously, much more to say about this issue. But if White and Elga are right-or even just on the right track-there are important metaphilosophical ramifications. One account of intuitions-Bealer's intellectual seemings view-assimilates naturally to the 'Lucky Moore' and 'Lucky Perceiver' cases, leaving the charge of intuitional sensitivity a real threat to philosophical practice. However, another popular account of intuition-

160 Alternatively: what evidence is available to the subject changes (from that there is a band to the appearance as of a hand). I prefer the formulation in the main text because I think evidence must always be relativized to a background of beliefs.

161 One might argue that the possibility of deception forces one to bracket one's evidence for $p$, but this would violate the epistemic norm on total evidence. 
Williamson's counterfactual possibilities view-assimilates naturally to the 'Lucky Russell' and 'Lucky Scholar' cases, rendering the charge of intuitional sensitivity harmless to traditional methodology.

In his 1996, Bealer proposes a theory of intuition on which intuition is analogous to perception. He writes, "For you to have an intuition that A is just for it to seem to you that A" (5). 'Seems' is here not used as an expression of caution or equivocation but rather to indicate the experience of "a genuine kind of conscious episode" (ibid.). Intuiting that $p$ is not exactly the same as perceiving that $\mathrm{p}$-after all, "this is intellectual seeming, not sensory or introspective seeming" (ibid.)—but the parallels are striking, even down to the verbiage in which the experience is expressed. When one reaches an intuitive judgment about a philosophical thought experiment, or otherwise undergoes the experience of having a philosophical intuition, something happens: “you suddenly 'just see' that [the proposition in question] is true" (ibid.).

If this is the right account of intuition, the experimental philosophy movement has indeed given the philosophical community something to be worried about. Learning that one's intellectual seemings are correlated with non-epistemic facts about oneself (race, gender, culture, socioeconomic status) or the presentation of the case (order, language, priming, affective content) raises the possibility that intellectual seemings do not reliably track the philosophical truth. In light of this etiological information, one might revisit one's evidence. But no matter how vividly one perceives (the appearance as of one's hands or 'sees' that the Gettier subject does not know, once the danger of deception is made salient, one is unjustified in clinging to one's initial belief. Given the etiological backdrop that the 
experiment philosophy movement has (allegedly) established, that it intellectually seems to you that the Gettier subject does not know no more supports the proposition the Gettier subject does not know than it does the proposition your cultural upbringing induced a psychology to which it would intellectually seem that the Gettier subject does not know.

Not all philosophers endorse Bealer's intellectual seemings model of intuition. Williamson in particular is dubious. He writes, "For myself, I am aware of no intellectual seeming beyond my conscious inclination to believe the Gettier proposition. Similarly, I am aware of no intellectual seeming beyond my conscious inclination to believe Naïve Comprehension, which I resist because I know better. [...] These paradigms provide no evidence of intellectual seemings" (2007: 217). In place of intellectual seemings, Williamson would prefer to speak of counterfactual judgments. In assessing philosophical cases, so the theory goes, we simply marshal the cognitive capacities we utilize to assess the sort of normal, mundane, a posteriori counterfactuals that allow us to navigate the world. Consequently, "[p]aradigm thought experiments in philosophy are simply valid arguments about counterfactual possibilities" (207). ${ }^{162}$

Evaluating counterfactuals is commonplace, but it is not a straightforward business. It requires conceptual application, prediction and retrodiction, empirical observation, and imaginative simulation disciplined by background knowledge. In short, "our capacity to evaluate counterfactuals recruits all our cognitive capacities to evaluate sentences" (152).

\footnotetext{
162 Here's an example (2005: 5) meant to capture the Gettier thought experiment (where GC = ' _ is in a Gettier case with respect to _,' JTB = '_ has a justified true belief that _,' and $\mathrm{K}=$ _ knows that_') :

1) $\diamond \exists x \exists p \mathrm{gC}(\mathrm{x}, \mathrm{p})$

2) $\exists \mathrm{x} \exists \mathrm{p} \mathrm{GC}(\mathrm{x}, \mathrm{p}) \square \rightarrow \forall \mathrm{x} \forall \mathrm{p}(\mathrm{GC}(\mathrm{x}, \mathrm{p}) \supset(\mathrm{JTB}(\mathrm{x}, \mathrm{p}) \& \neg \mathrm{K}(\mathrm{x}, \mathrm{p})))$

$\therefore$

3) $\diamond \exists x \exists p(J T B(x, p) \& \neg K(x, p))$
} 
Hence, on Williamson's view, intuiting that $\mathrm{p}$ is much more akin to inferential reasoning than it is to perception.

If Williamson's account is correct, then the intuitional sensitivity objection collapses. Learning that attributions of knowledge to Gettier subjects is (allegedly) correlated with cultural upbringing may obligate you to reassess the relevant counterfactuals, but once that reassessment is complete, there is nothing to be done but affirm the judgment that is supported by the evidence. Of course, there's no guarantee that your counterfactual reasoning will lead you to the truth, but if your well-vetted evidence supports one and only one conclusion, the rational thing to do is to continue to endorse that conclusion.

One might be unsettled by the thought that it is partly a matter of luck that one believes as one does. But learning that a belief is the product of chance does not thereby undermine one's justification for holding that belief, if the belief is in fact well-supported by the available evidence. Experimental philosophy may reveal interesting information about the etiology of intuition. ${ }^{163}$ But some types of reasoning yield justifications which are immune to defeat by etiology. If intuition is one of those types of reasoning, experimental philosophy cannot undermine our standard intuition-deploying practices.

\subsection{Expert Intuiters}

It's unclear to me if we must choose between Bealer's account of intuition and Williamson's account of intuition. A fine-grained taxonomy of intuition leaves open the possibility that some mental states currently called 'intuitions' are the product of deliberate

\footnotetext{
163 One might, for example, wonder why East Asians are (allegedly) worse at knowledge attributions than Westerners, and experimental philosophy might help answer this question.
} 
conscious reasoning while other mental states currently called 'intuitions' are not. ${ }^{164}$ Unfortunately, most contributions to the etiological debate presuppose a monolithic treatment of intuition, and this assumption leads to a familiar dialectical stalemate.

Responses to the argument from intuitional sensitivity tend to gravitate around the so-called 'expertise defense.' Williamson (2005, 2007, 2011) argues that philosophical training shields professional philosophers from the evidentially extraneous effects which taint the intuitions of non-philosophers. ${ }^{165}$ In reply, a group of philosophers again led by Weinberg ${ }^{166}$ contend that philosophy, because it lacks a robust source of independent feedback, is likely among the disciplines in which 'false experts' predominate. ${ }^{167}$

The debate over whether or not philosophers are expert intuiters suffers from a generality problem common in the metaphilosophical literature. Proponents of the intuitional sensitivity objection want to argue that philosophers' judgments about important philosophical cases (or principles) are sensitive to non-truth-tracking features. But to avoid a slide into the sort of radical, self-undermining skepticism discussed above, they must draw a principled distinction between philosophical cases and ordinary cases. Williamson picks up on this point when he writes,

If I judge 'You do not know how many coins I have in my pocket,' is that an intuitive judgment about a case? ... If such examples do count as judgments we are not currently justified in trusting, then the experimentalist critique is self-

\footnotetext{
164 Koksvik 2013 attempts to show just that.

165 More carefully: Williamson argues that the burden of proof is on his opponents to show that philosophical training doesn't shield professional philosophers from epistemically irrelevant influences. See Schwitzgebel and Cushman 2015 for an empirical study which purports to demonstrate that professional philosophers are just as sensitive as non-philosophers to evidentially extraneous influences.

166 Jonathan Weinberg, Chad Gonnerman, Cameron Buckner, and Joshua Alexander. (2010). “Are Philosophers Expert Intuiters?" Philosophical Psychology, Vol. 23, No. 3: 331-355.

167 Other disciplines in which false experts allegedly predominate include psychiatry, stock brokerage, gymnastic judging, intelligence analysis, and wine stewardship.
} 
destructively general. If we are currently justified in trusting such judgments about cases, what is supposed to differentiate them from those judgments in which, according to the experimentalist critique, we should not trust? (2011: 218)

Williamson considers the demarcation question a "major problem" (218) and goes on to bemoan the "extreme unclarity" (ibid.) of the target of the intuitional sensitivity critique.

Williamson is right to demand that proponents of the intuitional sensitivity objection find some way to carve intuitions more finely, but he is too dismissive of the prospects for doing so. Indeed, Williamson seems unsympathetic to the idea that we might be expert intuiters across some range of cases but not across others, or at least unsympathetic to the idea that we could ever discriminate between the expert domains and the non-expert domains. In chapter five I hope to demonstrate that this pessimism is unwarranted, by presenting three plausible ways intuitions might be parsed more finely.

\section{SELF-DefEAT}

I turn now to arguments from the pro-intuition camp. I begin with the argument from self-defeat. According to this line of reasoning, normative intuition skepticism is untenable because any argument against intuition must rely on intuition at some point, thus making the argument self-defeating. Below I consider two representative varieties of selfdefeat arguments, one from David Sosa $(\$ 4.2)$ and one from Williamson (\$4.3). But first $(\$ 4.1)$ more on the nature of self-defeating arguments.

\subsection{Constraints on Intuition Debates}

Any critique of philosophical methodology that takes a skeptical stance toward intuition faces two key constraints: it must not overgeneralize, and it must not be epistemically self-defeating. Debates in philosophical methodology begin with the assumption that Pyrrhonian skepticism is untenable. There is a large class of propositions 
we know. Hence, if skeptical charges against intuition are to stick, they must not generalize to a broad range of ordinary propositions. A skeptical argument against intuition overgeneralizes when it applies equally well to paradigm sources of knowledge, such as testimony or memory. A skeptical argument against intuition is self-defeating when belief in the conclusion undermines one's justification for believing one or more of the (essential) premises. ${ }^{168}$ The two constraints are related. Any account that dissolves into a widespread skepticism is likely to be self-undermining.

An argument can be self-undermining in either its premises or its inferences. For example, the argument

1) We know that $p$.

2) If we know that $\mathrm{p}$, knowledge is impossible.

$\therefore$

3) So knowledge is impossible.

is self-defeating because belief in (3) undermines belief in premise (1). On the other hand, the argument

1) If $\Phi$, then modus ponens is an invalid argument form.

2) $\Phi$.

$\therefore$

3) Modus ponens is an invalid argument form.

is self-defeating not because belief in the conclusion undermines belief in any of the premises but because belief in the conclusion undermines belief that the logical structure of the argument is valid. Thus, a skeptical argument against intuition will be self-defeating if either of two conditions obtain: 1) it employs the very sort of intuition that the argument

\footnotetext{
168 See Silva 2013 for more on epistemically self-defeating arguments and skepticism about intuition.
} 
purports to challenge ${ }^{169}$ or 2) it employs an inference rule that is illicit according to the argument's conclusion. A necessary condition on successful arguments against intuition is that those arguments do not employ the very sort of intuition that the argument challenges and that those arguments do not subvert the inferential maneuvers of the argument.

Self-defeat arguments are frequently deployed by pro-intuition metaphilosophers to argue that intuition skepticism is untenable. ${ }^{170}$ Below I examine self-defeat arguments from Sosa and Williamson. Although their respective conceptions of intuition are very different, they both conclude that traditional, intuition-reliant philosophical methodology is (more or less) fine as-is.

\subsection{Sosa}

Sosa argues that "[i]t is hard to see how opposition to intuition... does not itself ultimately rely on intuitive knowledge" (635) and that "opposition to the reliability of intuition appears to involve a self-defeating appeal to intuition" (643). Sosa labels the problematic intuition to which the intuition skeptic appeals " $(\mathrm{O}):$ ”

(O) If opposed intuitions cannot be reconciled, then at least one of them is unreliable (635). ${ }^{171}$

(O) is needed to justify the move from cases of intuitional disagreement, allegedly widespread, to claims of unreliability or justificatory defeat. But, argues Sosa, if (O) is known, it could only be known on the basis of intuition. So arguments against intuition which rely on $(\mathrm{O})$ are epistemically self-defeating.

\footnotetext{
169 An exception to this rule is reductio-style arguments that employ philosophical intuition to show that the deployment of philosophical intuition leads to a contradiction.

170 See, inter alia, Bealer 1993, BonJour 1998, Pust 2000.

${ }^{171}$ Here, we should take 'intuitions' to be shorthand for something like intuitional processes. It's a category mistake to call token intuitions reliable or unreliable.
} 
Sosa is correct that any argument which relies on $(\mathrm{O})$ and entails that one is unjustified in endorsing $(\mathrm{O})$ is self-defeating. And I'm willing to grant that if $(\mathrm{O})$ is known, it is only known via intuition. But why should we think that arguments against intuition which rely on $(\mathrm{O})$ always entail that one is unjustified in endorsing $(\mathrm{O})$ ? That is, why should we think arguments against intuition must be arguments against intuition generally? If we are more fine-grained, Sosa's result seems less interesting. After all, an argument against intuitions of type $x$ which relies on intuitions of type $y$ is not self-defeating (when $x \neq y$ ). Given the heterogeneity and particularity of intuition, Sosa's argument succeeds only against a radical type of anti-intuition position which holds that we are never justified in relying on intuition.

But Sosa seems to think that his argument shows more than that the radical antiintuition position is self-defeating. He sometimes claims that his argument shows us something positive about the general status of intuitions - they are "reliable" and "provide reason for belief' (646). Sosa's positive story depends on a purported analogy to other sources of justified belief. He writes, "Putative examples of intuition are sturdy stock, not easily dissolved. And scepticism about their epistemic status should rather, it seems to me, be initially as far-fetched as the corresponding scepticism about the status of perception and memory" (643). Notice the explicit admission to treating intuition at the same level of generality as perception and memory. Even if Sosa is right that there is some level of generality at which it's appropriate to draw parallels between intuition and perception (such that general skepticism about either is implausible), it's hard to see how we could draw any methodological conclusions from this point. Unless intuitions stand or fall together, 
discovering that radical anti-intuition skepticism is untenable gives us little leverage in pursuing RELIABILITY and JUSTIFICATION.

But perhaps Sosa thinks intuitions do stand or fall together. He argues that " $[\mathrm{t}]$ here is a special faculty of intuition that grounds some knowledge" (646), and this claim seems to commit him to a monolithic treatment of intuition. ${ }^{172}$ If there is only one faculty of intuition, and it is incoherent to regard relying on this faculty as an unjustified belief-altering process, then intuitions — all intuitions - must confer some level of justification. But, again, this argument only works if there is one faculty of intuition. If there are multiple faculties of intuition, then, for all Sosa's said, it may be coherent to regard some (but not all) faculties as unjustified belief-altering processes. And as we'll see in chapter five, if 'faculty' means anything like 'mental module,' then the position that one faculty governs all intuitions is increasingly implausible.

\subsection{Williamson}

Some metaphilosophers claim that we are unjustified in appealing to our epistemic intuitions to make a judgment in Gettier cases, that we are unjustified in appealing to our modal intuitions to make a judgment about the possibility of phenomenal zombies, that we are unjustified in appealing to our moral intuitions to make judgments of moral permissibility in trolley cases, and so on. But there is an obvious challenge to this position. If our epistemic, modal, and moral intuitions are unreliable, what justifies us when we claim that we know that Trump is president, that we could have had three cups of coffee this morning instead of two, that torturing babies for fun is wrong, and so on? Even if

\footnotetext{
172 This faculty is sui generis, and it "reliably delivers states that engage epistemically with abstract objects" (646), though Sosa is quick to note that this engagement is not causal.
} 
epistemic, modal, and moral intuitions all issue from distinct mental modules, that fact won't help us differentiate (e.g.) Gettier intuitions from ordinary, humdrum knowledge ascriptions. And without a way to distinguish philosophical intuitions from non-philosophical intuitions, doubts about the former quickly slide into an untenable, unwanted skepticism about the latter.

According to Williamson, the faculty of intuition is not some special rationalist ability to 'see' the truth of a proposition. Rather, the faculty of intuition, if it even makes sense to talk of such an entity, is just our ordinary capacity to assert and judge counterfactuals, a capacity we deploy all the time in everyday, run-of-the-mill reasoning. Because intuitive a priori judgments about philosophical cases are continuous with normal, a posteriori judgments about non-philosophical cases, and because our judgments about nonphilosophical cases are (on pain of skeptical regress) reliable, we should trust our intuitive judgments in Gettier cases and the like.

It will be useful to examine this argument in closer detail. The rough structure seems to be something like the following:

(1) Philosophical intuitions belong to the broad family of counterfactual judgments.

(2) We engage in counterfactual reasoning all the time.

(3) If utilizing counterfactual reasoning when forming judgments is not warranted, then many of our mundane, ordinary judgments are unjustified.

(4) Our mundane, ordinary judgments are justified.

(5) So utilizing counterfactual reasoning when forming judgments is warranted.

(6) There is nothing special about the nature of philosophical intuitions to separate them from other counterfactual judgments.

$\therefore$

(7) So utilizing intuitions to construct philosophical theories is warranted. 
As I see it, the controversial premises are (1) and (6). Let me briefly run through the uncontroversial premises before I turn my attention back to those two.

Counterfactual reasoning is essential to our successfully navigating the practical world. I spend fifteen minutes searching one level of the parking garage, judge that if I had parked on this level, I would bave found my car by now, and hence conclude that I should try searching for my car on a different level of the garage. I make some argument about philosophical humility, judge that if Williamson had heard this argument, he would have an objection, and hence conclude that I should try to come up with plausible objections to my argument and their rejoinders. So (2) is true. Because counterfactual reasoning is so important in the formation of our ordinary judgments, if our ability to justifiably engage in counterfactual reasoning were called into serious question, so too would the justificatory status of many of our mundane, everyday judgments. So (3) is true. But, on pain of a radical and selfundermining brand of skepticism, our mundane, everyday judgments are justified. So (4) is true. (5) is the logical consequence of (3) and (4).

Back to (1). Williamson thinks intuitions are continuous with other judgments, distinct neither in origin nor in epistemic status. In his 2005, Williamson claims that we "have no good reason to expect that the evaluation of 'philosophical' counterfactuals... uses radically different cognitive capacities from the evaluation of ordinary 'unphilosophical' counterfactuals" (13). In his 2007, he adds:

Our overall capacity for somewhat reliable thought about counterfactual possibilities is hardly surprising, for we cannot know in advance exactly which possibilities are or will be actual. We need to make contingency plans. In practice, the only way for us to be cognitively equipped to deal with the actual is by being cognitively equipped to deal with a wide variety of contingencies, most of them counterfactual. (137) 
Philosophy is an enterprise that is often conducted, as the saying goes, from the armchair. ${ }^{173}$ One element of the armchair methodology is the construction and evaluation of imaginary cases. For some imaginary cases, this methodology is necessary, because the envisioned scenario is technologically infeasible or physically impossible or morally dubious. But even for cases-like Gettier's - that could be replicated in the actual world, philosophers are typically content to evaluate them from the comfort of their studies. These thought experiments normally take the form of a subjunctive conditional: if Jones were to unwittingly drive into fake barn country, see a real barn, and form the belief there's a barn, that belief would be justified and true but would not constitute knowledge. This tendency to consult imaginary cases suggests that counterfactual reasoning is an important tool for philosophical theorizing. So (1) is at least plausible.

Williamson's mistake is his uncritical endorsement of (6). Even if intuitions are nothing more than counterfactual judgments, he misses the possibility that we can draw a principled distinction between philosophical and non-philosophical judgments. If we are justified in appealing to intuitions in some contexts but not others, then the context in which an intuition is elicited may bear on its evidential worth. Hence, if metaphilosophers are serious about pursuing RELIABILITY and JUSTIFICATION, they ought to investigate the contexts in which intuitions are invoked.

Avner Baz undertakes just such an investigation. ${ }^{174}$ He contends that there is something unique and potentially problematic about the context in which philosophical

\footnotetext{
173 Williamson thinks the range of propositions one can come to know from the armchair is much broader than is typically supposed.

174 See Wilkes 1988 for an early (though unacknowledged) forerunner of Baz's view.
} 
intuitions are elicited. He analyzes cases of conceptual application: cases in which a philosopher invites her audience to intuit whether an imagined state of affairs falls within the extension of some concept, e.g., Does the Gettier subject know? and Is the China-brain conscious? Baz labels questions of this sort "the theorist's questions," then suggests that there is a discontinuity between the theorist's questions and more commonplace questions.

Baz argues that the correct answer to a classificatory question is not fully determined by the meanings of the words which make up the question. The context in which the question is asked also contributes. ${ }^{175}$ Because the context in which the theorist asks her questions is allegedly so divorced from the context in which mundane classificatory questions are asked, we should not expect the justificatory status of our answers to be the same in both cases. He writes, "The judgments that we make in the course of our everyday experience, and the corresponding beliefs, are tied to the rest of our practical life in a way that the answers we (find ourselves inclined to) give to the theorist's questions typically are not" (2016: 116, fn. 21). Thus, there may be no determinate answers to the theorist's questions. Hence, there is a discontinuity between philosophical and non-philosophical intuitions.

In our non-philosophical lives, when we make epistemic ascriptions or inquire into the epistemic states of others, we typically have purposes in mind which go beyond mere epistemic classification. When I ask, 'Did you know it was my birthday?' what I'm really interested in is whether you can be excused for not sending me a card. When the headmaster asks, 'How many of the students knew Richmond is the capital of Virginia?'

\footnotetext{
175 This point is recognized (in different ways) by both pragmatists and contextualists in epistemology.
} 
what he's really interested in is how many of students marked the right choice on the test. These implicit sub-questions inform the correct answer to the explicit classificatory question. But when the philosopher asks, 'Does Smith know he will get the job?' there is no background context against which to evaluate the question. That doesn't entail that there is no correct answer to the philosopher's question, but it does mean the philosopher is engaged in a different sort of practice than the non-philosopher, even when the philosopher and non-philosopher use similar language. And this difference in context may affect the justificatory status of the answers we give to philosophical and non-philosophical questions. $^{176}$

\section{INNOCENCE-BY-ASSOCIATION}

Some metaphilosophers ${ }^{177}$ argue that the intuition that $\mathrm{p}$ does not confer prima facie justification on the belief that p. A common riposte ${ }^{178}$ to these attacks goes by way of analogy: intuition is analogous to perception; surely the perception that $\mathrm{p}$ confers prima facie justification on the belief that $\mathrm{p}$; so the intuition that $\mathrm{p}$ does confer prima facie justification on the belief that $\mathrm{p}$. Call this the innocence-by-association strategy. Below I examine the innocenceby-association strategy in more detail. In $\$ 5.1 \mathrm{I}$ offer some general remarks about the structure of analogical arguments. In $\ 5.2 \mathrm{I}$ introduce the intuition-perception analogy and the innocence-by-association strategy. Finally, in $\$ 5.3$ I sketch some ways dropping the

\footnotetext{
176 It is important to note that this discontinuity is not due to the abstruse nature of some classificatory questions. According to Baz, the difference between philosophical intuitions and non-philosophical intuitions is "due not to the peculiar nature of the theorist's cases but to the peculiar nature of his context: neither the theorist's questions nor the answers we give to them have the sort of point, or practical significance, that competent everyday questions and answers have, and which gives those questions and answers their determinate sense" (2016: 120, fn. 26).

177 See, inter alia, Stich 1990, Hintikka 1999, Machery et al. 2004.

178 See, inter alia, Bealer 1996, Connee 1998, Sosa 2006, Audi 2008, Chudnoff 2011, Nagel 2012, Hales 2012, Bengson 2014.
} 
assumption that intuitions constitute a unified kind affects the debate over the innocence-byassociation strategy.

\subsection{The Aim of Analogy}

An analogy is a comparison between two entities ${ }^{179}$ that highlights a pertinent similarity or set of similarities. An analogical argument is a type of argument in which an analogy appears among the (essential) premises. Analogical arguments can be found in science, history, math, law, politics, medicine, and, of course, philosophy. Indeed, analogical cognition appears to be central to human reasoning. ${ }^{180}$

Analogies play many roles. Some roles are pragmatic. Analogies can serve as useful heuristics or pedagogical tools. They may stimulate new discoveries, guide research programs, explain difficult concepts, or draw attention to areas of neglect. Other roles are epistemic. Analogical arguments may justify an ampliative inference from the properties of the source domain to the properties of the target domain. The innocence-by-association strategy uses analogy in this justificatory role. Given our beliefs about perception (the source domain), the analogy between intuition and perception is meant to justify further beliefs about intuition (the target domain). From here onwards, when I refer to the role of analogy, the reference will be to the epistemic role of analogy.

The basic structure of an analogy ${ }^{181}$ is as follows (where $E_{1}$ is the source domain and $\mathrm{E}_{2}$ is the target domain):

\footnotetext{
${ }^{179}$ Construed broadly enough to include people, places, events, ideas, properties, relations, systems, and objects

180 See Hofstadter 2001.

181 There is a corresponding structure for disanalogies.
} 
(1) Entity $E_{1}$ has some properties $P_{1} \ldots P_{n}$

(2) Entity $E_{2}$ has the same properties $P_{1} \ldots P_{n}$

(3) Entity $E_{1}$ has some further property $P_{n+1}$

$\therefore$

(4) Therefore, entity $E_{2}$ likely has the same property $P_{n+1}$

If the above argument form is to be at all useful, ${ }^{182}$ there must be restrictions placed on the properties which license the inference from (1)-(3) to (4): namely, the properties $\mathrm{P}_{1}$ through $P_{n}$ must be relevant to property $P_{n+1}$. Of course, it is by no means easy to determine the sense of 'relevant' necessary to make an analogy a good one. All analogies end somewhere. After all, if two entities are alike in every respect, then, by Leibniz's Law, they are identical. In evaluating an analogy, one faces at least two difficulties. First, one must determine which similarities are relevant. Second, one must determine what extent of similarity will warrant the conclusion. ${ }^{183}$

\subsection{Intuition and Perception}

The innocence-by-association strategy traces its roots to Gödel, who in 1964 claimed that "despite their remoteness from sense experience, we do have something like a perception also of the objects of set theory. [...] I don't see any reason why we should have less confidence in this kind of perception, i.e., in mathematical intuition, than in sense perception” (1983: 483-4). ${ }^{184}$ Since then, metaphilosophers have expanded Gödel's strategy

\footnotetext{
182 The trouble is, every distinct entity is similar in some respect to every other entity (in at least this respect: they are both entities) and every distinct entity is dissimilar in some respect to every other entity (in at least this respect: they are non-identical). So it's possible to construct an analogy between any two (distinct) entities and also possible to construct a disanalogy between any two (distinct) entities. Achinstein (1964) uses an analogy between swans and line segments to make the same point.

183 As a species of induction, the warranting relation will come in degrees. There are difficulties, however, in assuming that the correlation between the extent of similarity and the warranting relation is linear (or even positive). See Lee \& Holyoak 2008.

184 The intuition-perception analogy, however, dates back much further. Locke, for instance, in his Essay Concerning Human Understanding, writes, "This part of knowledge is irresistible, and, like bright sunshine, forces
} 
beyond mathematical intuition to philosophical intuitions more generally. David Sosa (2006: 646) observes, "The analogy between intuition on one hand and perception and memory on the other is fruitful." Ernest Sosa (2007: 106) argues that "the way intuition is supposed to function in epistemology and in philosophy more generally... is by analogy with the way observation is supposed to function in the natural sciences." Robert Audi (2008: 485) claims that "intuitions are analogous to visual beliefs grounded in seeing." Elijah Chudnoff (2011: 360) contends that "the explanation of intuitive knowledge is analogous to the explanation of perceptual knowledge." Jennifer Nagel (2012: 497) writes, "I assume that it is epistemically legitimate to take sensory observations as yielding evidence about the physical world; the aim is to show that we have roughly similar reasons to take epistemic intuitions as yielding evidence about knowledge." Steven Hales (2012: 180) maintains that "if perception produces prima facie justified beliefs about its target subject matter and thereby serves as a source of knowledge, then so does intuition." These authors all aim to demonstrate that intuition skepticism is mistaken.

The variety of intuition skepticism these authors aim to debunk is a local skepticism. It is not a manifestation of some broader skepticism. (The Pyhrronian skeptic is also an intuition skeptic, but that is not the sort of intuition skeptic addressed here.) For present purposes, the most salient feature of the intuition skepticism at hand is that it requires the rejection of perceptual skepticism. ${ }^{185}$ Proponents of the innocence-by-association strategy

itself immediately to be perceived, as soon as ever the mind turns its view that way; and leaves no room for hesitation, doubt, or examination, but the mind is presently filled with the clear light of it. 'Tis on this intuition that depends all the certainty and evidence of all our knowledge" (II.1).

185 All of the arguments for intuition skepticism in the current literature rely on one or more premises which can only be known if perceptual skepticism is false. I leave open the possibility of a completely a priori argument for intuition skepticism, but such an argument has not (yet) appeared in the literature. 
attempt to exploit this feature of intuition skepticism, trying to use the intuition skeptic's resources against her. They argue that, on the basis of the intuition skeptic's beliefs about perception, the intuition skeptic should abandon intuition skepticism. Intuition skepticism, they contend, is no more respectable than perceptual skepticism; the two forms of skepticism must stand or fall together.

The innocence-by-association strategy is meant to be a general refutation of intuition skepticism. It is not a repudiation of any particular argument for intuition skepticism but rather a refutation of the very possibility of a successful argument for intuition skepticism (at least of the brand defended in contemporary metaphilosophy). The goal of the innocenceby-association strategy is to draw a tight connection between intuition and perception, such that skepticism of one entails skepticism of the other. On the assumption that perceptual skepticism is untenable, it follows that intuition skepticism is also untenable.

\subsection{The Trouble with Innocence-by-Association}

Given the heterogeneity of the category 'intuition' we saw in chapter three, it's unlikely that intuition as a kind is fit to be compared to perception. Moreover, there are independent worries about the success of the argument from innocence-by-association. Proponents of the intuition-perception analogy point out that both intuition and perception are fallible, belief-inclining (but not belief-entailing) methods for investigating the world. While that's true, this similarity is epistemically irrelevant. Proponents also claim that intuition and perception are both psychologically and phenomenologically similar. This alleged similarity would be epistemically relevant, but it is far from established. 
But even if the argument from innocence-by-association did succeed, this success would not tell us anything terribly useful, at least from a methodological perspective. The problem with the intuition-perception analogy is by now familiar. Evaluating intuition at the same level of generality as perception does not help us pursue RELIABILITY and JUSTIFICATION. Learning that global intuition skepticism is untenable leaves wide open the possibility that certain types of intuition are problematic. No historian will be assuaged about the reliability of a specific text by learning that in general written testimony that $\mathrm{p}$ confers justification on the belief that $\mathrm{p}$. No scientist will be satisfied with her experimental set-up by learning that in general scientific instruments are reliable. Likewise, no philosopher should be confident that her modal intuitions track the modal facts merely because global intuition skepticism leads to global perceptual skepticism.

Moreover, the innocence-by-association strategy itself could be improved by a more finely-carved intuitional taxonomy. For example, Hales (2012: 204) argues that both intuition and perception can be characterized as a "diachronic mental process that is constructive, responsive to specific cases, spontaneous and unreflective." But as we've already seen, not everything that goes by the name 'intuition' is a response to a specific case, and not everything that goes by the name 'intuition' is spontaneous and unreflective. Similarly, Chudnoff (2011: 314) writes, "If it perceptually seems to you that $\mathrm{p}$, then you thereby possess some prima facie justification for believing that p." This claim is true because "perceptual experiences have a certain phenomenal character" (317). Correspondingly, "If it intuitively seems to you that $\mathrm{p}$, then you thereby possess some prima facie justification for believing that $\mathrm{p}$ " (322), and this claim is true because intuition experiences have the same 
kind of presentational phenomenology as perceptual experiences. But again, the extent to which intuitions exhibit presentational phenomenology is widely disputed. So it looks like if the innocence-by-association strategy does succeed, it only succeeds against a proper subset of intuitions. A finer-grained taxonomy of intuition makes this fact more apparent. 


\section{Chapter Five: Carving Intuitions More Finely ${ }^{186}$}

"[T] he difficulties and disagreements [of philosophy], of which its history is full, are mainly due to a very simple cause: namely to the attempt to answer questions, without first discovering precisely what question it is which you desire to answer."

-G.E. Moore, Principia Ethica (1903/1980: vii)

\section{INTRODUCTION}

In this chapter I sketch three different strategies for carving intuitions more finely: by their causal origins, by their context of employment, and by the exoticism of their content. Although these strategies are meant to be neither exclusive nor exhaustive, the three strategies were not chosen ad hoc out of a basket of possible intuition-carving tactics. An analogy will illustrate. Suppose you wish to measure something, say pressure. There are three ways your measurement could go wrong. The first and most obvious way your measurement could go wrong is if you use a bad instrument. If your tire pressure gauge is broken (and you might not even know that it is broken), then its readings are likely to be unreliable. So if you're concerned about the accuracy of your measurement, you should be concerned about the instrument making the measurement. This is analogous to investigating the causal origins of our intuitions. The second way your measurement could go wrong is if you use the right tool but under the wrong conditions. Your tire pressure gauge might be in perfect working order, but if you try to use it at the bottom of the ocean, you are likely to get unreliable results. So if you're concerned about the accuracy of your measurement, you should be concerned about the conditions under which the measurement was made. This is analogous to investigating the context in which we deploy philosophical intuitions. The final way your measurement could go wrong is if you use the right tool under the right conditions

\footnotetext{
186 Portions of this chapter appeared in my 2016 article "Carving Intuition at Its Joints," Metaphilosophy, Volume 47, Issue 3, pages 326-352
} 
to measure the wrong thing. Tire pressure gauges are designed to measure tire pressure. They can, of course, be co-opted to measure the pressure of objects other than tires (they can be used to measure fuel pressure in a pinch, for example), but beyond a narrow range, tire pressure gauges aren't very good at measuring pressure. Try to use the gauge to measure the pressure of the Goodyear Blimp, and you are likely to get unreliable results. So if you're concerned about the accuracy of your measurement, you should be concerned about the thing being measured. This is analogous to investigating the targets of philosophical intuition.

These strategies will be explained further in turn, but before I do so, a few clarificatory remarks on the nature of the broader project are in order. First, I don't suggest that there is any metaphysically correct way to parse philosophical intuitions; rather, we should look for the carving which best conduces to our twin metaphilosophical goals, RELIABILITY and JUSTIFICATION. Second, although I present the three strategies as if they were distinct, it may turn out that they are closely interrelated—so much so that it doesn't make sense to think of them as discrete strategies for carving intuition. Third, I don't definitively claim that any of the three strategies I outline will aid us in our pursuit of RELIABILITY and JUSTIFICATION. Rather, I merely intend to identify avenues for future research. I hope to have demonstrated that the current homogenous, monolithic treatment of intuitions which dominates the metaphilosophical literature isn't getting the job done, and if that's right, then it's time to look at alternatives.

The goal of this chapter is to identify principled means by which we can sub-divide intuitions in a way which facilitates investigation into their reliability and justificatory power. This goal is justified by at least the three following claims, which I hope to have established 
in the preceding chapters. First, the collection of mental states which philosophers have hitherto collected under the moniker 'intuition' do not constitute a natural, unified kind. Ampliative inferences from such a disparate base are likely to be unreliable. Hence, we should seek a more fine-grained taxonomy with smaller, more unified inference bases. Second, even if intuitions do constitute a natural kind, the category 'intuition' is situated at too general a level to facilitate the sort of investigation metaphilosophers undertake. If one were interested in the reliability of a given telescope, one would not investigate the category 'scientific instrument.' Again, the solution is a more fine-grained taxonomy with smaller inference bases. Third, even if intuitions do constitute a natural kind and the kind is situated the at the right level of generality, the possibility of breaking entrenched dialectical stalemates by parsing intuitions more finely (which I outlined in chapter four) is grounds for seeking just such a taxonomy.

There is one further motivation for the project. Most philosophers already take pains to separate trustworthy intuitions from intuitions that do not merit our trust. Intuitions generated in a cloud of rage are likely to be ignored or discounted. Intuitions generated while hungover are likely to receive the same treatment. The same goes for intuitions generated in more exotic situations, like when the mad scientist tells you that she is going to alter your neural wiring with the intent of influencing the content of your intuitions. The point is, because no practicing philosopher claims that intuition is infallible, there is, in effect, an initial carving which all philosophers make to separate the intuitions which meet the minimal conditions for prima facie respectability from those that don't. All agree that the latter carry no special evidential status and thus warrant no special discussion. Part of 
my project merely aims to systematize and justify the types of separation which are already implicit in the literature. Recognizing and legitimizing these types of separation suggests that it may be fruitful to search for other strategies which carve intuitions more finely.

\section{Causal Carving}

\subsection{Overview}

The first strategy for carving intuitions more finely aims to individuate classes of intuitions by their causal origins. ${ }^{187}$ This strategy rests on the hope that recent advances in neuroscience, psychology, and evolutionary biology can tell us something about the evidentiary status of philosophical intuitions. This hope may well be mistaken-either because the neuroscience is never sophisticated enough or because biological facts of this kind are philosophically irrelevant-but there is a prima facie plausible argument for the strategy. If we knew the etiology of a given (class of) intuition, and we knew something about the reliability or justificatory power of belief-altering processes with similar (or identical) etiologies, then we might be able to infer something about the reliability or justificatory power of that (class of) intuition. Of the three strategies for carving intuitions more finely I consider, causal carving is the strategy which to-date has received the most attention in the philosophical literature-though still an insufficient amount of attention, in my view. ${ }^{188}$ I discuss four examples below (and an objection), but first some remarks concerning the broad contours of the strategy.

\footnotetext{
187 When I say 'causal origin of an intuition,' I mean the causal origin of an intuition in the brain. Insofar as it makes sense to talk about a given culture sharing a given intuition, there might be an interesting anthropological project in investigating the sociological origins of the shared intuition (e.g., can it be traced back to a seminal text?). But such investigations won't concern us here.

188 See, inter alia, Greene 2003, Woodward \& Allman 2007, Scholl 2007, Fiala, Arico, \& Nichols 2012, Nagel 2012, Nado 2014, Fischer 2014, and De Cruz 2015.
} 
At the outset, it's important to distinguish causal carving from experimental philosophy more generally, at least as experimental philosophy was initially conceived and exemplified by its locus classicus Weinberg, Nichols, \& Stich $2001 .^{189}$ Experimental philosophy, in the sense with which it ought to be distinguished from causal carving, aims to do two things. The first is to determine if and to what extent important philosophical intuitions are shared by non-philosophers. The second is to determine if and to what extent important philosophical intuitions are malleable. ${ }^{190}$ Both projects are purely descriptive, though normative conclusions are temptingly nearby. If studies of the first sort reveal that important philosophical intuitions differ systematically according to gender or culture, then philosophers — a group which, until very recently, was dominated by members of one gender and one culture, at least in the Anglo-American academy-ought to be wary of putting too much stock in their collective intuitions. If studies of the second sort reveal that important philosophical intuitions co-vary systematically with affective content, order or language of presentation, or relatively simple priming, then we ought to conclude that intuitions are overly sensitive to non-evidential factors and thus unreliable.

Causal carving is different. Traditional experimental philosophers, like their rationalist opponents, often assume a monolithic treatment of intuition is appropriate. (We saw an example of this in chapter three.) While I think this assumption is a dialectical mistake, nothing inherent to the project of experimental philosophy demands that it be

189 In the terminology of Fischer \& Collins 2015 (4), I'm here distinguishing causal carving from "first generation" experimental philosophy. The methods and aims of causal carving are supposedly encompassed by "second generation" experimental philosophy. Of course, the term 'experimental philosophy' is somewhat nebulous and context-dependent.

190 The first project explicitly targets non-philosopher. The second project need not be restricted to nonphilosophers (though, in fact, most studies of the second type also test non-philosophers). 
dropped. In contrast, anyone engaged in the project of carving intuitions by their causal origins does so with the explicit hope that different etiologies will yield differing degrees of reliability or justificatory power. ${ }^{191}$ There is, however, a point of connection between causal carving and traditional experimental philosophy. If experimental philosophers discover that some class (however defined) of intuition is more sensitive to non-evidential factors than others, they may seek an explanation of this sensitivity which includes facts about the etiology of that class of intuition. This is sometimes called the "sources and warrant" project and its "ultimate hope is that we can use this [etiological] information to help determine whether the psychological sources of the [intuitive] beliefs undercut the warrant for the beliefs" (Knobe \& Nichols 2008: 7). Fischer 2014 conveniently summarizes this hope:

Sometimes... we can assess whether a given thinker has warrant for accepting particular intuitions by explaining why she has them: We can show them 'virtuous' by tracing them back to the exercise of cognitive competencies in propitious circumstances; and we can show them 'treacherous' by exposing them as cognitive illusions engendered under particular conditions, or in particular ranges of cases, by cognitive processes governed by specific heuristic rules. (574)

How might such an investigation go? One scenario proceeds by appeal to the modularity of human brains.

As we first saw in chapter three, there is plenty of evidence that the human brain is modular in one form or another. Dehaene \& Cohen 1997 report on two patients: one, impaired in subtraction but not multiplication; the other, impaired in multiplication but not subtraction. This suggests that there is a mental module dedicated to multiplication which is functionally distinct from the module dedicated to subtraction. Waltz et al. 1999 report

191 There is a related project which one sympathetic to the monolithic treatment of intuition might undertake, that of identifying the causal mechanisms responsible for the 'faculty of intuition.' But this project is distinct from causal carving, as it does not aim to carve intuition at all. 
similar modularity in the logical domain, and moral psychologists such as Joshua Greene and Jonathan Haidt have long known that utilitarian preferences are governed by a different part of the brain than deontic preferences. Drawing on a decade of neuroimaging results, Goel 2007 contends that "we need to confront the possibility that there might be no unitary reasoning system in the brain. Rather, the evidence points to a fractionated system that is dynamically configured in response to certain task and environmental cues" (440). For these reasons, psychologists and neuroscientists no longer make sweeping generalizations about inferential processes. For instance, due to the fact that "inferential procedures are carried out by many different modules using a variety of procedures," Mercier and Sperber 2009 argue that "it is pointless to ask how inference in general is performed or to try to generalise from the properties of inference in a given domain to all inferential processes" (153). If different types of intuitions issue from different mental modules, the lesson might apply equally well to metaphilosophy: sweeping generalizations about (e.g.) the (un)reliability of intuition might be unwarranted.

Thus, one strategy for parsing intuitions more finely is by appeal to the mental module which generates them. It's entirely possible that certain mental modules are more reliable than others. Hence, the (un)reliability of mathematical intuitions may not straightforwardly bear on the (un)reliability of modal intuitions. Discovering that a certain philosophical intuition $p$ issues from the same mental module which generates known-to-be unreliable judgments in other domains is surely reason to take a second look at $p$-maybe even to afford $p$ a diminished evidential status. Hence, if psychologists were ever in a position to evaluate the reliability of the mental modules that generate philosophical 
intuitions, such evaluations could greatly aid metaphilosophers in their pursuit of RELIABILITY and JUSTIFICATION. Of course, actual science is unlikely to be so clean; if psychology is to tell us something about the evidentiary status of philosophical intuitions it will almost certainly, as we'll see in the examples below, be less direct. Nonetheless, this toy model serves both to illustrate the strategy and as a simplified point of reference for objecting to the strategy.

\subsection{Examples}

An early forerunner of causal carving appears in Woodward and Allman's 2007 "Moral Intuition: Its Neural Substrates and Normative Significance." In the paper the authors attempt to gain some insight into the evidential status of moral intuition via an investigation into its neural underpinnings. Two tentative results of this investigation are worth noting. The first is negative: moral intuition is not generated by the same neural mechanisms that govern logical and mathematical reasoning. The argument for this conclusion is a simple modus tollens: "if moral intuition is a special case of insight into a priori truths like those found in logic and mathematics, one would expect subjects with damage to emotional processing areas but intact areas that are known to be involved in logical or mathematical reasoning to have unaffected intuitions - again, this is not what is found" (183). Support for the conditional premise is found in the "considerable empirical evidence that the neural areas involved in paradigmatic cases of moral intuition are also centrally involved in emotional processing and that manipulation of emotional processing 
affects the content of one's moral intuitions" (182). ${ }^{192}$ Already this is a significant result. It suggests that moral intuition is distinct from mathematical and logical intuition and that, in principle, the reliability of the former could come apart from the reliability of the latter. Such possibilities are what undergird the credibility of the causal carving strategy.

The second conclusion is positive. Woodward and Allman propose that moral intuitions arise as "part of the larger set of social intuitions that guide us through complex, highly uncertain and rapidly changing social interactions" (186). The hypothesis that the etiology of moral intuitions is similar to or a subset of the etiology of social intuitions is empirically testable; indeed, relatively easily so, given the plethora of research on the neurology of social cognition. The hypothesis suggests that damage to the part of the brain in charge of social cognition will often result in concomitant alteration of moral intuition. ${ }^{193}$ And, indeed, the authors found just such a relationship: "Adult subjects with lesions involving [fronto-insular] experience a narrower range of social emotions than do normal subjects (Zygourakis et al., submitted for publication)" and "Damage to orbito-frontal cortex during the first few years of life has a profound impact on adult moral intuition and judgment (Anderson et al., 1999), which stands in contrast with early damage to speech and motor cortex, which is well compensated for during later development (Finger et al., 2000)" (186-7).

192 The authors add, "The neurobiological substrate for these intuitions includes the insular, cingulate, and orbito-frontal cortices and associated subcortical structures such as basal ganglia and amygdala, all of which have been implicated by many functional imaging and brain lesion studies (Adolphs, 2006; Allman et al., 2005; Baron-Cohen et al., 1999; Berthoz et al., 2002; Damasio, 1994; de Quervain et al., 2004; Moll et al., 2001; Preston and de Waal, 2002; Rilling et al., 2002; Sanfey et al., 2003; Shin et al., 2000; Singer et al., 2004a,b; Zald and Kim, 2001)" (186).

193 Of course, the hypothesis does not suggest that damage to the part of the brain in charge of social cognition will always result in concomitant alteration of moral intuition. 
As I noted above, these results are tentative. But if the results withstand further scientific scrutiny, they will have direct implications for the taxonomy of intuition. Woodward and Allman claim that moral intuitions are generated by the same part of the brain that processes and issues social judgments and that this region of the brain is distinct from the part that processes and issues mathematical/logical judgments. If this is so, then the distinction between a priori and a posteriori intuitions, which is central to (e.g.) Bealer's understanding of intuition, begins to seem arbitrary. Of course, the collapse of the a priori/a posterioi distinction in the taxonomy of intuition doesn't directly tell us anything about the normative status of appeals to intuition. But Bealer uses the distinction to preemptively shield his view from any criticism which might emanate from cognitive psychology. If the distinction collapses, this preemptive shielding looks unwarranted. Thus, the Woodward and Allman paper nicely illustrates how paying attention to the taxonomy of intuition (in this case, taxonomy via causal origins) can influence the metaphilosophical dialectic.

Another example of causal carving comes from Fiala, Arico, and Nichols' 2012 "On the Psychological Origins of Dualism." The central goal of the paper is to provide a collection of psychological facts which together constitute a debunking explanation for a certain epistemic intuition which supports dualism. The intuition in question alleges that any purely physical explanation of consciousness is bound to leave something out. It is sometimes referred to as the "explanatory gap" between purely physical descriptions of mental goings-on and the intuition that these descriptions somehow fail to account for the phenomenology of consciousness. The authors purport to be able diminish the evidential force of the "explanatory gap" intuition by identifying how and why the cognitive 
architecture of the human brain is liable to generate feelings of explanatory inadequacy in precisely the sorts of cases to which dualists appeal. Because we have independent reason to believe that the cognitive processes that generate these feelings are not reliable in these sorts of cases, we shouldn't put much stock in the intuition that an explanatory gap exists.

The argument begins with an overview of dual-process theories of cognition, lately all the rage in psychology. ${ }^{194}$ The authors describe two ways one might attribute conscious states to an object (where object is construed broadly to include persons). One method, the so-called "high-road" method, involves explicit reasoning. This reasoning has virtually no limits on the types of evidence it could accept as relevant inputs. One might draw an inference to the conclusion that a given object is conscious based on behavioral similarity to other objects believed to be conscious; or one might reach the same conclusion based on sophisticated neurobiological information about the object; or one might come to the conclusion via the perceived truth of panpsychism. What these inferences have in common is that they are experienced as deliberate, high-effort, fairly slow forms of reasoning, where each step of the argument is relatively clear to the reasoner.

In contrast to the high-road method, so-called "low-road" attributions of consciousness are quick, easy, and automatic. These attributions are triggered only by a small set of conditions, and although the contents of this set are now known to psychologists, the triggering conditions are generally opaque to attributor. Three features reliably produce low-road attributions of consciousness: (1) the object possesses what appear to be eyes, (2) the object displays non-inertial motion, and (3) the object appears to engage in

\footnotetext{
194 See Kahneman 2011 for a popular overview.
} 
contingent interaction. The possession of any one of these features produces the impression that the object is conscious, even when the subject making the judgment knows that the object is a teddy bear or a dot on a screen. 'These impressions are often called 'gut feelings.' For our purposes, we might call them 'intuitions.'

In most situations, our low-road attributions of consciousness match our high-road attributions. We immediately and intuitively judge that our fellow humans are conscious. This judgment is supported when we reason from behavioral or biological similarity. When the two types of attributions come apart, it is usually the low-road system delivering a verdict of consciousness which the high-road system must explicitly override (as in the teddy bear case). These low-road false positives have a simple evolutionary explanation. Because the dangers (and, to a lesser extent, the benefits) of encountering another conscious agent are so high, it is more adaptive to be liberal rather than conservative in one's automatic attributions of consciousness, especially when the high-road system stands ready to make necessary corrections. Low-road false negatives, on the other hand, are exceedingly rare. Because our cognitive mechanism for making immediate and intuitive attributions of consciousness is evolutionarily programmed to be liberal, there just aren't a lot of natural opportunities for the low-road system to fail to attribute consciousness to an object which our high-road system reasons is conscious. Thus, we should expect alleged false negatives to feel particularly jarring. And, according to physicalists, their explanation of consciousness falls under precisely this category:

[O] ur low-level, low road process remains silent where it would normally provide intuitive confirmation of our high road output. In place of the harmony between systems that we typically experience when looking at other people (or any other mammal, for that matter), discussions of neurons, neurotransmitters, and so on 
create a disparity between the two systems, which in turn produces a feeling that the characterization is somehow incomplete. This, we think, is an important part of the explanation for why dualism is so attractive and the explanatory gap is so vexing. (Fiala, Arico, and Nichols 2012: 97)

Hence, we should be wary of putting too much stock in our intuitions concerning an explanatory gap between purely physical descriptions of brain states and the experienced phenomenology of consciousness.

It's important not to overstate what this argument establishes. Fiala, Arico, and Nichols argue that physicalism "seems counterintuitive in virtue of contingent psychological facts about us" (104). This conclusion alone does little to dent the evidential weight of the explanatory gap intuition. After all, the tomato seems red to me in virtue of contingent psychological facts about me. (To the colorblind person, the tomato does not seem red.) This contingency does not, by itself, undermine my confidence in the claim that the tomato is red. And while it's true that Fiala, Arico, and Nichols have revealed that the cognitive mechanism that produces the explanatory gap intuition also produces (other) false judgments, this fallibility too does nothing, by itself, to weaken the intuition. No one (today) thinks intuition is infallible, so a demonstration that the mechanism that produces a certain intuition is not one hundred percent reliable is hardly surprising or worrying.

To the extent that Fiala, Arico, and Nichols have undermined intuitive support for dualism, they have done so in two ways. First, their findings constitute an error theory for the explanatory gap intuition. That is, if Fiala, Arico, and Nichols are right, then the explanatory gap intuition is not a bullet that the physicalist must bite but rather merely another datum that the physicalist's theory predicts. Second, Fiala, Arico, and Nichols purport to have given reason to think that the low-road mechanism which produces the 
explanatory gap intuition is untrustworthy. The dualist must agree that the mechanism is prone to deliver false positives, and this is some evidence that the mechanism is unreliable. More importantly, the dualist must agree that the features which the mechanism tracks (the appearance as of eyes, non-inertial motion, the appearance as of interaction) are neither necessary nor sufficient for consciousness. ${ }^{195}$ This doesn't prove that the explanatory gap intuition is mistaken, but it does suggest that we should treat the intuition the same way we treat the products of other psychological heuristics—namely, with caution.

Two more brief example will suffice. Like Woodward, Allman, Fiala, Arico, and Nichols, Helen De Cruz argues that "understanding the aetiology of philosophical intuitions is vital for making headway in debates on their evidential value" (2015: 234). ${ }^{196}$ De Cruz offers her own preview of what such projects might look like. She takes design intuitions in natural theology as her case study. A design intuition takes the following form: object $\mathrm{x}$ has a high degree of complexity; therefore $\mathrm{x}$ must have been intentionally designed. Given the complexity of the world, design intuitions are used to motivate the position that the world was intentionally designed. This is often referred to as the "design argument" for God's existence.

Design intuitions belong to a broader family of teleological intuitions. Teleological intuitions - and especially teleological explanations - are widespread and deeply-ingrained. Human beings have an innate tendency to assign purpose, intention, and design to both organic and inorganic objects. ${ }^{197}$ This tendency has an evolutionary explanation. It serves us quite well in dealing with fellow human beings and, to a lesser extent, in our interactions

195 This fact might be known only through intuition. Recall that one of the advantages of carving intuitions more finely is that one can question the justificatory force of one type of appeal to intuition without thereby questioning the justificatory force of all appeals to intuition.

196 See also Nado 2014, especially p. 32, for a similar claim.

197 See Bloom 2004, especially chapter two, for a popular overview. 
with animals. But it proves disastrously unreliable when applied to inanimate objects. It's not the case that mountains exist for climbing or mosses exist to stop soil erosion, yet even Ivy League scientists are prone to endorse explanations of this sort when under time pressure. ${ }^{198}$ De Cruz concludes that "the well-attested tendency for false positives in this domain does give some cause for concern as to the cogency of intuitions that underlie the design argument" (242). Of course, it doesn't follow from this conclusion that we ought never offer teleological explanations. We are evolutionarily programmed to see purpose and design everywhere, but if we consciously restrict our teleological explanations to events involving (at some level) entities with mental states, then these explanations need not be problematic. Nonetheless, we ought to be wary—alleges De Cruz-of teleological explanations as applied to events which do not obviously involve entities with mental states.

Finally, it's worth noting that not all projects which engage in the project of carving intuitions by their causal origins need be hostile to a priori philosophical methodology. In her 2012 "Intuitions and Experiments," Jennifer Nagel defends the traditional armchair methodology in epistemology. ${ }^{199}$ In particular, Nagel aims to defend the so-called "method of cases," in which epistemologists describe some hypothetical situation involving a subject and then issue an intuitive epistemic judgment about the subject (e.g., 'the subject does not know that $\mathrm{p}$ ' or 'the subject justifiably believes that $\mathrm{p}$, even though $\mathrm{p}$ is false') with the expectation that the audience will agree with the intuitive judgment.

\footnotetext{
198 De Cruz cites these examples from the work of Boston University psychologist Deborah Kelemen (2004, 2013).

${ }^{199}$ As we'll see, Nagel's results don't immediately generalize beyond epistemology.
} 
Nagel argues that our "pre-theoretical epistemic intuitions arise from a generally reliable natural capacity," namely what psychologists call mindreading - the ordinary ability "for ascribing states of knowledge, belief and desire" to others (496). This is an empirical claim, and Nagel offers empirical support. She reports that "similar brain regions are activated when experimental subjects read narratives about the knowledge and beliefs of others (but not about their appearance or subjective states such as hunger or thirst), and when they are engaged in live interaction with others, playing a game that requires them to attribute knowledge or belief to a partner (Redcay et al., 2010; Saxe \& Wexler, 2005)” (501). Thus, if we are justified in ascribing epistemic states to other persons in our everyday life, then we are probably also justified in ascribing epistemic states to hypothetical persons we encounter in thought experiments. ${ }^{200}$

Although the details of the four case studies above are controversial at almost every step, the examples serve to illustrate a broader methodological point which is sound. If metaphilosophers are serious about pursuing RELIABILITY and JUSTIFICATION, they need to engage seriously with the psychology and neuroscience of intuition. Unless, of course, neuroscience is_-and always will be-normatively insignificant to philosophy. It is to that objection I turn next.

\subsection{Objection}

In his 2009 "The Normative Insignificance of Neuroscience," Selim Berker argues that "either attempts to derive normative implications from neuroscientific results rely on a

\footnotetext{
200 Though see $\$ 3$ for the view that even though the causal mechanisms for ascribing epistemic states to agents are the same whether we encounter the agent in the real world or merely in a thought experiment, the peculiar context of the latter encounter undermines our justification for trusting our epistemic intuitions
} 
shoddy inference, or they appeal to substantive normative intuitions... that render the neuroscientific results irrelevant to the overall argument" (294). To illustrate his argument, Berker describes a version of the toy model I used in $\$ 2.1$ to introduce the possibility that carving intuitions by their causal origins might tell us something about their evidential status. He calls that model "the best-case scenario" (329):

The Best-Case Scenario: We notice that a portion of the brain which lights up whenever we make a certain sort of obvious, egregious error in mathematical or logical reasoning also lights up whenever we have a certain moral intuition.

If neuroscience can tell us anything about the evidential status of intuition, reasons Berker, this should be just such a case. But Berker is skeptical that even the best-case scenario can yield normative implications. He writes,

In this case, should we discount the moral intuition? That depends on how we fill in the details of the case. If, for all we can see, there is no connection between the content of the moral intuition and the content of the mistaken bit of mathematical/logical reasoning, then I am inclined to think we should continue to trust the intuition and hold out for later neuroscience to make finer distinctions between the portions of the brain activated in the moral and nonmoral cases. (Suppose the same part of the brain that lights up whenever we affirm the consequent also lights up whenever we have an intuition that infanticide is impermissible; would you be willing to start killing babies on those grounds?) $(329)^{201}$

The heart of Berker's argument is the brief thought experiment which appears in the parenthetical. He imagines a case where the best neuroscience of the day tells us that the part of the brain which is activated whenever we infer $\mathrm{p}$ from $\mathrm{p} \rightarrow \mathrm{q}$ and $\mathrm{q}$ is also activated whenever we intuit that infanticide is morally impermissible. He then rhetorically asks if we

201 Berker adds that if there is a structural similarity between the fallacious inference and the moral intuition, then we should discount the intuition. But in that case the neuroscience is normatively inert. The reason we should discount the intuition is because it looks like it's an instance of specious reasoning. 
would start killing babies on those grounds, to which the obvious answer is 'no.' We can regiment the thought experiment into a modus tollens argument.

\section{The Normative Insignificance of Neuroscience}

(1) If neuroscience is normatively significant and the best neuroscience of the day tells us that the part of the brain which is activated whenever we infer $\mathrm{p}$ from $\mathrm{p} \rightarrow \mathrm{q}$ and $\mathrm{q}$ is also activated whenever we intuit that infanticide is morally impermissible, then we ought to judge that infanticide is morally permissible.

(2) It's not the case that we ought to judge that infanticide is morally permissible.

(3) So it's not the case that neuroscience is normatively significant and the best neuroscience of the day tells us that the part of the brain which is activated whenever we infer $\mathrm{p}$ from $\mathrm{p} \rightarrow \mathrm{q}$ and $\mathrm{q}$ is also activated whenever we intuit that infanticide is morally impermissible.

The conclusion of this argument is the negation of a conjunction. But the second conjunct is a contingent empirical claim and so cannot be rejected from the armchair. Given that our current best neuroscience is silent on the truth of this conjunct, if we currently think that the conjunction is false, it must be because we think the first conjunct is false. So we must think, as Berker alleges, that neuroscience is normatively insignificant.

In what follows I won't challenge the truth of the second premise. I also won't challenge the possibility of the thought experiment (though it may be helpful to reflect on its likelihood). Given the obvious validity of the argument, the only way to resist the conclusion is to reject the first premise. Doing so requires some clarification of Berker's thought experiment. We can distinguish two relevant versions of the best-case scenario. Call them BSC-1 and BSC-2.

BSC-1: All moral intuitions are generated by the same part of the brain which is activated when we engage in fallacious reasoning.

BSC-2: Only the intuition 'infanticide is morally impermissible' is generated by the same part of the brain which is activated when we engage in fallacious reasoning. Other moral intuitions are generated by other (unproblematic) regions of the brain. 
I'll take these scenarios in turn.

Suppose BSC-1 is true. The neuroscientists tell us that all moral intuitions are generated by the same cognitive mechanisms which generate instances of fallacious reasoning. If neuroscience is normatively significant, then we thus have some evidence that moral intuitions do not reliably track the truth. If moral intuitions constitute crucial data points, without the aid of which robust moral reasoning is impossible, then we have some evidence that our moral reasoning cannot yield justified moral beliefs. Thus, if there are moral facts, we don't have epistemic access to them. ${ }^{202}$

I contend that the best explanation of our lack of epistemic access to the moral facts is that there are no moral facts. Hence, if the neuroscientists reported the data as Berker describes, I would take that data to be extremely good evidence that moral nihilism is true. ${ }^{203}$ What follows from the truth of moral nihilism? Certainly not the moral permissibility of infanticide. Moral nihilism is the view that there are no moral permissibility facts, so it entails the negation of the claim that infanticide is morally permissible. Granted, it also entails the negation of the claim that infanticide is morally impermissible, but what follows from that? Again, not much. The truth of moral nihilism is no reason to start killing babies, nor is it inconsistent with expressing outrage at the thought of infanticide. This sort of objection was levelled at (and refuted by) Bertrand Russell nearly eighty years ago: "I am accused of inconsistency... because, although I hold ultimate ethical valuations to be subjective, I nevertheless allow myself emphatic opinions on ethical questions" (1944: 720). To which he

\footnotetext{
202 So-called 'evolutionary debunking arguments' (e.g., Street 2006/2008 and Joyce 2006/2013) argue for a similar conclusion on the basis of considerations emanating not from neuroscience but from evolutionary psychology. Presumably Berker thinks that evolutionary psychology is also normatively insignificant, but I don't have space to explore the comparison here.

203 I use the term 'nihilism' as a catch-all to include, inter alia, quasi-realism, subjectivism, and fictionalism.
} 
replied: "I am quite at a loss to understand why any one should be surprised at my expressing vehement ethical judgments. By my own theory, I am, in doing so, expressing vehement desires as to the desires of mankind; I feel such desires, so why not express them?" (722). ${ }^{204}$

Berker is running a reductio where the absurd claim is that it's morally permissible to commit infanticide. This is, indeed, an absurd claim, and any argument which entails it ought to be rejected. But the thought experiment Berker considers does not entail this claim. It entails the much weaker (though still surprising) claim that it's not the case that it's morally impermissible to commit infanticide. It's a mark against a theory that it entails this second claim, but unlike the first claim, it's hardly the basis of a reductio. ${ }^{205}$ Moral nihilists have for centuries recognized that their view entails this claim. Metaethics is a contentious field, and the debate between moral realists and moral nihilists is particularly prickly. Berker's argument tacitly presupposes that all nihilist strategies for dealing with the counterintuitive nature of the claim that it's not the case that it's morally impermissible to commit infanticide ultimately fail. Of course, it's (epistemically) possible that they do fail. But it's also (epistemically) possible_ as all participants in the dialectic will admit — that they don't fail. Berker's argument rests on a controversial issue in metaethics turning out one way rather than another. But given our epistemic uncertainty, it seems that rather than wait for a contentious metaethical issue to be settled, we ought to take the neuroscience seriously now,

\footnotetext{
204 Three decades later, J.L. Mackie dealt with a similar objection: "The denial of objective values can carry with it an extreme emotional reaction, a feeling that nothing matters at all, that life has lost its purpose. Of course this does not follow; the lack of objective values is not a good reason for abandoning subjective concern or for ceasing to want anything" (1977: 34).

205 That is, the second claim is not a good basis for a reductio on its own. Of course, in most contexts, the second claim straightforwardly entails the first claim and so can be used indirectly as the basis of a reductio.
} 
even if taking the neuroscience seriously means conditionalizing on the possibility of moral nihilism.

Moreover, not all neuroscientific data will support nihilism. Suppose, for instance, $B S C-2$ is true. The neuroscientists tell us that although the vast majority of our moral intuitions are issued by areas of the brain unaffiliated with any problematic inference patterns, one very widespread moral intuition (namely, the intuition that infanticide is impermissible) is generated by the part of the brain associated with fallacious reasoning. In this case, I agree with Berker that we should not give up our belief that infanticide is morally impermissible. But there is difference between ignoring the empirical evidence altogether and thus thinking that the level of justification in the belief is unchanged, and maintaining that the belief is still all things considered justified, although slightly less justified than before the neuroscientific data was brought to light. We might respect the neuroscientific evidence, and thus afford the intuition that infanticide is impermissible a diminished evidential status, while nonetheless hanging on to the belief that infanticide is wrong.

Of course, if the neuroscientific data give us reason to the discount the infanticide intuition, and yet we hold onto the belief that infanticide is wrong, we might wonder where the residual justification comes from which warrants the belief. After all, one might worry that in the case of morality, intuitions are, ultimately, our only data points. If intuition is our only guide to the moral truth, and we have reason to distrust the intuition that infanticide is wrong, what could justify the belief that infanticide is wrong?

The answer is other intuitions. If $B S C-2$ is true, then we don't have reason to distrust moral intuition generally; merely reason to distrust one particular intuition. But even 
if we assign zero evidential weight to the intuition that infanticide is wrong-and the neuroscientific evidence need not convince us that intuitions have no weight-we can still derive the conclusion that infanticide is wrong from other, independent intuitions. In the scenario in question, we would still have no reason to doubt our general intuition that it's wrong to unjustly kill a human person. We would still have our intuition that babies are human persons. We would still have our belief that babies aren't capable of doing anything meriting death. And so we could infer the wrongness of infanticide, absent any direct intuition to that effect.

The same point can be brought out differently by way of analogy. Suppose an astronomical experiment is designed with the intent to measure the diameter of the moon. Berker* comes along and asks us (rhetorically), 'if the result of the experiment indicates that the moon is one hundred trillion miles wide, would you thereby come to believe that the moon is one hundred trillion miles wide?' 'Of course not,' we reply. 'Aha,' says Berker*, 'then we need not run the experiment; its results are insignificant to our astronomical beliefs.' That would be a terrible argument, and Berker* would be laughed out of the lab. The real Berker might respond that there is a crucial disanalogy between the moon example and the infanticide example, namely that we have independent reason to believe that the moon is less than one hundred trillion miles wide, but we don't have independent reason to believe that infanticide is wrong. Again, though, if we are considering BSC-2, that's just wrong. We have plenty of other moral intuitions, and if they're right, they collectively entail that infanticide is impermissible. 
The broader lesson is this. If Berker is right, not only would neuroscience be normatively insignificant, it would be insignificant simplicter. Not only would neuroscience be useless to questions about the reliability of normative judgment, it would also be useless for debates about the reliability of any sort of brain process. Imagine if all our perceptual beliefs lit up in the area of the brain that processes logical fallacies. Does reflecting on this hypothetical scenario show that neuroscience can tell us nothing about perception? Of course not. Berker is correct that neuroscience can't show that all normative beliefs are unjustified. But that's only because nothing can show, on pain of skeptical regress, that all normative beliefs are unjustified. At best, Berker shows that some types of data won't influence very central elements of our web of beliefs. But that doesn't show that that type of data can't affect the periphery of our web of beliefs. Neuroscience can't tell us everything about intuition, but it might be able to tell us something.

\section{Context Carving}

\subsection{Overview}

The next strategy for carving intuitions more finely individuates classes of intuition by their context of employment. Very roughly, I take a context to be "constituted by the situation the speaker or thinker is in, his particular interests and purposes in that situation, the kinds of activity he is engaging in, the relevant rules or principles or standards that he is using" and probably a great many other factors (Wong 2006: 281-282). ${ }^{206}$ The central idea behind context carving is that intuitive judgments might provide different levels of justificatory support in different contextual conditions. Of course, it's widely recognized

\footnotetext{
206 We can distinguish the context of utterance from the context of evaluation. In what follows the distinction won't make much of a difference, so I'll suppress it for simplicity's sake.
} 
that intuitions might be unreliable under some conditions. If an intuition is generated while the intuiter is in the throes of a manic depression or while the intuiter is high on hallucinogenic drugs, then that intuition might be reasonably discounted. Context carving, however, is different. If the central idea behind context carving is correct, then there are certain situations in which the process of intuiting proceeds without fault, but contextual factors nevertheless conspire to make it the case that the intuition produced carries less evidential weight than intuitions generated in other contexts. This contextual worry is particularly pertinent when philosophers use case-descriptions to elicit intuitive judgments. ${ }^{207}$ These case-descriptions may be hypothetical, as when one uses a thought experiment to pump an intuition, but they may also be characterizations of actual, real-world evidence which the author takes to motivate some intuitive verdict. When these descriptions are lifted from one context to another, we may be deceived, so the worry goes, into thinking that we have a strong intuition about a case when in fact we do not. We might fail to appreciate the contextual shift. Even when the thought experiment is totally mundane or the described evidence is utterly commonplace, there still may be something peculiar about the type of question the philosopher poses to elicit an intuitive judgment. If this type of question shifts the context, we need to carefully distinguish our pre-shift intuitions from our post-shift intuitions. And if this new context of inquiry is sufficiently divorced from ordinary contexts, we may have reason to doubt our intuitive judgments therein, even absent concerns about the causal origins of the judgment or the exoticism of the thought experiment.

\footnotetext{
207 The worry is less clear for intuitions which spring ex nihilo into one's head.
} 
We are already familiar with cases where we have to pay attention to the difference between philosophical and non-philosophical contexts. If you ask someone in casual conversation - even a philosopher-whether she has hands, or whether there is a chair in her house, or whether seven is a prime number, that person will almost certainly respond 'yes.' But we shouldn't infer on the basis of these responses the falsity of external world skepticism or mereological nihilism or nominalism in the philosophy of math. Such views cannot be refuted so easily. ${ }^{208}$ Something happens when we step into a philosophical setting. Appeals to commonplace beliefs about hands, chairs, and numbers suddenly become problematic. Perhaps the context changes the content of the question or raises our epistemic or dialectical standards. In any event, the shift is important and worth tracking. The strategy for parsing intuitions by their context of employment relies on the idea that these sorts of contextual shifts are more common than we realize.

Context carving has been explored from both an a priori perspective, reflecting broadly Wittgensteinian concerns about the malleability of language, and more recently from an empirical perspective, with concerns emanating from the psychology of language. I'll address the empirical work first before moving on to the more general, and much deeper, a priori worry.

\subsection{Examples}

In their 2016 “Intuitions’ Linguistic Sources: Stereotypes, Intuitions and Illusions," Eugen Fischer and Paul Engelhardt argue that "engagement with the psychology of language can help us resolve philosophical problems" (98). To illustrate the fruitfulness of this

\footnotetext{
208 Or perhaps they can. The point is only that it's contentious.
} 
interdisciplinary approach, they take a case study in the philosophy of perception. They purport to obtain a debunking explanation for certain phenomenal intuitions which undergird an alleged paradox in the philosophy of perception. The paradox in question sometimes appears under the header 'argument from illusion.'209 Arguments from illusion attempt to establish that sense-data are required to explain non-veridical perception. According to the sense-data theorist, when a subject views a round quarter from an angle, she is directly aware not of the coin itself but rather of an elliptical sense-datum. Fischer and Engelhardt contend that the argument from illusion fails because it relies on intuitions which are the product of a failure to detect a contextual shift. The culprit is "the undue mixing of ordinary and philosophical use, in automatic and subsequent conscious inference, [which] creates the impression of a conflict" (88) between our commonsense convictions and our phenomenal intuitions.

Fischer and Engelhardt begin their argument by observing that many words are associated with archetypes or paradigms. When we use or encounter those words, the associated archetypes are activated, facilitating certain sorts of inferences and inhibiting others. Crucially, this activation occurs involuntarily and subconsciously. We can resist it, but only when we are aware that it needs resisting. For this reason, there is a danger in inadvertently using an old term to refer to a new concept. When "speakers unwittingly start to give a well-established word a new rarefied use, [...] unmarked stereotype-inconsistent applications of the word will trigger stereotype-driven inferences to wrong conclusions

\footnotetext{
209 It's unclear to me why we should think this argument is paradoxical. It's true that the conclusion of the argument is surprising, but not all arguments with surprising conclusions need be paradoxical. But I'll mostly defer to Fischer and Engelhardt's characterization of the argument.
} 
which contextual integration need not correct... Due to the effortlessness or fluency of such stereo-type driven inferences, $[\ldots]$ such inferences are bound to lead to cognitive illusions: to predictable wrong intuitions which strike us as plausible" (74). Fischer and Engelhardt charge philosophers of perception with this mistake. They argue that philosophers of perception often "recruit well-established words which already have a more specific or subtly different remit in ordinary language, and thus endow familiar words with rarefied new uses, without noticing their novelty" (ibid.). In particular, Fischer and Engelhardt allege, "Without realizing it and taking the usual precautions, philosophers make a non-dominant use of 'seem', 'appear', or 'look', in premises that describe situations which do not conform to the stereotypes strongly associated with these verbs in their dominant uses” (87). They explain:

philosophers of perception use the verbs 'seem' and 'appear' to speak simultaneously about how things look or sound or smell or taste or feel to the subject of perception or awareness. They often take themselves to be using these verbs in a purely phenomenal sense, in which they imply nothing about what people are inclined to judge or believe... Where philosophical authors don't notice the need to explicitly mark this deviation from the stereotypes associated with the dominant uses of these verbs, they and their reader are then liable to automatically attribute such doxastic inclinations to patients, despite the contextual impropriety. (75)

Philosophers of perception use 'seems' and related vocabulary to describe the phenomenal states of their subjects while ostensibly remaining silent on the doxastic states of those subjects. But according to Fischer and Engelhardt, the dominant usage of ' $\mathrm{x}$ seems $\mathrm{G}$ to $\mathrm{S}$ ' strongly suggests (absent explicit contextual clues to the contrary) that $\mathrm{S}$ is inclined to judge that $\mathrm{x}$ is $\mathrm{G}$. So if one describes a situation in which something seems elliptical to a subject, the reader of that description will automatically and unconsciously be inclined to judge that something in that situation is elliptical. But we already know that the coin is round, so if the 
subject is aware of something that is elliptical, she must be aware not of the coin but of an elliptical sense-datum. Hence the intuitive pull of the argument from illusion. ${ }^{210}$

The claim that the dominant usage of ' $x$ seems $G$ to $S$ ' suggests that $S$ is inclined to judge that $F$ is $G$ is an empirical claim about linguistic usage patterns, and Fischer and Engelhardt subject the claim to empirical scrutiny. In an accompanying study, they employ a forced-choice plausibility-ranking task to determine the relevant stereotypes associated with various appearance and perception verbs. According to the results of the study, "“x appears F to S', 'x seems F to S', and 'x looks F to S' are strongly stereotypically associated with the doxastic patient-property $S$ is inclined to judge that $x$ is $F^{\prime \prime}$ (81). This association is subconscious, and it is activated automatically when we use or encounter the relevant locutions. The association facilitates a way of thinking about the case which is conducive to the argument from illusion, even when the propositional content of the presentation of the case gives no such advantage. More research is needed to confirm these results, but if they are correct, they give us some reason to discount the phenomenal intuitions which drive the argument from illusion. It is an open question how much we ought to discount these intuitions. ${ }^{211}$ It is consistent with respecting the results of the study that we still endorse the argument from illusion upon reflection. Nonetheless, one broader moral is clear: lessons from the psychology of language teach us that the words we use to present a thought experiment or describe some evidence matter. Care is needed to ensure that diction is not inadvertently affecting our intuitions.

\footnotetext{
210 Here's as good a place as any to note that I'm not very sympathetic to Fischer and Engelhardt's argument. Nevertheless, I think it represents, in broad contours, an interesting line of research that deserves more attention.

211 Fischer and Engelhardt seem to think that their results are grounds for discounting the intuitions quite a lot. It's not clear that this belief is justified.
} 
Avner Baz goes further. He contends that no amount of attention to diction can salvage our philosophical intuitions. The problem, he says, is not the unforeseen connotations of our word choice, but the peculiar context in which philosophical questions get asked and answered. ${ }^{212}$ Of course, it's a commonplace that sometimes the appropriate answer to a question depends in part on the context in which the question is embedded. If I ask you if you've been to the restaurant, what I'm normally interested in is whether you've eaten at the restaurant. If you respond 'yes' on the grounds that you once used the restroom, you would be answering inappropriately. Or (more famously) if I ask you if there's a gas station around the corner, what I'm normally interested in is whether I can fill up my car with gas around the corner. If you respond 'yes' on the grounds that there is a longabandoned, out-of-operation gas station around the corner, you would be answering inappropriately. In short, the point or practical significance of a question often helps determines what makes for an appropriate answer.

Baz worries that questions asked in a philosophical context almost always lack the practical significance associated with identically-worded questions asked in nonphilosophical settings and that without this piece of contextual information, it is indeterminate which answer is appropriate. We miss this indeterminacy because we focus too much on the form or content of the question and not enough on the context in which the question is asked. If the question under consideration is asked and answered easily in everyday contexts (such as 'does S know that p?') we assume that the question can be determinately asked and answered in a philosophical context devoid of practical significance.

212 We first encountered this argument in chapter four, $₫ 4.3$. 
This, according to Baz, is a mistake. He writes, "it is one thing to have shown that we could have encountered outside philosophy the cases that feature in philosophers' examples or ones philosophically relevantly like them, and quite another thing to have shown that the question we are invited by the theorist to answer in the face of his examples is philosophically relevantly no different from questions that we normally and ordinarily answer in our everyday judgments" (2012a: 318).

The heart of the problem, according to Baz, is a certain widespread representationalist conception of language which has it that, aside from a few obvious exceptions (e.g., indexicals and demonstratives), the meaning of a question is solely determined by the words which compose the question. He writes,

A major source of philosophical difficulty is the idea that it ought to be possible for us to get at and grasp the meanings of our words, or the concepts they express, apart from a consideration of the work they are fitted to do and of the conditions under which they can do it. A related source of difficulty is the idea that it ought to be possible for us just to 'apply' any of our 'referring' words to cases, even apart from doing any specific work with it, and that the application would then always be felicitously assessable in terms of truth or falsity. (2012b: 139)

The idea that hypothetical cases are evaluable absent the sort of detailed contextual background which accompanies our normal communication is central to contemporary philosophical methodology. Thought experiments are a crucial philosophical tool. But according to Baz, the questions we ask in response to hypothetical cases usually prompt unjustified answers. The problem is twofold. ${ }^{213}$ First, thought experiments are often so under-described that careful readers could reasonably fill in the details in different enough ways that the filled-in cases call for different answers. This under-description helps explain

\footnotetext{
$213 \mathrm{Baz}$ is not explicit about this division, but I think there's a good exegetical case to be made for it.
} 
intuitive disagreement. Second, and more importantly, the thing we are called on to do when answering a philosophical question is often radically divorced from anything we are asked to do in our non-philosophical lives. The meaning of our words depends in part on their practical import, and when nothing of practical import hangs on a question, the question itself may not be clear enough to be answered determinately.

Baz argues for this position inductively. ${ }^{214}$ He considers various classificatory questions which get asked in philosophy (e.g., Is the entity conscious? Does the subject know? Is the action free?) and tries to show that without being embedded in a particular context, the questions lack determinate meaning and hence lack determinate answers. He summarizes his procedure thusly:

take some version of the theorist's question - by which I mean, the form of words in which his question is couched - and ask how it might reasonably be understood if raised outside philosophy, in the course of everyday discourse, with respect to a case such as the one described by the philosopher. One thing that would then emerge is that, depending on the circumstances in which it arose, there are any number of different senses the similarly worded but non-merely-theoretical question could have-different ways the theorist's words would, or could, reasonably be understood, depending on the context in which they were uttered or considered, even though the case under consideration remained the same. That would show that... the words and case by themselves do not suffice for fixing the theorist's question with a determinate sense, and a correct answer. (2015: 898)

Baz makes central use of Gettier-type examples. He also considers more recent examples from, inter alia, Keith DeRose, Stewart Cohen, and Jason Stanley. The details of these case studies are interesting and contentious, but they need not detain us here. A more pressing issue looms. For our purposes, the central question is whether paying more attention to context in which an intuition is employed or elicited can tell us something about the

214 Ultimately, Baz admits, there may be no non-circular way for he and his dialectical opponent to argue. 
evidential status of that intuition. An affirmative answer to this question depends on there being an intelligible difference between philosophical contexts and non-philosophical contexts. But some philosophers have denied this. It is to this objection I turn next.

\subsection{Objection}

But first, some clarificatory remarks. There is a loose sense in which it is easy to distinguish philosophical contexts from non-philosophical contexts. Philosophy is, among other things, a profession (at least today). When a philosophy professor is giving a paper at the APA, or discussing a student's essay in her office, or working on an R\&R at Analysis, she is in a professional philosophical context. When she is mowing her lawn or watching a movie or doing her taxes, she is not. But this is an uninteresting distinction. There are analogous distinctions between accounting and non-accounting contexts, journalism and non-journalism contexts, water polo and non-water polo contexts, etc. One desideratum in drawing the distinction between philosophical and non-philosophical contexts is that the distinction be distinctive. That is, the difference between philosophical and non-philosophical contexts must make a difference to our judgments in a way that the difference between, say, accounting and non-accounting contexts does not.

Moreover, if the contextual difference is to be distinctive, it must be of a certain kind. Contextual variation is widespread in natural language. There are a great many contexts in which contextual factors raise (or lower) our dialectical or epistemic standards. The standard for determining whether Jones committed the crime is higher in a legal context than in most non-legal contexts. The standard for determining whether the beam will support the load is higher in an engineering context than in most non-engineering contexts. 
The standard for determining whether the drug cured the illness is higher in a scientific context than in most non-scientific contexts. Something similar almost certainly happens in the philosophy classroom. Standards of precision and care are higher in a philosophical context than in most non-philosophical contexts. But standards of precision and care are high across academic disciplines. The standard in philosophy does not seem to be noticeably higher than the standards in chemistry, linguistics, or math, so we cannot appeal to this variance (alone) to explain the (alleged) difference between philosophical and nonphilosophical contexts.

Here is another, albeit harder, way to draw an uninteresting distinction. Philosophers are generally interested in a fairly unique set of questions. Or, to put the point more aptly, philosophizing, the activity, generally targets some subjects and not others. It is difficult to delineate this set with any precision, ${ }^{215}$ but paradigmatic instances are easy to come by. It's hard to imagine investigating metaphysical grounding outside a philosophical context. Nevertheless, this distinction, however well-defined, does not satisfy the above desideratum. After all, it's hard to imagine investigating the relevant merits of galvanized steel pipes versus polyvinyl chloride pipes outside a plumbing context. Drawing the distinction this way does not generate any distinctive worry. Philosophical debates might be harder to settle than most non-philosophical debates, but if this is true, it's not because of the peculiar context in which philosophical debates occur.

\footnotetext{
215 Even identifying general characteristics is difficult. It's tempting to say that answers to philosophical questions have a certain modal status or are universal in a certain sense or occupy a certain place in our web of beliefs or play a certain explanatory role, but counterexamples abound.
} 
One final distinction is worth noting and setting aside. Some authors have argued that when one properly philosophizes, one is not merely engaged in theory construction; one is also engaged in language construction. For example, Ted Sider argues that when we investigate mereological questions, commonsense intuitive judgments (e.g., there is a desk in my office) ought to be set aside. Although these judgments express truths in English, they don't bear on the issue at hand. Mereologists are interested in a superior language-call it Ontologese - and nobody has pre-theoretic intuitions about what's true or false in Ontologese. ${ }^{216}$ Ontologese allegedly enjoys a host of advantages over English (not the least of which is its precision), and thus when we construct metaphysical theories of the world we should do so in Ontologese rather than English. By doing so, our theories will more closely mirror the actual structure of reality.

There are strong metasemantic reasons to be skeptical of this position, ${ }^{217}$ but even if it is correct, it still does not quite make sense of the difference between philosophical and non-philosophical contexts (though it comes closer than the other attempts canvassed above). If Sider is right that we should discount commonsense intuitive judgments about composite objects in the metaphysics classroom, it's not because the context of philosophizing has given us any particular reason to doubt them. Indeed, the judgments themselves are perfectly sound. They are just irrelevant to the metaphysical project. We can probably also ignore our commonsense intuitive judgments about aesthetics in the

\footnotetext{
216 See Sider 2009 and 2011.
}

217 See Hirsch 2011. 
metaphysics classroom. ${ }^{218}$ But that doesn't impugn our aesthetic intuitions. They are just irrelevant to the metaphysical project.

The relevant distinction is best brought to light by examining instances in which we (allegedly) investigate the same sort of question in (what prima facie look to be) both philosophical and non-philosophical contexts. Ordinary non-philosophers often ask questions of the form 'Does S know that p?'. Practicing professional philosophers also consider questions of the form 'Does S know that p?'. ${ }^{219}$ There is a prima facie case to be made that the questions should be treated analogously. Recall the Williamson position (discussed in chapter 4) that our ability to respond appropriately to philosophical cases is continuous with our ability to respond appropriately to non-philosophical cases. He claims that we "have no good reason to expect that the evaluation of 'philosophical' counterfactuals... uses radically different cognitive capacities from the evaluation of ordinary 'unphilosophical' counterfactuals" (2005: 13), adding

Our overall capacity for somewhat reliable thought about counterfactual possibilities is hardly surprising, for we cannot know in advance exactly which possibilities are or will be actual. We need to make contingency plans. In practice, the only way for us to be cognitively equipped to deal with the actual is by being cognitively equipped to deal with a wide variety of contingencies, most of them counterfactual. (2007: 137)

Furthermore, because there are only differences of degree along the spectrum, questioning the legitimacy of one type of counterfactual judgment threatens to extend to other types of counterfactual judgment, leading to an intellectually paralyzing brand of judgment

\footnotetext{
218 Though not vice versa

219 The knowledge question is a good case study, but it's important not to let the discussion digress into an argument over the truth of epistemic contextualism. Epistemic contextualism is the view that the truth value of knowledge ascriptions depends on the context of attribution, where the contextual factors which are relevant are normally taken to be the practical stakes of the situation. In contrast, someone like Baz who urges us to be cautious about our judgments in Gettier cases doesn't think it's the high practical stakes which drives our uncertainty.
} 
skepticism. ${ }^{220}$ If Williamson is right, there is no robust difference between philosophical and non-philosophical contexts because there is no difference in kind between the classificatory activities which occur in the philosophy classroom and the classificatory activities which occur outside the philosophy classroom.

Williamson claims that philosophical counterfactuals are not different in kind than non-philosophical counterfactuals. But if the context in which philosophical counterfactuals are used and evaluated is significantly different than the context in which non-philosophical counterfactuals are used and evaluated, then we would have a reason for distinguishing the two. When a philosopher describes a thought experiment and asks "Were a subject S in such conditions, would S be in a state of knowledge?' there is usually nothing of practical import hanging on the answer. This is not to say that nothing hangs on the answer. The answer to the question might have great theoretical consequences. Nor is it to say, as Baz sometimes seems to suggest, that such a question somehow occurs in a contextual vacuum. The context is fixed, at least in part, by the purpose of asking and answering the question.

One way, then, to start demarcating the difference between the philosophical and non-philosophical is to think about the goal of philosophical inquiry. One aim of philosophy is to learn important truths. 'Learning the truth' may sound like a rather commonplace goal, but in fact I think it's quite rare. Outside philosophy, learning the truth is almost always an instrumental, not a final, goal. If a congressional investigation wants to learn the truth about financial dealings between the president and a foreign government, it's because they want to do something with that information. If your eighth grade geography

220 2007: 220-225 
teacher wants you to learn the names of major European capitals, it's because she thinks that information will be useful in the future. With that said, philosophy almost certainly doesn't have a monopoly on pursuing truth for truth's sake. Theoretical physicists and mathematicians, for example, might also pursue truth as an intrinsic goal. What's distinctive about philosophy, I suggest, is its method of employing counterfactuals with the goal of learning the truth.

One initial step towards responding to Williamson starts by acknowledging that counterfactual conditionals are context-sensitive. ${ }^{221}$ Consider, for instance, the famous example discussed by Goodman, Quine, and Lewis (among others). ${ }^{22}$ With respect to some mid-to-late $20^{\text {th }}$ century American war, say the Vietnam War, we are to evaluate two counterfactual claims:

(1) If Caesar had been in command, he would have used the atom bomb.

(2) If Caesar had been in command, he would have used catapults.

The antecedent alone does not provide enough information to allow us to imagine the situation in detail sufficient to determine the truth of the consequent. We must turn to the conversational context to make up the difference. And what we find is that the first conditional is true in some contexts and the second is true in others. When we emphasize Caesar's ruthlessness, we are liable to imagine a modernized Caesar utilizing every weapon at his disposal. When we emphasize Caesar's historical position, we are liable to imagine a time-traveling Caesar using the only weapons he knows. Either context might be appropriate, so there is little reason to privilege one context over the other. Thus, there is

221 To the extent that counterfactuals are context-sensitive, this sensitivity might just be a byproduct of the context-sensitivity of language in general. So there may not be anything special about counterfactuals.

222 See Lewis 1971 for the canonical discussion. 
nothing to be done if one is asked to evaluate the truth of the conditionals simplicter- that is, without contextual information.

Of course, not all counterfactual conditionals are context-sensitive. The counterfactual if Caesar had been in command, Caesar would have been in command is true regardless of the context. So is if Caesar had been married, be wouldn't have been a bachelor. ${ }^{223}$ Furthermore, not all philosophizing utilizes counterfactual reasoning, nor does all philosophizing aim merely at the truth, important or otherwise. Nevertheless, there is still a lesson to be learned, at least for the small corner of philosophy that does aim at the truth and that essentially engages in context-sensitive counterfactual reasoning.

Williamson is right that the difference between philosophical and non-philosophical counterfactuals is a difference in degree, not in kind. But he's wrong to think that differences in degree can't make for genuine differences in evidential weight or justificatory force. Even though knowledge-ascription is a common human activity, the way in which knowledge is ascribed in hypothetical thought experiments is often different (in degree) than its parallel in ordinary life. In ordinary life, we are accustomed to context playing a significant role in determining how to ascribe knowledge. But when a philosopher asks 'In conditions $\mathrm{C}$, does subject $\mathrm{S}$ know that $\mathrm{p}$ ?' she is merely trying to figure out the truth; that is, she just wants to know whether $\mathrm{S}$ in fact knows that $\mathrm{p}$. This is indeed a perfectly legitimate context, but it is not a particularly rich context. That is, the context doesn't do much to fix

223 The difference between context-sensitive counterfactuals and context-insensitive counterfactuals isn't mysterious (at least, not in broad strokes). It's like the difference between 'It's raining' and 'It's raining in Austin on March $4^{\text {th }}$ at noon.' For context-sensitive counterfactuals, the antecedent alone doesn't determine in sufficient detail what background facts are relevant for assessing the consequent. For the context-insensitive counterfactuals, the antecedent alone does determine in sufficient detail what background facts are relevant for assessing the consequent. 
how to evaluate the counterfactual. So if the question is intelligible, it must be because conditions $\mathrm{C}$ are described in sufficient detail to fix whether $\mathrm{S}$ knows that $\mathrm{p}$. And this might be harder to do than it sounds.

In the final analysis, the insight to be garnered from this sort of metaphilosophical reflection borders, I'm afraid, on the platitudinous. There is a rough way to draw the distinction between philosophical and non-philosophical contexts, but it is hardly robust enough to capture all philosophical activity. So we must narrow our focus. Once narrowed, the moral seems to be: be careful! Philosophy is a contextually thin enterprise. If our thought experiments are to do the work we need them to, they must be presented in their full, glorious detail. Otherwise, we are apt to slip into a more familiar, practically-oriented context in which our intuitions are driven by factors outside the explicit scope of the case. The solution seems to be what philosophers have been doing all along (at least collectively): offer many different thought experiments with many minor variations and see how our intuitions differ accordingly. ${ }^{224}$

Sometimes, however, the details of the case are so byzantine that, even once the particulars of the thought experiment are fully in view, we should be wary of our intuitions. I turn next to carving intuitions by the exoticism of their content.

\section{Content Carving}

\subsection{Overview}

The final strategy that I will consider for carving intuitions more finely differentiates intuitions based on the exoticism of their content. The idea that intuitions elicited by exotic

\footnotetext{
224 And when there is intuitive disagreement, see if describing the case in more detail can make the disagreement go away.
} 
philosophical thought experiments may carry less evidential weight or justificatory force is widely recognized, though rarely precisified. Brian Weatherson (2003: 8) writes, "Not all counterexamples are as damaging to a theory as others... the more obscure or fantastic a counterexample, the less damaging it is to a theory" (emphasis added). Timothy Williamson (2007: 164) writes, "A nuanced account of our handling of counterfactuals is likely to predict that we are more reliable in evaluating some kinds than others... We may be correspondingly more reliable in evaluating the possibility of everyday scenarios than of 'farout' ones, and extra caution may be called for in the latter case" (emphasis added). Michael Devitt (2015: 44) writes that "judgments arising from thought experiments... about humdrum hypothetical situations should be distinguished from those arising from thought experiments about fanciful hypothetical situations, cases like Kripke's one of 'Gödel"' (emphasis added). ${ }^{225}$ The trouble is identifying what constitutes an obscure, fantastic, farout, or fanciful thought experiment.

Before we address this problem, two clarificatory remarks are necessary. First, we need to distinguish the reasons we might find exotic thought experiments potentially problematic. For instance, we might just be less likely to form intuitions one way or the other about exotic cases. (Those that claim to have intuitions about exotic cases might just be deceiving themselves.) Or it might be that exotic cases are harder to describe, so much so that differing responses aren't good evidence for differing intuitions. ${ }^{226}$ (Those who ostensibly disagree are really just filling out the details of the case differently.) These are essentially

\footnotetext{
225 Such examples could be multiplied many-fold. Here is just one more for good measure: "It is worth emphasizing, however, that the issue of concept identity cannot be settled by a mere appeal to intuitions-and this is doubly true of exotic cases..." (Schroeter \& Schroeter 2014: 7, emphasis added).

226 See van Inwagen 1998 and Koksvik 2015: 327 for more on this point.
} 
practical concerns; they reflect the difficulty we might have in forming or accessing our intuitions about exotic cases. These concerns need to be clearly separated from the lingering epistemic worries one might have about the evidential weight of exotic intuitions once one knows one is having a genuine, fully determinate intuition-experience. ${ }^{227}$

Second, just because intuitions elicited by exotic thought experiments may confer a diminished justificatory status does not mean that we ought to exclude exotic thought experiments from philosophical arguments. After all, physicists don't prohibit exotic physical experiments (involving, say, very small particles moving at very high velocities in the Large Hadron Collider). However, we ought to recognize when the intuitions elicited by our thought experiments are likely to be less reliable and take appropriate precautions. Physicists devote much attention to the calibration of their instruments before those instruments are employed. The more exotic the experimental set-up, the greater the need for calibration. Analogous safeguards are, perhaps, needed in philosophy.

Back to the central matter-how ought we to identify exotic thought experiments? Undoubtedly, exoticness comes in degrees, so we will need some metric which admits of gradations. A natural idea is that we could measure exoticness by remoteness in modal space. Some thought experiments invite us to imagine actual scenarios (e.g., some Gettier cases). Others invite us to imagine physically possible but highly unlikely scenarios (e.g., twin earth cases). Still others invite us to imagine physically impossible scenarios (e.g.,

\footnotetext{
227 These two types of concerns are often conflated, for example in Kathy Wilkes (otherwise excellent) 1988 chapter on thought experiments.
} 
phenomenal zombie cases). ${ }^{228}$ On this view, the further one has to go from the actual world in imagining the thought experiment, the less justified one is in endorsing one's intuitive response to the thought experiment.

Unfortunately, matters quickly get complicated. Here, for instance, is one obviously necessary modification: before modal distance comparisons are made, the thought experiments will have to be stripped to their essential details. Otherwise, one could generate differences in modal distance between Gettier cases by subtly altering the laws of nature in remote corners of the (imagined) universes. But in almost every case, such alterations would be irrelevant to whether or not the subject knew the proposition in question.

Moreover, many of our intuitions about modally distant scenarios are perfectly clear and wholly warranted. Imagine an immaterial being who uses physically impossible time travel to torture and kill every sentient being that ever lived or will live. ${ }^{229}$ Now consider the question, 'Would such a being have done something wrong?' I take it the answer is obvious and obviously well-justified. So if modal distance is epistemically relevant, it must merely be because in general (though not always) the farther out one goes in modal distance, the less justified one's intuitions are.

Another worry concerns our epistemic access to the modal facts. There's no easy way to measure modal distance, and, more worryingly still, our judgments of modal distance often crucially rely on our modal intuitions. Now, our modal intuitions don't constitute the modal facts, but there is something viciously circular about evaluating our modal intuitions

\footnotetext{
228 Other thought experiments go out even further in modal space. Lyons (2013: 14-15) invites his readers to imagine a metaphysically impossible situation involving individuals from different possible worlds mingling at the "Grand Interworld Station."

229 Thanks to David Sosa for this example.
} 
by appeal to considerations which depend on modal intuitions. (Though this circularity does not rule out evaluating other types of intuitions by appeal to modal distance.)

I think the answer to these and related difficulties lies in relativizing modal space to the historically relevant conditions under which the faculties which undergird our responses to thought experiments evolved. The imaginative faculties that generate these types of intuitions did not evolve to evaluate philosophical thought experiments, but they can probably be co-opted to do so (in the same way that they can be co-opted to create and entertain fiction), at least up to a certain point. The worry, though, is that as the thought experiments we consider grow more esoteric, more removed from the conditions under which our imaginative faculties evolved, the less justified we will be in relying on our intuitions about those thought experiments. ${ }^{230}$ This certainly seems to be the case for our physical judgments. Human beings are relatively adept at predicting the behavior of mediumsized objects moving at medium speeds, but their predictions about very small or very large objects moving at very slow or very fast speeds are terrible. ${ }^{231}$ There is a clear explanation for this fact. Human beings evolved under conditions in which making accurate judgments about near-at-hand middle-sized dry goods conferred a fitness advantage. Making accurate judgments about very small or very large objects moving at very slow or very fast speeds conferred no such advantage. So there was no evolutionary pressure to develop the ability to make accurate physical judgments outside a certain domain. Mutatis mutandis, perhaps, for certain philosophical judgments.

\footnotetext{
230 See Canfield 1990: 104 for a similar point.

231 See Bird 2004, especially pp. 274-5, for more on this point.
} 
On this understanding, an exotic thought experiment involves an invitation to press one's cognitive faculties into services for which they are not equipped. When we press our cognitive faculties into services for which they are not equipped, we should give the outputs of those faculties correspondingly less trust. This claim as applied to intuitions is not meant to be controversial. Neither, however, is it very informative in the abstract. There is much room for disagreement about just which thought experiments count as exotic by this description. The only way to make the claim useful, and to actually effect a carving of intuitions by the exoticism of their content, is to undertake an investigation into the faculties which undergird our responses to philosophical thought experiments. Fortunately, at least one such investigation is already available.

\subsection{Example}

In his 2015 "Constructing Answers and Intuitions," Bryce Huebner examines the psychological mechanisms we rely on to construct counterfactual representations in philosophy. He draws on a decade of work at the intersection of philosophy, psychology, and the social sciences more broadly. He finds, unsurprisingly, that the cognitive faculties employed to evaluate philosophical thought experiments are, in broad strokes, the same faculties we use to entertain fictional scenarios (in literature or film, say) and to plan for the future. In rough form, this imaginative ability requires no special training. Huebner observes that the "capacity emerges early, and five-year-old children possess a clear sense of the features that are shared, as well as the features that differ across different imaginable possibilities; and they also have a strong sense of what is possible in different fictional 
worlds (Skolnick \& Bloom 2006a, 2006b)" (72). Counterfactual reasoning is thus an early and ubiquitous feature of human life.

According to Huebner (following the terminology of Fauconnier \& Turner 2002), when we imagine a counterfactual scenario-whether as a means to plan for the future or as a reaction to a fictional narrative-our imaginative faculties activate a conceptual integration network to create a blended mental space from which to evaluate the scenario. ${ }^{232}$ Something similar happens when one encounters a philosophical thought experiment:

When someone is presented with a thought experimental scenario... subpersonal conceptual integration mechanisms are automatically brought on-line to construct fleshed-out representations of the skeletal content presented in the scenario... $[T]$ his process draws on multiple sources of information, including the representations presented in a thought experimental scenario, stored representations of previously encountered facts about the world, and representations constructed on-the-fly, to bridge the gap between these other kinds of representations. (75)

No thought experiment can be usefully described to the same level of detail we have available to us when we encounter events and states of affair in the actual world. Thought experiments are hence not best characterized as full-fledged scenarios. Rather, they are scenario schemata; that is, families of full-fledged scenarios. When a thought experiment is constructed properly, the description of the case constrains the way the reader fills in the details and emphasizes to the reader which elements of the description are relevant to an evaluation of the case. Still, because the thought experiment is hypothetical, some representative reconstruction will inevitably occur. Huebner writes, "As people read a

\footnotetext{
232 Huebner adds, "Conceptual integration networks have their original home in our richly textured social world, and they often depend on the fact that many aspects of the world are stable enough that they don't need to be encoded. But no matter where they are produced, constraints on processing speed and limitations on working memory ensure that the elements and features in a mental space are only represented skeletally (they yield a gist-based representation of a counterfactual situation, rather than a florid and detailed representation of a possible world)" (74).
} 
thought experimental scenario they reflexively construct mental spaces in working memory that integrate the details of the narrative with previously imagined or encountered situations" (76). The more closely the thought experiment resembles actually encountered events or states of affair, the more the reader can rely on facts about the actual world in her reconstruction. Thought experiments which are unfamiliar are more cognitively demanding in part because they require a greater degree of imaginative reconstruction. When a task is cognitively demanding, we are apt to employ heuristics to lighten the cognitive load. These heuristics are at times problematic. In an exotic thought experiment, we are liable to rely on irrelevant information, "such as culturally local assumptions as well as idiosyncrasies of an individual's experience" (ibid.). This is one ground for treating our intuitions about exotic thought experiments with less confidence.

Recent work in experimental philosophy and moral psychology illustrates this phenomenon, at least in non-philosopehrs. For instance, work published in 2009 demonstrates that small, ethically irrelevant changes to the wording of a moral thought experiment can significantly alter the judgments study participants are apt to deliver. In one study, Uhlmann et al. found that when the individual to be sacrificed in a fat-man-style trolley problem was identified as "Chip Ellsworth III," participants were statistically more likely to favor a consequentialist response. When the individual was identified as "Tyrone Payton," participants were statistically more likely to favor a deontological response. This variation occurred despite the fact that $87 \%$ of the participants regarded race and nationality as features irrelevant to moral consideration. ${ }^{233}$ When one encounters a trolley-style thought

233 See pp. 481-84. 
experiment, one spontaneously creates a blended mental space from which to evaluate the scenario. But because the scenario is so unfamiliar, both the construction process and the evaluation process are arduous. Implicit biases (in this case, apparently against the wealthy and/or privileged) are more likely to be used as mental shortcuts.

This is a reason to regard trolley-style thought experiments as exotic, in spite of their physical possibility and in contrast to what the simple modal distance theory would predict. Because the stark trade-off described in a trolley-style thought experiment is so rare in the actual world, our ability to reason about the case is hindered. As we saw in chapter four, well-confirmed psychological research shows that humans are significantly more reliable when reasoning with familiar terms than with unfamiliar terms: success in algebraic reasoning drops off markedly when the customary $x$ and $y$ are replaced by the unfamiliar $b_{1}$ and $b_{2}{ }^{234}$ reasoning about percentages is notoriously difficult, while structurally analogous questions about populations are answered much more easily; ${ }^{235}$ performance on the Wason selection task is generally miserable but improves drastically when numbers and letters are replaced with beverages and ages, ${ }^{236}$ and so on.

Here, however, it is important to remember the distinction sketched above between practical and epistemic concerns. A practical worry about exotic thought experiments is that respondents might fill in the details differently to the extent that different responses to the same presented case are not in fact incompatible. The more important epistemic worry about exotic thought experiments is that respondents will have trouble evaluating them,

\footnotetext{
234 See E.L. Thorndike 1922 for the first of many such studies.

235 See Tversky and Khaneman 1983, pp. 308-309.

236 See Jonathan Evans 1998 for an overview of this literature.
} 
especially if this difficulty is introspectively indiscernible. Both concerns are evident in Uhlmann's work. Nothing about the names "Chip Ellsworth III" and "Tyrone Payton" entails that the two individuals occupy different socioeconomic positions. ${ }^{237}$ But Pizarro's research indicates that (at least some) subjects are importing what they believe about name correlations in the actual world and applying that information to the described case. They then use that information to more fully imagine the scenario. The additional details then serve to reinforce either the deontological or consequentialist intuition. This is the practical concern about whether the necessarily skeletal description of an exotic case can reliably lead one's audience to imagine the same scenario. Alternatively, the subjects in Pizarro's experiments might indeed be imagining the same case. According to this account of the discrepancy, the subjects are primed by the negative emotions associated with "Chip Ellsworth III" and/or the positive emotions associated with "Tyrone Payton." These triggered emotive reactions get confused for (or incorporated into) intuitions about the moral permissibility of pushing any person off a bridge to save five others. This is the epistemic worry about exotic thought experiments engendering more confident intuitions than the cases merit.

Because these mental shortcuts are hard to detect, one might reasonably be wary of reactions to exotic thought experiments, even when the respondents report strong, clear intuitions. Moreover, as Huebner notes, "[v]ery little of this process is accessible to first person cognition" (76), meaning we don't have introspective access to the resources we draw

\footnotetext{
237 I'm using differing attitudes about different levels of socioeconomic status as a working explanation of the difference in subject responses. But I'm open to hearing more complicated (or altogether) different explanations. Whatever the explanation, the difficulties sketched here remain.
} 
from when we engage in imaginative reconstruction or evaluation. Thus, our opportunities for self-correction may be limited. These difficulties are compounded by the fact that incorporating information from the actual world and consulting one's moral emotions are not, in general, bad responses to a thought experiment. But in an exotic thought experiment, it's harder to see which pieces of information and which emotions are relevant.

To take just one more example, consider Ned Block's famous (1978) China-brain thought experiment. ${ }^{238}$ Suppose we want to know whether there is anything it's like to be the China-brain. That is, does the China-brain feel (e.g.) pains and pleasures? We could ask it if it feels pain, but we know antecedently (more or less by stipulation) that it will say "yes," so asking it if it feels pain is supposed to be irrelevant to answering our phenomenological question. But in normal cases, asking whether someone is in pain is an excellent way to determine whether someone is in pain. If a person cannot communicate with us (and we can't observe the person's behavior) an alternative strategy might be to examine the person's brain. But here again, in the exotic case it's hard to tell how to weigh the evidence. After all, in some respects the China-brain is exactly like a human brain in pain. There's a one-to-one mapping of neurons to people. But in other respects, the China-brain is fundamentally different. After all, the China-brain is composed of people, not neurons. Determining which type of similarity is relevant is no easy task.

Although much clarificatory work remains, it seems plausible to me that carving intuitions by the exoticism of their content will conduce to our metaphilosophical goals

\footnotetext{
238 Block's case was apparently anticipated four years earlier by Lawrence Davis during a colloquium talk at MIT. See Dennett 1978. Also, the argumentative work that Block's case is supposed to effect has often been exaggerated in the metaphilosophical literature. Block's argument against functionalism doesn't hinge on one's reaction to the case. Nonetheless, the case is, I think, paradigmatically exotic (again, in spite of its physical possibility).
} 
RELIABILITY and JUSTIFICATION. Exotic thought experiments are likely to trigger problematic heuristics which obscure which pieces of information are relevant. Of course, it might be that this is exactly what successful philosophical training endows one with: the ability to detect what evidence is relevant to what question. And if that's true, then maybe professional philosophers are equipped to deal with exotic thought experiments (even if non-philosophers are not) and thus metaphilosophers would be wasting their time trying to precisify the notion of exoticness. I turn next, then, to the so-called 'expertise defense.'

\subsection{Objection}

We first encountered the expertise defense in chapter four, but it's worth considering the issue in more detail here. Experts are found in many walks of life. We talk about experts in relation to academic subjects: he's an expert in medieval French literature; she's an expert in condensed matter physics. We talk about experts in relation to professions: she's an expert accountant; he's an expert dental hygienist. We talk about experts in relation to skills: he's an expert gymnast, she's an expert surgeon. We even talk about experts with relation to sense modalities. Gustatory experts can perceive flavor profiles hidden from the common palate. Auditory experts can perceive variations in pitch and tone that the average listener cannot. Tactile experts (normally, those blind at birth) can identify an object by its shape and texture much more quickly and accurately than the haptic plebeians. So the idea of philosophical experts is very far from far-fetched.

But we must carefully distinguish expertise in the practical sense from expertise in the epistemic sense. The intuition reports of philosophers might be more credible than the intuition reports of non-philosophers merely in virtue of the fact that professional 
philosophers are much more likely to have genuine intuitions about exotic cases. Nonphilosophers may simply be at a loss as to what to say when confronted with such cases. Similarly, professional philosophers might be much better than non-philosophers at understanding the details of an exotic case. Hence, given a certain description of a case, professional philosophers might be much more likely than non-philosophers to imagine the same scenario. This type of expertise does not straightforwardly entail that professional philosophers are expert intuiters in the epistemic sense. The real question is this: when two people-one a philosopher and the other a non-philosopher-both fully understand a case and have genuine intuitions about the case, is there reason to prefer the philosopher's intuitive judgment over the non-philosopher's judgment?

Proponents of the expertise defense argue that the burden of proof is on their dialectical opponents to show that philosophical training doesn't correlate with increased sensitivity and sophistication in philosophical judgment. These authors maintain that the intuitions of professional philosophers are more reliable than the intuitions of nonphilosophers because philosophical training shields one from the evidentially extraneous effects which taint the intuitions of those not so-trained. Interestingly, both Devitt and Williamson go in for some version of the expertise defense. ${ }^{239}$ Just a few sentences after advancing a distinction between Kripke's famous 'Gödel' case and more humdrum reference ascriptions, Devitt writes, "When we move to intuitions about hypothetical fanciful cases like 'Gödel', I have argued that we should forget about the folk (as indeed we had until

\footnotetext{
239 Both men are defenders of the methodological orthodoxy. One reason they may want to draw a distinction between exotic and non-exotic cases is to explain why experimental philosophers find consensus between philosophers and folk regarding some cases but not others. Only experts are likely to get the exotic cases right.
} 
Machery et al): these intuitions require too much expertise... For cases like this, the only intuitions worth worrying about are those of philosophers and similar experts" (2016: 44). Thus, according to Devitt, we can make at least a rough carving of intuitive judgments based on the exoticism of their content, and exotic cases are more difficult to evaluate correctly, but professional philosophers shouldn't worry too much about using such cases in their arguments. So long as philosophical training is conducted to the high standards it currently is, professional philosophers will be adequately equipped to judge these cases well. ${ }^{240}$

According to proponents of the expertise defense, one piece of evidence in favor of the claim that philosophers are better intuiters than non-philosophers is "manifested in the considerable agreement about philosophical cases that one does not find among nonprofessionals" (Hales 2012: 190). Williamson agrees: "Levels of disagreement over thought experiments seem to be significantly lower among fully trained philosophers than among novices" (2007: 191). Of course, the extent of philosophical consensus regarding thought experiments is an empirical question, and to my knowledge neither Hales nor Williamson have offered empirical support for the claim. Still, even granting that there is “considerable agreement" among professional philosophers that one does not find outside philosophy, nothing concerning expertise follows immediately. We must be careful that whatever consensus does exist among professional philosophers is not simply an artifact of various selection effects. It might be that a prerequisite on becoming a member of the philosophy club is possession of intuitions in agreement with the rest of the club. Those

\footnotetext{
240 This is perhaps too strong. The Devitt quote commits him to the view that professional philosophers (and similar experts) are much better at evaluating exotic cases than non-philosophers. But 'much better' does not entail 'good.'
} 
with differing intuitions either abandon pursuit of the club voluntarily, frustrated by repeated rebuffs of what they take to be genuine alternatives to the received orthodoxy, or else they are rejected on grounds of insufficient philosophical sophistication, evidenced by their 'incorrect' intuitive judgments.

There is another, related worry. Far from correcting and improving one's intuitive judgments, philosophical training might taint or otherwise color one's intuitions. Such theoretically-contaminated intuitions might be less worthy of our trust than the pre-theoretic intuitions of non-philosophers. Huebner writes,

When a thought experiment is deployed in a philosophical argument, it can function as an intuition pump because it's embedded within a theoretical background that constrains the range of plausible strategies for fleshing-out its simplified and idealized representation of a possible world. But this doesn't always happen in 'epistemically benevolent' ways. Sometimes, previously defended theoretical commitments are taken up in the construction of a blended mental space. Sometimes a directed search for a blended mental space will confirm antecedently held principles, leading to the construction of answers grounded on little more than 'wishful thinking'; and where this happens, the expression of an answer can conceal a tacitly and unconsciously circular argument. (2015: 77)

Williamson recognizes this worry but thinks that it is ungrounded. He writes,

We should not regard philosophical training as an illegitimate contamination of the data, any more than training natural scientists how to perform experiments properly is a contamination of their data. Although the philosophically innocent may be free of various forms of theoretical bias, just as the scientifically innocent are, that is not enough to confer special authority on innocent judgment, given its characteristic sloppiness. (2007: 191)

In his 2011, Williamson clarifies the above quotation, noting that "the expertise defence does not imply that a good philosophical education involves the cultivation of a mysterious sui generis faculty of rational intuition, or anything of the kind. Rather, it is supposed to improve 
far more mundane skills, such as careful attention to details in the description of the scenario" (216).

Two points regarding this exchange are worth observing. The first is the failure to distinguish between practical and epistemic expertise. As I argued above, professional philosophers might be much better than non-philosophers at understanding the details of an exotic thought experiment, and thus their intuitions might be more narrowly centered on one fleshed-out scenario than the intuitions of non-philosophers, but this fact doesn't entail that philosophers are better at evaluating exotic thought experiments. The second point is that the analogy to natural scientists is slightly misleading. The hard sciences have an independent source of feedback, namely the pointer-readings of their experimental instruments. Philosophical training is full of feedback, but at least with respect to intuitive judgments, it's unclear to what extent this feedback is independent.

Williamson acknowledges this second difficulty but doesn't think it goes very deep. He argues that "in most branches of philosophy there are many sufficiently uncontentious thought experiments, such as fictional cases of unjustified true beliefs that do not constitute knowledge, on which beginners are often started" (2011: 225) and that these judgments form something like a calibration base from which one can fine-tune one's ability to evaluate thought experiments. I agree that these judgments can be used in the early stages of one's philosophical training to help refine one's ability to evaluate cases, and although these judgments aren't strictly speaking independent, I agree that we must endorse them on pain of a vicious and widespread skepticism. Nonetheless, so it seems to me, this line of response doesn't address the fundamental problem with appealing to exotic thought experiments. On 
almost any plausible understanding of 'exotic,' exotic thought experiments differ radically from the uncontentious thought experiments Williamson cites. It is precisely this dissimilarity that makes them problematic. Without an independent source of feedback with respect to exotic thought experiments, the consensus to which Williamson points doesn't give us much reason to think that philosophers are better than non-philosophers at evaluating such cases. Hence, the expertise defense fails to defuse the worry about appealing to exotic thought experiments, and thus metaphilosophers would be well-served to continue investigating and precisifying the relevant notion of exoticness.

\section{CONCLUSION}

Metaphilosophers often compare intuition to perception. Although in many ways I find this comparison deeply problematic, there is a way to frame the analogy which dovetails nicely with the claims I have been making. Suppose we were interested in the following methodological question: when ought we to rely on perceptual evidence? To answer this question, we would carve up perception using much the same techniques I advocated for intuition. First, we know that (visual) perception is suited to receive some inputs but not others. Light with wavelengths between $\sim 450$ and $\sim 650$ nanometers can be interpreted comfortably, but electromagnetic radiation with wavelengths longer or shorter become much more difficult (and once we hit the ultraviolet and infrared spectrums, impossible) to interpret. So we should take care that our (visual) perceptions are of a certain type. This is content carving. Second, we know that (visual) perception is reliable in certain conditions but not in others (e.g., when the subject is stressed or lighting conditions are poor, vision is likely to be unreliable). If we knew something about the conditions under which the perceptual evidence was gathered, we might have a better handle on how the subject should 
use that evidence to form beliefs. This is context carving. Finally, we might worry about hallucinations. Hallucinations are often phenomenally indistinguishable from veridical perception experiences, but the hallucination as of a chair does not tell us about the world in the same way that the veridical perception as of a chair does. Fortunately, the cognitive mechanisms that govern hallucination can be distinguished (in principle) from the cognitive mechanisms that govern veridical perception. So if we knew something about the neurological state of a subject undergoing purported perceptual experiences, we might have a better handle on how the subject should use those experiences to form beliefs. This is causal carving.

In this monograph I've argued that the category 'intuition' is both too broad and too heterogeneous to serve as the appropriate target for metaphilosophical inquiry. Focusing on more finely-grained mental states changes the way four popular metaphilosophical arguments are run and may break entrenched dialectical stalemates. I've identified three plausible strategies for parsing intuitions more finely: by their causal origins, by their context of employment, and by the exoticism of their content. If metaphilosophers insist on discussing intuition, they must first carve intuition at its joints. 


\section{Bibliography}

Alexander, Joshua. 2012. Experimental Philosophy: An Introduction. Cambridge: Polity Press.

Alexander, Joshua and Jonathan Weinberg. 2007. "Analytic Epistemology and Experimental Philosophy.” Philosopby Compass 2, no. 1:56-80.

Achinstein, Peter. 1964. "Models, Analogies and Theories." Philosophy of Science 31: 328-349.

Andow, James. 2015. “How Distinctive Is Philosophers' Intuition Talk?” Metaphilosophy 46, nos. 4-5:515-538.

Audi, Robert. 2005. The Good in the Right: A Theory of Intuition and Intrinsic Value. Princeton: Princeton University Press.

- 2008. "Intuition, Inference, and Rational Disagreement in Ethics." Ethical Theory and Moral Practice 11:475-92.

Aristotle. 1973. Posterior Analytics. Translated by Richard McKeon. Chicago: University of Chicago Press.

Augustine. 2006. Confessions, translated by F.J. Sheed, edited by Michael P. Foley. Indianapolis, In.: Hackett Publishing.

Baker, Alan. 2003. "Quantitative Parsimony and Explanatory Power." The British Journal for the Philosophy of Science 54, no. 2:245-259.

Baz, Avner. 2012a. "Must Philosophers Rely on Intuitions?" Journal of Philosophy 109, no. $4: 316-37$.

- 2012b. When Words Are Called For: A Defense of Ordinary Language Philosophy. Harvard University Press.

- 2015. "Questioning the Method of Cases Fundamentally-Reply to Deutsch." Inquiry 58, no. 7-8:895-907.

- 2016. "Recent Attempts to Defend the Philosophical Method of Cases and the Linguistic (Re)turn." Philosophy and Phenomenological Research 92, no. 1:105-30.

Bealer, George. 1993. "The Incoherence of Empiricism." Proceedings of the Aristotelian Society Supplementary Volume 66:99-138.

—. 1996. "On the Possibility of Philosophical Knowledge.” Noûs 30, no. 10:1-34.

- 1998. "Intuition and the Autonomy of Philosophy." In Rethinking Intuition: The Psychology of Intuition and Its Role in Philosophical Inquiry, edited by Michael DePaul and William Ramsey, 201-240. Lanham, Md.: Rowman and Littlefield.

—. 1999. "A Theory of the A Priori." Philosophical Perspectives 13: 29-55. 
Bengson, John. 2013. "Experimental Attacks on Intuitions and Answers." Philosophy and Phenomenological Research 86, no. 3:495-532.

- 2014. "How Philosophers Use Intuition and 'Intuition." Philosophical Studies 171:555-76.

- 2015. “The Intellectual Given.” Mind 124, no. 495:707-760.

Berker, Selim. 2009. "The Normative Insignificance of Neuroscience." Philosopby and Public Affairs 37, no. 4:293-329.

Bird, Alexander. 2004. "Strong Necessitarianism: The Nomological Identity of Possible Worlds." Ratio 17, no. 3:256-276.

Black, Max. 1954. Problems of Analysis. Ithaca, N.Y.: Cornell University Press.

Block, Ned. 1978. "Troubles with Functionalism." Minnesota Studies in the Philosophy of Science 9:261-325.

Bloom, Paul. 2004. Descartes' Baby: How the Science of Child Development Explains What Makes Us Human. New York: Basic Books.

Bonjour, Laurence. 1998. In Defense of Pure Reason: A Rationalist Account of A Priori Justification. Cambridge: Cambridge University Press.

Brown, Jessica. 2013. "Immediate Justification, Perception, and Intuition." In Seemings and Justification: New Essays on Dogmatism and Phenomenal Conservatism., edited by Chris Tucker, 71-89. Oxford: Oxford University Press.

Buckwalter, Wesley, and Stephen Stich. 2014. "Gender and Philosophical Intuition." In Experimental Philosophy, Volume 2, edited by Joshua Knobe and Shaun Nichols, 307346. Oxford: Oxford University Press.

Canfield, John V. 1990. The Looking-Glass Self: An Examination of Self-Awareness. New York: Praeger.

Cappelen, Herman. 2012. Philosophy Without Intuitions. Oxford: Oxford University Press.

Carruthers, Peter. 2006. The Architecture of the Mind. Oxford: Oxford University Press.

Chalmers, David. 1996. The Conscious Mind: In Search of a Fundamental Theory. Oxford: Oxford University Press.

Chisholm, Roderick. 1973. The Problem of the Criterion. Marquette University Press.

Chudnoff, Elijah. 2011. “The Nature of Intuitive Justification.” Philosophical Studies 153:31333.

- 2014. "Is Intuition Based on Understanding?" Philosophy and Phenomenological Research 89, no. 1:42-67.

Cohen, Gerald. 2000. If You're An Egalitarian, How Come You're So Rich? Harvard University Press. 
Conee, Earl. 1998. "Seeing the Truth." Philosophy and Phenomenological Research 58, no. 4:84757.

Connee, Earl, and Richard Feldman. 1998. "The Generality Problem for Reliabilism." Philosophical Studies 89:1-29.

—. 2004. Evidentialism: Essays in Epistemology. Oxford: Oxford University Press.

Costa, Alberta, Alice Foucart, Sayuri Hayakawa, Melina Aparici, Jose Apesteguia, Joy Heafner, and Boaz Keysar. 2014. "Your Morals Depend on Language." PLOS ONE 9, no. 4:1-7.

Cummins, Robert. 1998. "Reflections on Reflective Equilibrium." InRethinking Intuition: The Psychology of Intuition and Its Role in Philosophical Inquiry, edited by Michael DePaul and William Ramsey, 113-127. Lanham, Md.: Rowman and Littlefield.

Dancy, Jonathan. 1983. "Ethical Particularism and Morally Relevant Properties." Mind, 92: 530-47.

-1993. Moral Reasons. Oxford: Blackwell.

- 2004. Ethics without Principles. Oxford: Clarendon Press.

Davidson, Donald. 1987. "Knowing One's Own Mind." Proceedings and Addresses of the American Philosophical Association 60, no. 3:441-58.

De Cruz, Helen. 2015. "Where Philosophical Intuitions Come From.” Australasian Journal of Philosophy 93, no. 2:233-49.

Dehaene, Stanislas, and Laurent Cohen. 1997. "Cerebral Pathways for Calculation: Double Dissociation Between Rote Verbal and Quantitative Knowledge of Arithmetic." Cortex 33, no. 2:219-50.

Dennett, Daniel. 1978. "Toward a Cognitive Theory of Consciousness." Reprinted in Brainstorms: Philosophical Essays on Mind and Psychology (1981), 149-173. Cambridge, Mass.: MIT Press.

Deutsch, Max. 2009. "Experimental Philosophy and the Theory of Reference." Mind and Language 24, no. 4: 445-466.

- 2010. "Intuitions, Counterexamples, and Experimental Philosophy." Review of Philosophy and Psychology 1, no. 3: 447-460.

- 2015. The Myth of the Intuitive. Cambridge, Mass.: MIT Press.

Dever, Josh. 2016. "What Is Philosophical Methodology?" In The Oxford Handbook of Philosophical Methodology, edited by H. Cappelen, T. Gendler, and J. Hawthorne, 3-26. Oxford University Press.

Devitt, Michael. 1994. “The Methodology of Naturalistic Semantics." The Journal of Philosophy 91, no. 10:545-572.

—. 2006. "Intuitions in Linguistics." British Journal for the Philosophy of Science 57: 481513. 
- 2015. “Testing Theories of Reference." In Advances in Experimental Philosophy of Language, edited by Jussi Haukioja, 31-64. London: Bloomsbury.

Dorr, Cian and Gideon Rosen. 2002. "Composition as Fiction." In Blackwell's Guide to Metaphysics, edited Richard Gale, 151-174. Blackwell.

Elga, Adam. Unpublished Manuscript. "Lucky To Be Rational.”

Evans, Jonathan. 1998. "Matching Bias in Conditional Reasoning: Do We Understand It after 25 Years?” Thinking and Reasoning 4: 45-82.

Fauconnier, Gilles and Mark Turner. 2002. The Way We Think: Conceptual Blending and the Mind's Hidden Complexities. New York: Basic Books.

Feyerabend, Paul. 1975. Against Method. London: Verso. . 1978. Science in a Free Society. London: New Left Books.

Fiala, Brian, Adam Rico, and Shaun Nichols. 2012. "On the Psychological Origins of Dualism: Dual-Process Cognition and the Explanatory Gap." In Creating Consilience: Issues and Case Studies in the Integration of the Sciences and Humanities, edited by Edward Slingerland and Mark Collard. Oxford University Press.

Fischer, Eugen. 2014. "Philosophical Intuitions, Heuristics, and Metaphors." Synthese 191:569-606.

Fischer, Eugen and John Collins. 2015. "Rationalism and Naturalism in the Age of Experimental Philosophy." In Experimental Philosophy, Rationalism, and Naturalism: Rethinking Philosophical Method, edited by Eugen Fischer and John Collins, 3-33. Routledge.

Fischer, Eugen and Paul Engelhardt. 2006. 'Intuitions' Linguistic Sources: Stereotypes, Intuitions and Illusions." Mind \& Language 31, no. 1:67-103.

Franklin, Allan. 1997. "Calibration.” Perspectives on Science 5, no. 1:31-80.

Gendler, Tamar Szabó. 2007. "Philosophical Thought Experiments, Intuitions, and Cognitive Equilibrium." Midwest Studies in Philosophy, 31: 68-89.

Gendler, Tamar Szabó and John Hawthorne. 2005. "The Real Guide to Fake Barns: A Catalogue of Gifts for Your Epistemic Enemies.” Philosophical Studies 124: 331-352.

Gödel, Kurt. 1964. “What is Cantor's continuum problem?” revised version of Gödel 1947, in Benacerraf, P. and Putnam, H. (eds.), 1983, Philosophy of mathematics: selected readings (2nd ed.), Cambridge: Cambridge University Press.

Goel, Vinod. 2007. "Anatomy of Deductive Reasoning." TRENDS in Cognitive Sciences 11, no. 10:435-441.

Goldman, Alvin. 1992. Liaisons: Philosophy Meets the Cognitive and Social Sciences. Cambridge, Mass.: MIT Press.

Goodman, Nelson. 1955. Fact, Fiction, and Forecast. Cambridge, Mass.: Harvard University Press. 
Goodman, Nelson, and W. V. O. Quine. 1947. "Steps Toward a Constructive Nominalism.” Journal of Symbolic Logic 12, no. 4:105-22.

Gopnik, A. and Eric Schwitzgebel. 1998. "Whose Concepts are they, Anyway?: The Role of Philosophical Intuition in Empirical Psychology.” In Rethinking Intuition: The Psychology of Intuition and Its Role in Philosophical Inquiry, edited by Michael DePaul and William Ramsey, 75-94. Lanham, Md.: Rowman and Littlefield.

Greene, Joshua. 2003. 'From Neural 'Is' to Moral 'Ought:' What Are the Moral Implications of Neuroscientific Moral Psychology?” Nature Reviews Neuroscience 4, 847-850.

Greene, Joshua, and Jonathan Haidt. 2002. "How (and Where) Does Moral Judgment Work?” Trends in Cognitive Sciences 6, no. 12:517-23.

Grice, H.P. 1986. "Reply to Richards," In Philosophical Grounds of Rationality: Intentions, Categories, Ends, edited by R. Grandy and R. Warner. Oxford: Clarendon Press.

Gupta, Anil. 2006. Empiricism and Experience. Oxford: Oxford University Press.

Hales, Steven. 2000. “The Problem of Intuition.” American Philosophical Quarterly 37, no. 2: 135-147.

—. 2012. “The Faculty of Intuition.” Analytic Philosophy 53, no. 2:180-207.

Heilbron, John. 2010. Galileo. Oxford University Press.

Hintikka, Jaakko. 1999. “The Emperor's New Intuitions.” The Journal of Philosophy, 96: $127-$ 147.

Hirsch, Eli. 2011. Quantifier Variance and Realism: Essays in Metaontology. New York: Oxford University Press.

Hobbes, Thomas. 1645/1999. "Of Liberty and Necessity." In Hobbes and Bramball on Liberty and Necessity, edited by Vere Chappell. Cambridge: Cambridge University Press.

Hofstadter, Douglas. 2001. "Analogy as the Core of Cognition." In The Analogical Mind: Perspectives from Cognitive Science, edited by Dedre Gentner, Keith James Holyoak, and Boicho N. Kokinov. MIT Press.

Huebner, Bryce. 2015. "Constructing Answers and Intuitions." Discipline filosofiche 25, no. 1:65-88.

Huemer, Michael. 2001. Skepticism and the Veil of Perception. Lanham, MD: Rowman and Littlefield.

—. 2007. "Compassionate Phenomenal Conservatism." Philosophy and Phenomenological Research 74, no. 1:30-55.

—. 2013. "Phenomenal Conservatism Uber Alles." In Seemings and Justification: New Essays on Dogmatism and Phenomenal Conservatism, edited by Chris Tucker. Oxford: Oxford University Press.

Ichikawa, Jonathan. 2013. "Review of Philosophy Without Intuitions." International Journal of Philosophical Studies 21:111-131. 
Jackson, Frank. 1982. “Epiphenomenal Qualia.” Philosophical Quarterly 32, no. 127:127-36.

Joyce, Richard. 2006. The Evolution of Morality. Cambridge, Mass.: MIT Press.

—. 2013. "Irrealism and the Genealogy of Morals.” Ratio 26, no. 4:351-72.

Kahneman, Daniel. 2011. Thinking, Fast and Slow. Farrar, Straus and Giroux.

Kelemen, Deborah. 2004. "Are Children 'Intuitive Theists'? Reasoning About Purpose and Design in Nature." Psychological Science 15, no. 5:295-301.

Kelemen, Deborah, Joshua Rottman, and Rebecca Seston. 2013. "Professional Physical Scientists Display Tenacious Teleological Tendencies: Purpose-Based Reasoning as a Cognitive Default." Journal of Experimental Psychology: General 142, no. 4:1074-83.

Kelly, Thomas. 2005. "Moorean Facts and Belief Revision, or Can the Skeptic Win?" Philosophical Perspectives, 19:179-209.

-2008. "Common Sense as Evidence: Against Revisionary Ontology and Skepticism." Midwest Studies in Philosophy, 32: 53-78.

Klein, Peter and Ted Warfield. 1994. "What Price Coherence?”'Analysis 54, no. 3:130-131.

Knobe, Joshua and Shaun Nichols. 2008. "An Experimental Philosophy Manifesto." In Experimental Philosophy, edited by Joshua Knobe and Shaun Nichols, 3-14. Oxford: Oxford University Press.

Koksvik, Ole. 2013. "Intuition and Conscious Reasoning." The Philosophical Quarterly 63, no. 253:709-715.

- 2015. "Phenomenal Contrast: A Critique." American Philosophical Quarterly 52, no. 4:321-334.

Korman, Dan. 2005. "Law Necessitarianism and the Importance of Being Intuitive." Philosophical Quarterly 55, no. 221:649-57.

Kornblith, Hilary. 1998. "The Role of Intuition in Philosophical Inquiry: An Account with No Unnatural Ingredients." In Rethinking Intuition: The Psychology of Intuition and Its Role in Philosophical Inquiry, edited by Michael DePaul and William Ramsey, 129-142. Lanham, Md.: Rowman and Littlefield.

Kriegel, Uriah. 2013. "The Epistemological Challenge of Revisionary Metaphysics." Philosophers' Imprint 13, no. 12:1-30.

Kripke, Saul. 1980. Naming and Necessity. Cambridge, Mass.: Harvard University Press.

- 1982. Wittgenstein on Rules and Private Language. Cambridge, Mass.: Harvard University Press.

Ladyman, James and Don Ross. 2007. Every Thing Must Go: Metaphysics Naturalized. Oxford: Oxford University Press.

Lee, H.S. and Holyoak, K.J. 2008. “Absence Makes the Thought Grow Stronger: Reducing Structural Overlap Can Increase Inductive Strength.” In Proceedings of the Thirtieth 
Annual Conference of the Cognitive Science Society, edited by V. Sloutsky, B. Love, and K. McRae, 297-302. Austin: Cognitive Science Society.

Lemos, Noah. 2004. Common Sense: A Contemporary Defense. Cambridge: Cambridge University Press.

Lewis, David. 1971. "Completeness and Decidability of Three Logics of Counterfactual Conditionals." Theoria 37: 74-85.

-1 1983. Philosophical Papers: Volume One. New York: Oxford University Press.

. 1986. On the Plurality of Worlds. Oxford: Blackwell.

Locke, John. 2008. An Essay Concerning Human Understanding. ed. by Pauline Phemister. Oxford University Press.

Luper Steven. 2003. The Skeptics: Contemporary Essays. Ashgate Publishing.

Lycan, William. 1996. "Bealer on the Possibility of Philosophical Knowledge." Philosophical Studies 81:143-50.

—. 2001. "Moore Against the New Skeptics.” Philosophical Studies 103:35-53.

Lyons, Jack. 2013. "Should Reliabilists Be Worried About Demon Worlds?” Philosophy and Phenomenological Research 86, no. 1:1-40.

Machery, Edouard; Ron Mallon; Shaun Nichols; and Stephen Stich. 2004. "Semantics, Cross Cultural Style. Cognition 92: B1-B12.

Mackie, J.L. 1977. Inventing Right and Wrong. London: Penguin Books.

Maclaurin, James and Heather Dyke. 2012. "What Is Analytic Metaphysics for?” Australasian Journal of Philosophy 90, no. 2: 291-306.

Malmgren, Ann-Sara. 2011. "Rationalism and the Content of Intuitive Judgements." Mind 120, no. 478:263-327.

McGahhey, Marcus and Neil Van Leeuwen. Forthcoming. "Interpreting Intuitions." In Third-Person Self-Knowledge, Self-Interpretation, and Narrative, edited by Julie Kirsch and Patrizia Pedrini. Springer.

Mercier, Hugo, and Dan Sperber. 2009. "Intuitive and Reflective Inferences." In In Two Minds: Dual Processes and Beyond, edited by J. St. B. T. Evans and K. Frankish, 149-170. Oxford: Oxford University Press.

Molyneux, Bernard. 2014. "New Arguments that Philosophers Don't Treat Intuitions as Evidence." Metaphilosophy 45, no. 3: 441-461.

Moore, G.E. 1903/1980. Principia Ethica. Cambridge: Cambridge University Press.

Nado, Jennifer. 2014. "Why Intuition?” Philosophy and Phenomenological Research 89, no. 1:1541.

. 2016. "The intuition deniers." Philosophical Studies 173 (3): 781-800. 
Nagel, Jennifer. 2012. "Intuitions and Experiments: A Defense of the Case Method in Epistemology." Philosophy and Phenomenological Research 85 (3): 495-527.

Nichols, Shaun, and Joshua Knobe. 2007. "Moral Responsibility and Determinism: The Cognitive Science of Folk Intuitions.” Noûs 41, no. 4:663-85.

Papineau, David. 2009. "The Poverty of Analysis." Proceedings of the Aristotelian Society Supplementary Volume 83:1-30.

Parfit, Derek. 1971. "Personal Identity." Philosophical Review 80, no. 1:3-27.

Petrinovich, Lewis, and Philip O’Neil. 1996. "Influence of Wording and Framing Effects on Moral Intuitions." Ethology and Sociobiology 67:145-171.

Plantinga, Alvin. 1993. Warrant and Proper Function. Oxford: Oxford University Press.

Pollock, John. 1974. Knowledge and Justification. Princeton: Princeton University Press.

Pust, Joel. 2000. Intuitions as Evidence. New York: Routledge.

—. 2001. "Against Explanationist Skepticism Regarding Philosophical Intuitions." Philosophical Studies 106: 227-258.

—. 2016. "Intuition." The Stanford Encyclopedia of Philosophy (Spring 2016 Edition), edited by Edward N. Zalta. URL = <http://plato.stanford.edu/archives/spr2016/entries/intuition/>

Quine, Willard Van Orman. 1964. Word and Object. Cambridge, Mass.: MIT Press.

Rawls, John. 1971. A Theory of Justice. Cambridge, Mass.: Harvard University Press.

Rea, Michael. 1995. "The Problem of Material Constitution." The Philosophical Review 104, no. 4:525-552.

Rinard, Susanna. 2013. "Why Philosophy Can Overturn Common Sense." Oxford Studies in Epistemology 4: 185-213.

Ross, W.D. 1930. The Right and the Good. Oxford: Clarendon Press.

Russell, Bertrand. 1944/1999. "Reply to Criticisms." Reprinted in Russell on Ethics, edited by Charles Pigdeon, 145-150. London: Routledge.

Scholl, Brian. 2007. "Object Persistence in Philosophy and Psychology.” Mind \& Language 22, no. 5:563-591.

Schroeter, Laura, and François Schroeter. 2014. "Normative Concepts: A Connectedness Model.” Philosophers' Imprint 14 no. 25: 1-26.

Schukraft, Jason. 2016. “Carving Intuition at Its Joints.” Metaphilosophy 47, no. 3:326-352.

Schwitzgebel, Eric, and Fiery Cushman. 2015. "Professional Philosophers' Susceptibility to Order Effects and Framing Effects in Evaluating Moral Dilemmas." Cognition 141:127-37. 
Sider, Ted. 2009. “Ontological Realism.” In Metametaphysics, edited by Chalmers, Manley, and Wasserman, 384-423. Oxford and New York: Oxford University Press.

- 2011. Writing the Book of the World. Oxford: Oxford University Press.

—. 2013. "Against Parthood." In Oxford Studies in Metaphysics, volume 8, edited by Karen Bennett and Dean W. Zimmerman, 237-93. Oxford: Oxford University Press.

Silva, Paul Jr. 2013. "Epistemically Self-Defeating Arguments and Skepticism About Intuition.” Philosophical Studies 164, no. 3:579-89.

Sober, Elliott. 2002. "What Is the Problem of Simplicity?" In Simplicity, Inference, and Modelling, edited by A. Zellner, H. Keuzenkamp, and M. McAleer, 13-31. Cambridge: Cambridge University Press.

Sosa, David. 2006. "Sceptism About Intuitions.” Philosophy 81, no. 4:633-48.

- 2011. "Some of the Structure of Experience and Belief." Philosophical Issues 21, no. 1:474-84.

Sosa, Ernest. 1998. "Minimal Intuition." In Rethinking Intuition: The Psychology of Intuition and Its Role in Philosophical Inquiry, edited by Michael DePaul and William Ramsey, 257-269. Lanham, Md.: Rowman and Littlefield.

- 2007. "Experimental Philosophy and Philosophical Intuition." Philosophical Studies 132:99-107.

- 2009. "A Defense of the Use of Intuitions in Philosophy" in Murphy \& Bishop (eds.) Stich and His Critics. Oxford: Wiley.

- 2014. "Intuitions: Their Nature and Probative Value." In Intuitions, edited by Anthony Robert Booth and Darrell P. Rowbottom. Oxford: Oxford University Press.

Stambor, Zak. 2006. "How Reliable Is Eyewitness Testimony?” Monitor on Psychology, 37, no. $4: 26-27$

Sterelny, Kim, and Philip Kitcher. 1988. "The Return of the Gene." Journal of Philosophy 85, no. 7:339-61.

Stich, Stephen. 1990. The Fragmentation of Reason. Cambridge, Mass.: MIT Press.

Strawson, Peter. (1959). Individuals: An Essay in Descriptive Metaphysics. London: Routeledge.

Street, Sharon. 2006. “A Darwinian Dilemma for Realist Theories of Value." Philosophical Studies 127: 109-166.

- 2008. "Reply to Copp: Naturalism, Normativity, and the Varieties of Realism Worth Worrying About." Philosophical Issues, 18: 207-28.

Swain, Stacy, Joshua Alexander, and Jonathan Weinberg. 2008. "The Instability of Philosophical Intuitions: Running Hot and Cold on Truetemp." Philosophy and Phenomenological Research 76, no. 1: 138-155. 
Swinburne, Ricahrd. 1997. Simplicity as Evidence for Truth. Milwaukee: Marquette University Press.

Thomson, Judith Jarvis. 1976. "Killing, Letting Die, and the Trolley Problem.” The Monist 59, no. 2:204-217.

Thorndike, E.L. 1922. "The Effect of Changed Data on Reasoning." Journal of Experimental Psychology 5 (1): 33-38.

Tidman, Paul. 1996. "The Justification of A Priori Intuitions." Philosopby and Phenomenological Research 56, no. 1:161-71.

Tversky, Amos and Daniel Kahneman. 1983. "Extensional Versus Intuitive Reasoning: The Conjunction Fallacy in Probability Judgment.” Psychological Review 90, no. 4: 293-315.

Uhlmann, Eric, David Pizarro, David Tannenbaum, and Peter Ditto. 2009. "The Motivated Use of Moral Principles." Judgment and Decision Making 4:479-91.

Unger, Peter. 1979. “There Are No Ordinary Things.” Synthese 41: 117-154.

Van Inwagen, Peter. 1990. Material Beings. Ithaca, N.Y.: Cornell University Press. . 1998. "Modal Epistemology." Philosophical Studies 92:67-84.

Waltz, James, Barbara Knowlton, Keith Holyoak, Kyle Boone, Fred Mishkin, Marcia de Menezes Santos, Carmen Thomas, and Bruce L. Miller. 1999. "A System for Relational Reasoning in Human Prefrontal Cortex." Psychological Science 10, no. 2:119_ 25.

Weatherson, Brian. 2003. "What Good Are Counterexamples?” Philosophical Studies 115:1-31.

Weinberg, Jonathan. 2007. "How to Challenge Intuitions Empirically Without Risking Skepticism." Midwest Studies in Philosophy 31:318-43.

Weinberg, Jonathan, Chad Gonnerman, Cameron Buckner, and Joshua Alexander. 2010. “Are Philosophers Expert Intuiters?” Philosophical Psychology 23, no. 3:331-55.

Weinberg, Jonathan, Stephen Crowley, Chad Gonnerman, Ian Vandewalker, and Stacey Swain. 2012. "Intuition and Calibration." Essays in Philosophy, 13, no. 1,256-283.

Weinberg, Jonathan, Shaun Nichols, and Stephen Stich. 2001. "Normativity and Epistemic Intuitions." Philosophical Topics 29:429-60.

White, Roger. 2010. "You Just Believe That Because...” Philosophical Perspectives 24: 573-615.

Wilkes, Kathleen. 1988. Real People: Personal Identity Without Thought Experiments. Oxford: Oxford University Press.

Williamson, Timothy. 2005. "Armchair Philosophy, Metaphysical Modality, and Counterfactual Thinking." Proceedings of the Aristotelian Society 105:1-23.

- 2007. The Philosophy of Philosophy. Oxford: Blackwell.

. 2011. "Philosophical Expertise and the Burden of Proof." Metaphilosophy 42, no. 3:215-29. 
Wong, Wai-Hung. 2006. "Moore, the Skeptic, and the Philosophical Context." Pacific Philosophical Quarterly 87: 271-287.

Woodward, James and John Allman. 2007. "Moral Intuition: Its Neural Substrates and Normative Significance.” Journal of Physiology - Paris 101: 179-202.

Wright, Jennifer. 2010. "On Intuitional Stability: the Clear, the Strong, and the Paradigmatic.” Cognition 115: 491-503. 